CIVIL ENGINEERING STUDIES

Illinois Center for Transportation Series No. 19-004

UILU-ENG-2019-2004

ISSN: 0197-9191

\title{
Evaluation of Adaptive Signal Control Technology- Volume 3: Comparison of TBC 2017 and ASCT 2017
}

\author{
Prepared By \\ Rahim F. Benekohal \\ Behnoush Garshasebi \\ Hongjae Jeon \\ Mingfeng Shang \\ University of Illinois at Urbana-Champaign
}

Research Report No. FHWA-ICT-19-003

A report of the findings of

ICT PROJECT R27-127

Safety and Efficiency Benefits of Implementing Adaptive Signal-Control Technology in Illinois

https://doi.org/10.36501/0197-9191/19-004

Illinois Center for Transportation

March 2019 
Technical Report Documentation Page

\begin{tabular}{|l|l|}
\hline $\begin{array}{l}\text { 1. Report No. } \\
\text { FHWA-ICT-19-003 }\end{array}$ & 2. Government Accession No. \\
\hline
\end{tabular}

3. Recipient's Catalog No.

N/A

\section{Title and Subtitle}

Evaluation of Adaptive Signal Control Technology-Volume 3:

Comparison of TBC 2017 and ASCT 2017

5. Report Date

March 2019

6. Performing Organization Code N/A

8. Performing Organization Report No. ICT-19-004

UILU-ENG-2019-2004

10. Work Unit No.

N/A

11. Contract or Grant No.

R27-127

University of Illinois at Urbana-Champaign

205 North Mathews Avenue, MC-250

Urbana, IL 61801

12. Sponsoring Agency Name and Address

Illinois Department of Transportation (SPR)

Bureau of Research

126 East Ash Street

Springfield, IL 62704

\section{Supplementary Notes}

Conducted in cooperation with the U.S. Department of Transportation, Federal Highway Administration. https://doi.org/10.36501/0197-9191/19-004

\section{Abstract}

Data were collected at five intersections along the Neil Street corridor in Champaign, Illinois, before deployment of SynchroGreen, an adaptive signal control technology (ASCT). The volume, delay, and queue length data from the field for TBC (time based coordination) 2017 conditions were compared to the data from ASCT (adaptive signal control technology) 2017 conditions, at the $97 \%$ confidence level. The field volumes were compared for 57 lane groups (approaches). Traffic volume on $7 \%$ of the lane groups significantly increased, on $72 \%$ remained unchanged, and on only $21 \%$ significantly decreased. Stopped delays increased in $56 \%$ of the cases, remained unchanged in $40 \%$, and decreased in $4 \%$. Queue length increased in $35 \%$ of the cases and remained unchanged in $65 \%$. To determine ASCT performance, the changes in volume, delay, and queue length combined were considered. An overall performance indicator (PI) was determined for each approach of each intersection at each time period. The performance indicators were Imp (Improved), Unch (Unchanged), and Det (Deteriorated), with 91\% confidence. One lane group was excluded from further analysis due to insufficient volume; of the 56 lane groups analyzed, $5 \%$ showed improvement, $32 \%$ remained unchanged, and $63 \%$ ( 35 cases) showed deterioration. Out of 35 cases, deterioration in 20 cases could be explained by contributing factors such as frequency of unfavorable arrival types under ASCT 2017, as compared to TBC 2017; a few cases of volume increase under ASCT 2017; ASCT miscount of traffic volumes; signal timing changes under ASCT 2017; and increased proportion of vehicles stopped under ASCT 2017. However, in the 15 remaining cases, there was no reasonable explanation for the PI deteriorations when ASCT was operating.

\section{Key Words}

Adaptive traffic signals, ASCT, signalized intersections, corridor travel time, traffic coordination, field data on delay, queue length, HCM, saturation flow, signal timing.

19. Security Classif. (of this report) Unclassified 20. Security Classif. (of this page) Unclassified

FORM DOT F 1700.7 (8-72)

\section{Distribution Statement}

No restrictions. This document is available through the National Technical Information Service, Springfield, VA 22161.
13. Type of Report and Period Covered Volume 3 Report

14. Sponsoring Agency Code 


\section{ACKNOWLEDGMENT AND DISCLAIMER}

This publication is based on the results of ICT-R27-127, Safety and Efficiency Benefits of Implementing Adaptive Signal Control Technology in Illinois. ICT-R27-127 was conducted in cooperation with the Illinois Center for Transportation; the Illinois Department of Transportation; and the U.S. Department of Transportation, Federal Highway Administration.

Members of the Technical Review Panel are the following:

- Kyle Armstrong, TRP Chair, IDOT

- David Burkybile, IDOT

- Yogesh Gautam, IDOT

- Michael Hine, FHWA

- Eric Howald, IDOT

- Mike Irwin, IDOT

- Paul Lorton, IDOT

- Dean Mentjes, FHWA

- Jon Nelson, Lake County Highway Department

- Tim Sheehan, IDOT

- Gary Sims, IDOT

- Kristen Micheff, IDOT

The contents of this report reflect the view of the authors, who are responsible for the facts and the accuracy of the data presented herein. The contents do not necessarily reflect the official views or policies of the Illinois Center for Transportation, the Illinois Department of Transportation, or the Federal Highway Administration. This report does not constitute a standard, specification, or regulation.

We acknowledge the contribution of graduate students: Siao Zhou in queue length data reduction and data cleaning tasks, and Yan Bai in queue length data reduction tasks.

Trademark or manufacturers' names appear in this report only because they are considered essential to the object of this document and do not constitute an endorsement of a product by the Federal Highway Administration, the Illinois Department of Transportation, or the Illinois Center for Transportation. 


\section{EXECUTIVE SUMMARY}

Traffic signal operation in the United States has evolved from pre-timed, to vehicle-actuated, to the present-day advanced traffic signal systems called adaptive signal control technology (ASCT). An adaptive traffic signal adjusts its phase plan and signal timing in response to real-time traffic demand. Field evaluation of ASCT is very important in understanding the system's contribution to traffic safety and operational performance improvement. The Illinois Department of Transportation (IDOT) was interested in field evaluation of an ASCT on a corridor. Through a competitive bidding process, a Trafficware product called SynchroGreen ${ }^{\circledR}$ was selected for field implementation. Six intersections along Neil Street in Champaign, Illinois, were selected for this implementation. To evaluate the SynchroGreen system, the corridor's performance was measured during two conditions: under timebased coordination (TBC) in February and March 2017 and under the ASCT condition in April 2017. This report presents the study methodology, data collection, data reduction, and data analysis under the TBC 2017 and ASCT 2017 (implementation of SynchroGreen). The SynchroGreen system was installed in early 2015 and fined tuned by the vendor to get the "best" performance. It was further fine-tuned in late 2016 and early 2017 before data collection for this evaluation. Traffic characteristics for three different time periods (AM peak, noon peak, and PM peak) were obtained from field videotapes. The traffic characteristics include peak periods, hourly volumes, saturation flow rates, signal timings, arrival types, field delays, and queue lengths.

The volume, delay, and queue length data from the field for TBC 2017 were measured and individually compared with the data for ASCT 2017, at the $97 \%$ confidence level. The field data were compared for 57 lane groups (approaches). At the $97 \%$ confidence level, traffic volume on $7 \%$ of the lane groups significantly increased; but on $72 \%$ it did not change significantly; and on $21 \%$, it significantly decreased. Delay showed significant increase in $56 \%$ of the cases, no significant change in $40 \%$, and significant decrease in 4\%. Queue length was also compared for the 57 lane groups: $35 \%$ showed significant increase, $65 \%$ showed no significant change, and none showed significant decrease in queue length.

Further analysis was carried out to determine ASCT performance at approach, intersection, and corridor levels. Based on the changes in volume, delay, and queue length combined, an overall performance indicator (PI) was determined for each approach of each intersection at each time period. The performance indicators are Imp (Improved), Unch (Unchanged), and Det (Deteriorated). Because we considered the $97 \%$ confidence interval for individual comparisons of volume, delay, and queue length, so the PI would present the results at the $91 \%$ confidence level, the product of three individual confidence levels of $97 \%(0.97 * 0.97 * 0.97)$. One lane group was excluded from further analysis due to insufficient volume; so out of the total of 56 lane groups analyzed, the PI showed improvement in 5\%, remained unchanged in $32 \%$, but showed deterioration in $63 \%$. In summary, on $37 \%$ of the lane groups, ASCT either improved or did not change performance; however, on 63\% (35 cases) of the lane groups, performance deteriorated with ASCT.

Further investigations were performed to find the contributing factors to the ASCT performance deterioration. Out of 35 cases, deterioration in 20 cases could be explained by contributing factors such as frequency of unfavorable arrival types under ASCT 2017, as compared to TBC 2017; a few 
cases of volume increase under ASCT 2017; ASCT miscount of traffic volumes; signal-timing changes under ASCT 2017; and an increased proportion of vehicles stopped under ASCT 2017. However, in 15 remaining cases, there was no reasonable explanation for the PI deteriorations when ASCT was operating. 


\section{CONTENTS}

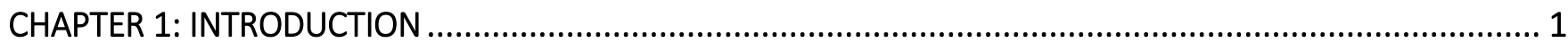

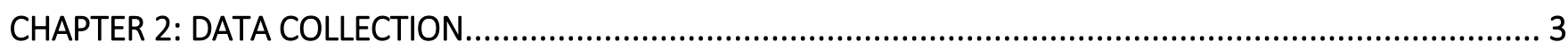

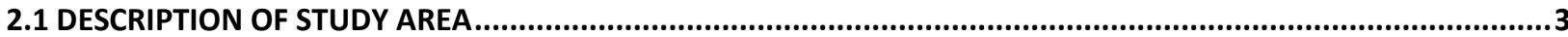

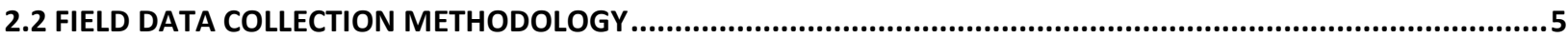

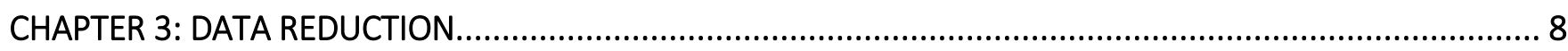

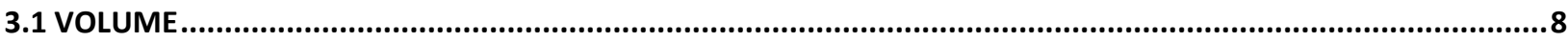

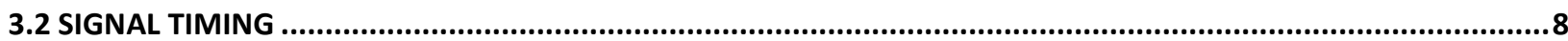

3.3 FIELD DELAY

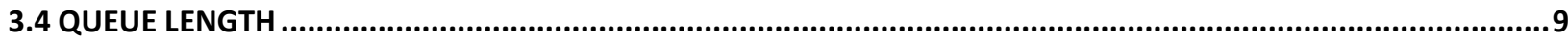

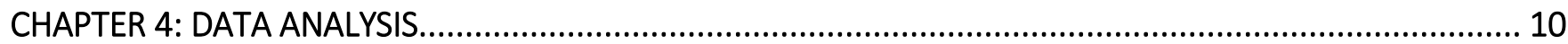

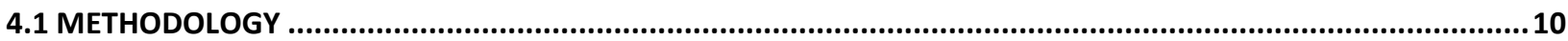

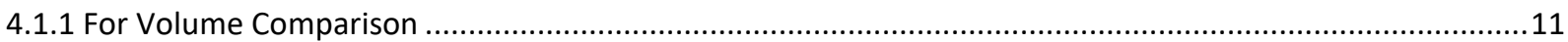

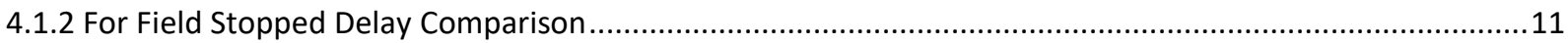

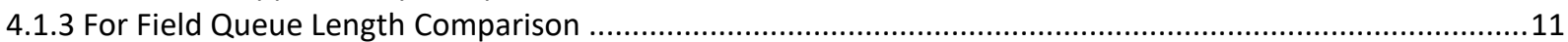

4.2 COMPARISONS OF VOLUME, DELAY, AND QUEUE LENGTH (TBC 2017 VS. ASCT 2017 AT APPROACH LEVEL)..11

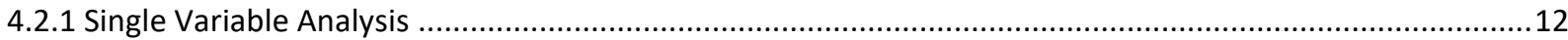

4.2.2 Delay and Volume Combination Analysis ..................................................................................... 15

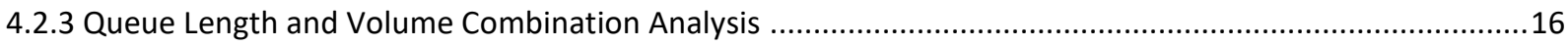

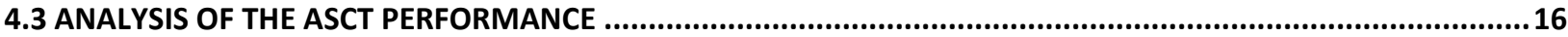

4.3.1 Number of Cases Involved in Performance Analysis ....................................................................... 17

4.4 DETAILED ANALYSIS OF PI AT INTERSECTION LEVEL...........................................................................20

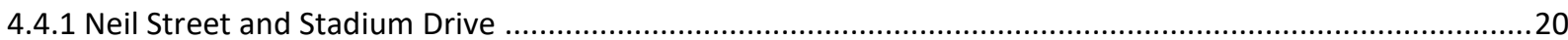

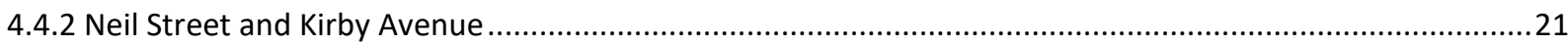

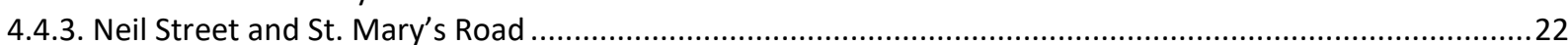

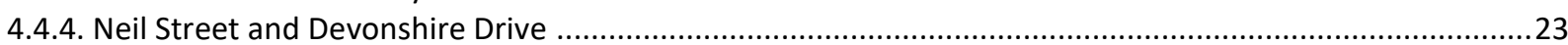

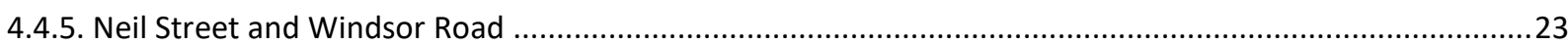

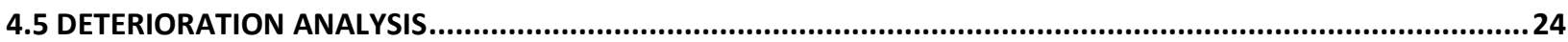

4.5.1. Deterioration due to Arrival Type Changes under ASCT 2017 .............................................................24

4.5.2 Deterioration due to Insufficient System Response to Volume Increase ................................................30

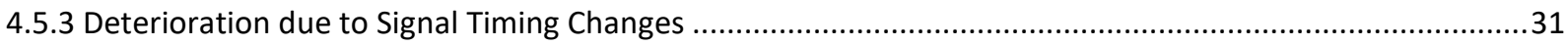

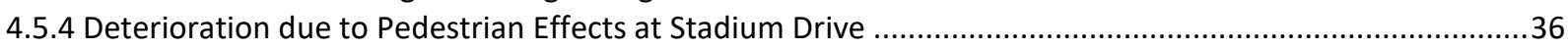

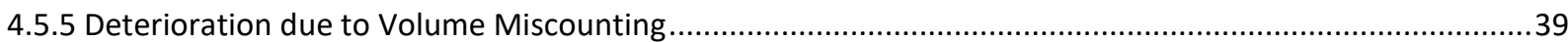

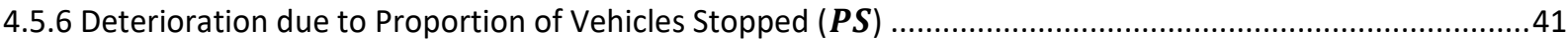




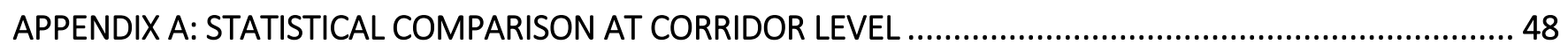

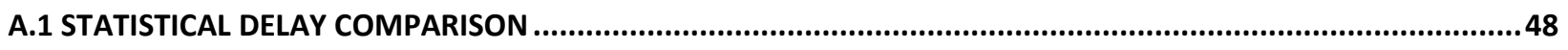

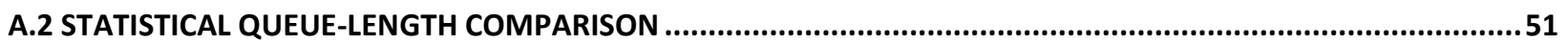

APPENDIX B: COMBINATION ANALYSIS (DELAY VS. VOLUME, QUEUE LENGTH VS. VOLUME) ................... 53

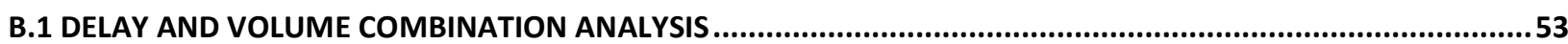

B.2 APPLICATION OF HCS IN DETERMINING CONDITION OF CASES WITH BOTH INCREASED OR DECREASED DELAY AND VOLUME.

B.3 QUEUE LENGTH AND VOLUME COMBINATION ANALYSIS . .56

B.4 APPLICATION OF HCS IN DETERMINING CONDITION OF CASES WITH BOTH INCREASED OR DECREASED QUEUE LENGTH AND VOLUME .58

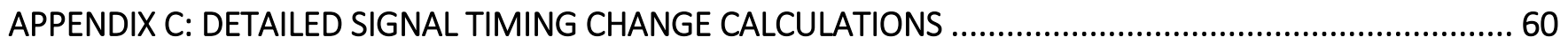

C.1. ENTIRE TIME LENGTH AND ENTIRE GREEN TIME .......................................................................................60

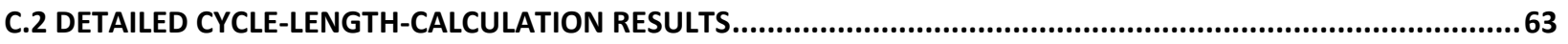

C.3 DETAILED AVERAGE EFFECTIVE GREEN-TIME-COMPARISON RESULTS ........................................................64

APPENDIX D: DETAILED COMPARISON OF SYSTEM VOLUME COUNTS AND FIELD VOLUME COUNTS ........ 65

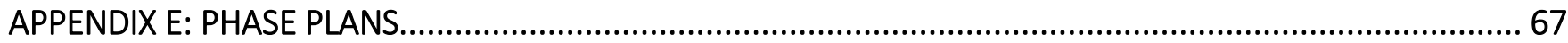

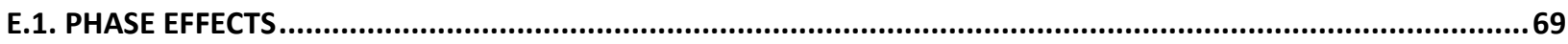

APPENDIX F: SYSTEM TECHNICAL ERRORS OBSERVED IN THE FIELD ........................................... 70

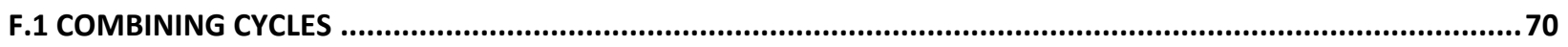

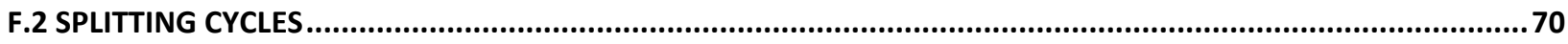

F.3 GREEN TIME WRONGLY ALLOCATED TO MINOR STREETS .......................................................................... 71

F.4 VOLUME MISCOUNTED BY SYSTEM .......................................................................................... 


\section{CHAPTER 1: INTRODUCTION}

Intersection traffic signal control has evolved from pre-timed operation, to vehicle-actuated, to the present-day adaptive signal systems. Adaptive signal control technologies (ASCT) are used to make traffic signal operation more responsive to real-time traffic demand. These technologies have the potential to provide a more efficient and safer operation. In the United States, adaptive systems are relatively new and are deployed in various parts of the country.

In 2014, as a result of congestion, it is estimated that urban Americans traveled 6.9 billion hours more and purchased an extra 3.1 billion gallons of fuel-resulting in total congestion costs of about $\$ 160$ billion dollars (1). Thus, increased deployment of more efficient signal systems is necessary to reduce congestion.

The Illinois Department of Transportation (IDOT) has expressed interest in field evaluation of an ASCT for deployment at intersections throughout the state. Through a competitive process, SynchroGreen was selected from available ASCTs for field evaluation. It is a real-time ASCT system from Trafficware, Inc. (2). Field evaluations of ASCTs are very important in understanding their contribution to performance improvement-and, hence, their effectiveness. Some field evaluations of SynchroGreen have been reported in the recent past (3), at locations such as Seminole County, Florida (4), and Boca Raton, Florida (5).

Therefore, this study was undertaken on behalf of IDOT to evaluate the performance of the SynchroGreen system -in terms of traffic safety and traffic operational efficiency.

This report presents the data analysis results for the April 2017 conditions in which the adaptive signalcontrol technology (ASCT 2017) was in place, compared to the February and March 2017 conditions in which time-based coordination (TBC 2017) was in place. Volume 1 (6) of this report discusses the base conditions in 2013, before the ASCT was implemented. Volume 2 (7) compares the performance of the ASCT system in 2015 to the base conditions in 2013, to document the performance of ASCT during the first year after implementation. The base condition in 2013 was also operating as a TBC system.

Installation of the ASCT system began in the spring of 2015 on the Neil Street corridor in Champaign, Illinois, as shown in Figure 1. The six intersections along Neil Street, from north to south, are as follows:

Neil Street and Stadium Drive

Neil Street and Kirby Avenue

Neil Street and St. Mary's Road

Neil Street and Devonshire Drive

Neil Street and Knollwood Drive

Neil Street and Windsor Road

In addition, the traffic signal at Kirby Avenue and State Street was linked to the traffic signal at Kirby and Neil so that they worked in a coordinated manner. 


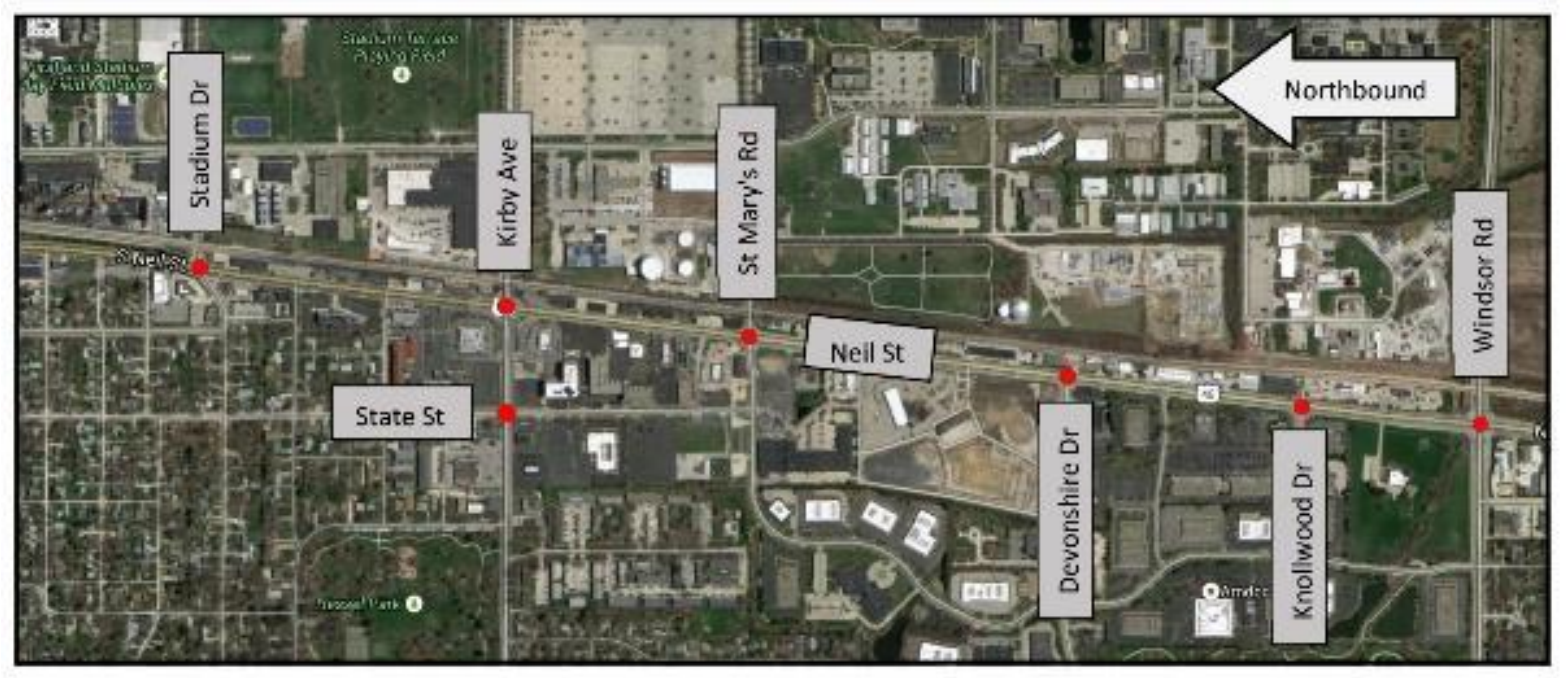

Figure 1. Deployment location on Neil Street in Champaign, Illinois.

This report is organized as follows: Chapter 2 contains a description of the study area and the datacollection methodology used in the study. Chapter 3 presents the methodology and outcomes of data reduction performed following collection of the traffic data for 2017. Chapter 4 discusses statistical comparisons between February/March 2017 and April 2017 (TBC versus ASCT conditions) in terms of volume, stopped delay, and queue length-as well as the relationships between delay and volume performance, and queue and volume performance. This chapter also evaluates the traffic performance at both corridor and intersection levels by analyzing the comparison results and presents a detailed analysis of the cases with deteriorated performances. Chapter 5 presents the main findings and conclusions. 


\section{CHAPTER 2: DATA COLLECTION}

This chapter describes the study area and presents the methodology used for data collection.

\subsection{DESCRIPTION OF STUDY AREA}

The study area consisted of six intersections along the Neil Street corridor, Champaign, Illinois (Figure 2). For this report, we used data for five intersections on Neil Street that were operating through an active ASCT system. The Knollwood intersection was not used because the operation there is heavily influenced by the nearby signal at Windsor Road; also, the traffic on minor streets was so low that some cycles were skipped. The traffic pattern on Neil Street has higher volume northbound in the morning (toward downtown Champaign) and southbound in the afternoon. Four of the crossing streets that create typical four-legged intersections are Stadium Drive, Kirby Avenue, St. Mary's Road, and Windsor Road. On the cross streets, the heavy volume direction in the morning is eastbound toward the campus of the University of Illinois at Urbana-Champaign. In the afternoon, the heavy-volume direction is westbound, away from campus. Schematic geometries of the five intersections are shown in Figures 2 to 7 (drawings not to scale).

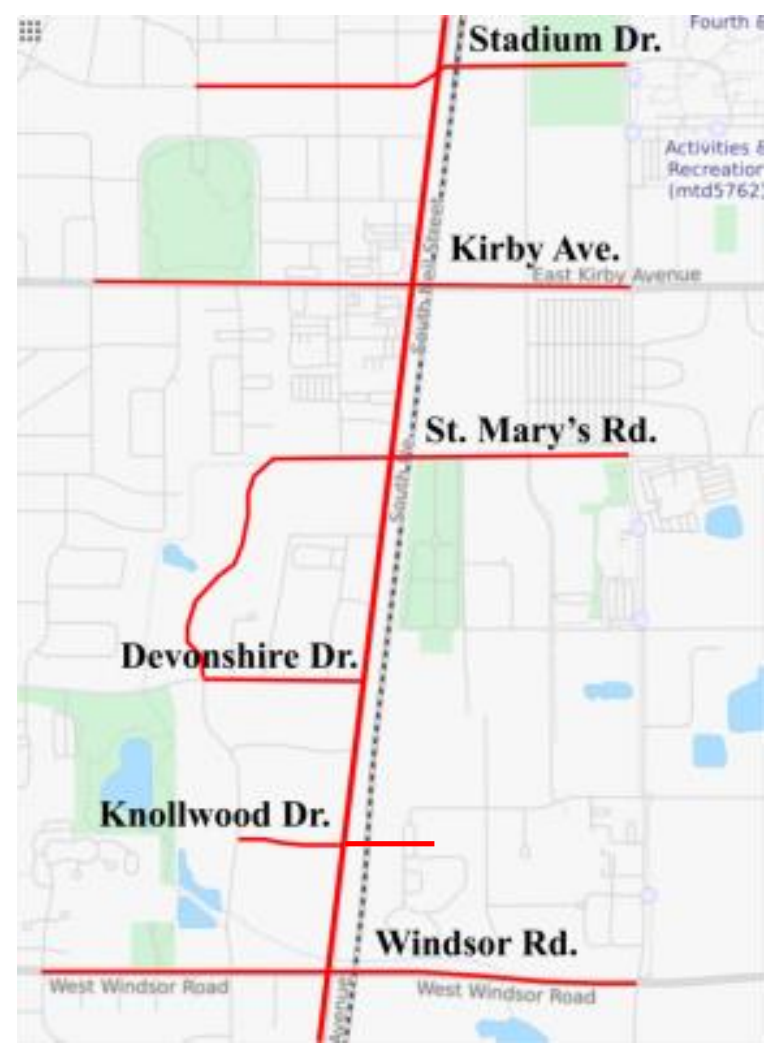

Figure 2. Five intersections were studied along the Neil Street corridor, Champaign, Illinois: Stadium Drive, Kirby Avenue, St. Mary's Road, Devonshire Drive, and Windsor Road. 


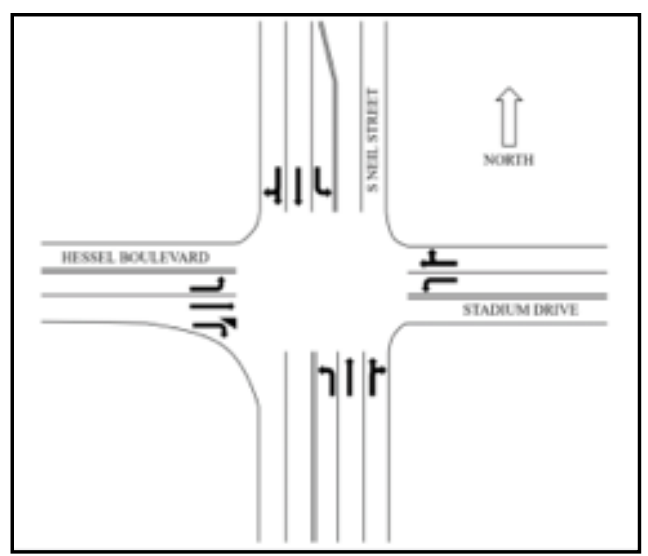

Figure 3. Geometry of the intersection of Neil Street and Stadium Drive.

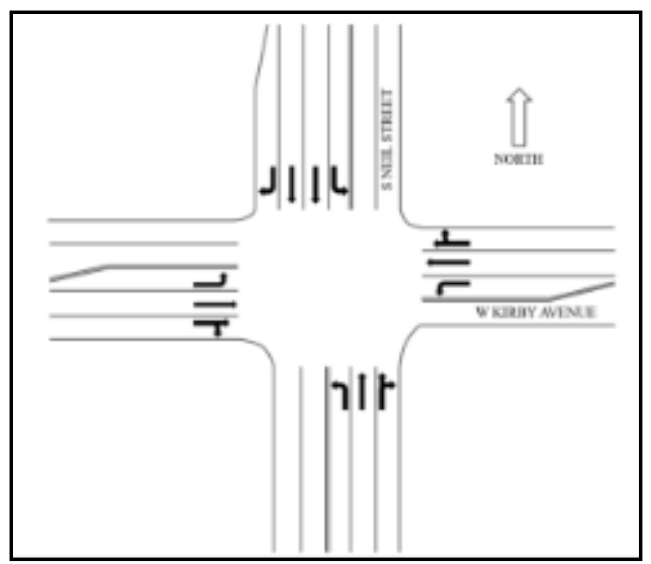

Figure 4. Geometry of the intersection of Neil Street and Kirby Avenue.

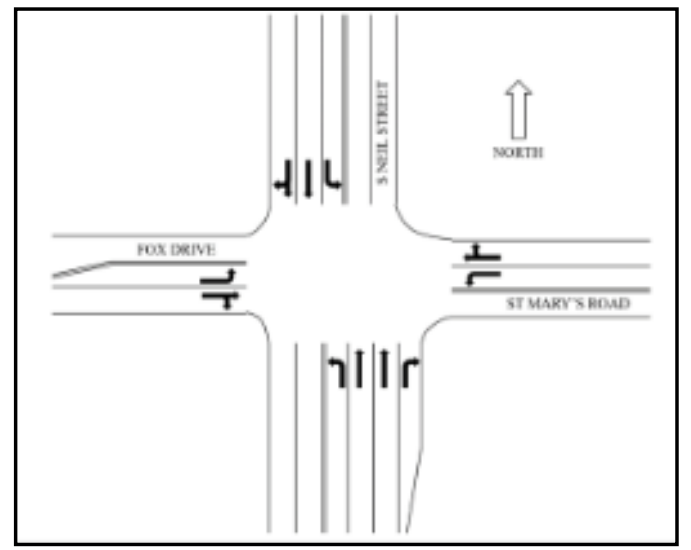

Figure 5. Geometry of the intersection of Neil Street and St. Mary's Road. 


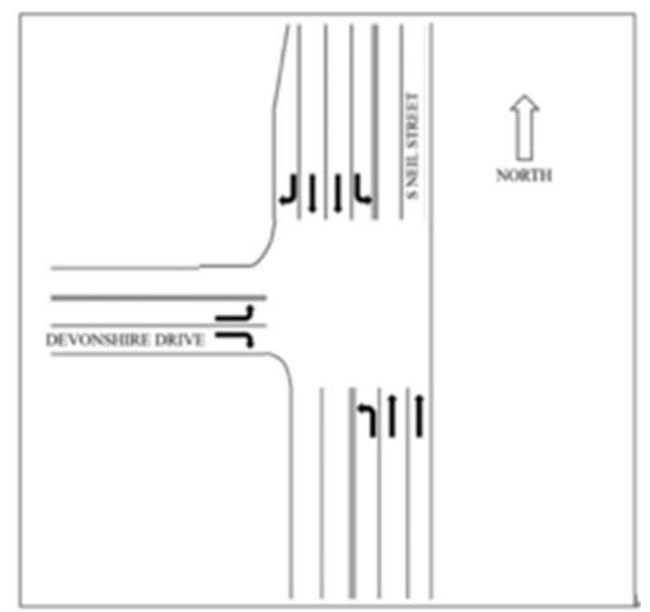

Figure 6. Geometry of the intersection of Neil Street and Devonshire Drive (since 2015).

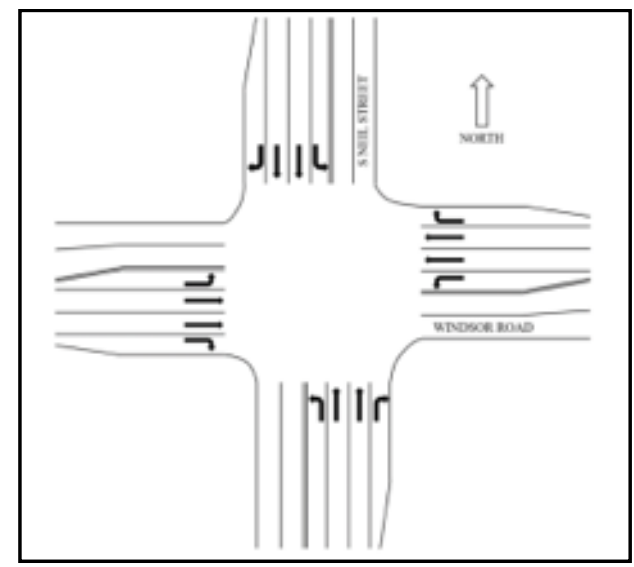

Figure 7. Geometry of the intersection of Neil Street and Windsor Drive.

\subsection{FIELD DATA COLLECTION METHODOLOGY}

During data-collection dates for the TBC 2017 and ASCT 2017 conditions, traffic operation was normal; and there were no roadway-construction activities. For both conditions, data collection was conducted by recording the online streaming traffic videos provided by the ASCT cameras at the five intersections. Two video sets of data were recorded for each condition under TBC 2017 and ASCT 2017, during morning peak (7:30-8:30 a.m.), noon peak (12:10-1:10 p.m.), and afternoon peak (4:40-5:40 p.m.) hours in a day. Tables 1-4 show the dates of data collection at each intersection and data reduction. 
Table 1. TBC 2017 Data Collection Dates (Video Sets 1 and 2)

\begin{tabular}{|l|l|l|l|l|}
\hline Intersection & AM Peak & Off Peak & Noon Peak & PM Peak \\
\hline Stadium & Feb 15, 2017 & Feb 15, 2017 & Feb 15, 2017 & Feb 15, 2017 \\
\hline Kirby & Feb 15, 2017 & Feb 15, 2017 & Feb 15, 2017 & Feb 15, 2017 \\
\hline St. Mary's & Feb 16, 2017 & Feb 16, 2017 & Feb 16, 2017 & $\begin{array}{l}\text { Feb 16, 2017; } \\
\text { Feb 22, 2017 }\end{array}$ \\
\hline Devonshire & Feb 16, 2017 & Feb 16, 2017 & Feb 16, 2017 & $\begin{array}{l}\text { Feb 16, 2017; } \\
\text { Feb 22, 2017 }\end{array}$ \\
\hline Knollwood & Feb 28, 2017 & Feb 28, 2017 & Feb 28, 2017 & Feb 28, 2017 \\
\hline Windsor & Feb 28, 2017 & Feb 28, 2017 & Feb 28, 2017 & Feb 28, 2017 \\
\hline
\end{tabular}

\begin{tabular}{|l|l|l|l|l|}
\hline Intersection & AM Peak & Off Peak & Noon Peak & PM Peak \\
\hline Stadium & March 1, 2017 & March 1, 2017 & March 1, 2017 & March 1, 2017 \\
\hline Kirby & March 1, 2017 & March 1, 2017 & March 1, 2017 & March 1, 2017 \\
\hline St. Mary's & March 2, 2017 & March 2, 2017 & March 2, 2017 & March 2, 2017 \\
\hline Devonshire & March 2, 2017 & March 2, 2017 & March 2, 2017 & March 2, 2017 \\
\hline Knollwood & March 7, 2017 & March 7, 2017 & March 7, 2017 & March 7, 2017 \\
\hline Windsor & March 7, 2017 & March 7, 2017 & March 7, 2017 & March 7, 2017 \\
\hline
\end{tabular}

Table 2. ASCT 2017 Data Collection Dates (Video Sets 1 and 2)

\begin{tabular}{|l|l|l|l|l|}
\hline Intersection & AM Peak & Off Peak & Noon Peak & PM Peak \\
\hline Stadium & April 11, 2017 & April 11, 2017 & April 11, 2017 & April 11 2017 \\
\hline Kirby & April 12, 2017 & April 12, 2017 & April 12, 2017 & April 12 2017 \\
\hline St. Mary's & April 13, 2017 & April 13, 2017 & April 13, 2017 & April 13 2017 \\
\hline Devonshire & April 13, 2017 & April 13, 2017 & April 13, 2017 & April 13 2017 \\
\hline Knollwood & April 14, 2017 & NA & April 14, 2017 & April 14 2017 \\
\hline Windsor & April 12, 2017 & April 12, 2017 & April 12, 2017 & April 12 2017 \\
\hline
\end{tabular}

\begin{tabular}{|l|l|l|l|l|}
\hline Intersection & AM Peak & Off Peak & Noon Peak & PM Peak \\
\hline Stadium & April 25, 2017 & April 25, 2017 & April 25, 2017 & April 25, 2017 \\
\hline Kirby & April 18, 2017 & April 18, 2017 & April 18, 2017 & April 18, 2017 \\
\hline St. Mary's & April 25, 2017 & April 25, 2017 & April 25, 2017 & April 25, 2017 \\
\hline Devonshire & April 19, 2017 & April 19, 2017 & April 19, 2017 & April 19, 2017 \\
\hline Knollwood & April 19, 2017 & April 19, 2017 & April 19, 2017 & April 19, 2017 \\
\hline Windsor & April 18, 2017 & April 18, 2017 & April 18, 2017 & April 18, 2017 \\
\hline
\end{tabular}


Table 3. TBC 2017 Data Reduction Dates

\begin{tabular}{|l|l|l|l|}
\hline Intersection & AM Peak & Noon Peak & PM Peak \\
\hline Stadium & Feb 15, 2017 & Feb 15, 2017 & Feb 15, 2017 \\
\hline Kirby & $\begin{array}{l}\text { March 1, 2017; } \\
\text { Feb 15 2017 }\end{array}$ & Feb 15, 2017 & $\begin{array}{l}\text { March 1, 2017 (NB, EB, } \\
\text { WB); Feb 15, 2017 (SB) }\end{array}$ \\
\hline St. Mary's & March 2, 2017 & $\begin{array}{l}\text { March 2, } \\
2017\end{array}$ & March 2, 2017 \\
\hline Devonshire & March 2, 2017 & $\begin{array}{l}\text { March 2, } \\
2017\end{array}$ & March 2, 2017 \\
\hline Knollwood & March 7, 2017 & $\begin{array}{l}\text { March 7, } \\
2017\end{array}$ & March 7, 2017 \\
\hline Windsor & March 7, 2017 & $\begin{array}{l}\text { March 7, } \\
2017\end{array}$ & Feb 28, 2017 \\
\hline
\end{tabular}

Table 4. April 2017 Data Reduction Dates

\begin{tabular}{|l|l|l|l|}
\hline Intersection & AM Peak & Noon Peak & PM Peak \\
\hline Stadium & April 11, 2017 & April 11, 2017 & April 11, 2017 \\
\hline Kirby & April 12, 2017 & April 12, 2017 & April 12, 2017 \\
\hline St. Mary's & April 13, 2017 & April 13, 2017 & April 13, 2017 \\
\hline Devonshire & April 13, 2017 & April 13, 2017 & April 13, 2017 \\
\hline Knollwood & April 19, 2017 & April 19, 2017 & April 19, 2017 \\
\hline Windsor & April 12, 2017 & April 12, 2017 & April 12, 2017 \\
\hline
\end{tabular}




\section{CHAPTER 3: DATA REDUCTION}

This chapter describes the methodology used for reducing the data elements from the traffic videos. Several types of characteristics data were extracted from the traffic videos: hourly volume, signal timing, proportion of vehicles stopping, arrival type, field delay, and queue length. Data reduction was performed for the three time periods (AM peak, noon peak, and PM peak). In the following sections, a detailed description of the data reduction, along with the outcomes for each item, is presented.

\subsection{VOLUME}

The through volumes during the three time periods were determined for all approaches of the five intersections. Averaged hourly volumes were used in the delay and capacity analysis, which are discussed later in the report.

The through movement volumes for one hour were manually counted using the recorded traffic videos. The volume counts were obtained at 20 second intervals for the entire time period. Traffic volume for each approach in every cycle was counted manually. The average volumes per cycle are presented in Chapter 4, Table 5. NBT, SBT, EBT, and WBT are abbreviations for northbound through, southbound through, eastbound through, and westbound through, respectively. The same abbreviations are used in the following tables and figures. AM, NP, and PM indicate the morning peak, noon peak, and afternoon peak, respectively; and the same indicators are used in the following tables and figures.

\subsection{SIGNAL TIMING}

Signal timing data were reduced to obtain the green time ratio data. Signal timing data are obtained from the SynchroGreen reports. In the reports, the cycle length, phases used, and split times in each cycle for the intersections are listed. The corresponding movements for these green splits are determined by checking the traffic videos. The green time ratio for each through movement per cycle can be computed, and thus the green time ratio for each through movement is obtained. In Chapter 4, Table 27 shows the green-time ratio for each through movement for the five intersections under the TBC 2017 and ASCT 2017 conditions.

\subsection{FIELD DELAY}

The control delay and stopped delay in the field were calculated from the video data for TBC 2017 and ASCT 2017. The field measurement technique for intersection control delay, as described in Chapter 31 of HCM 2010 (8), was adopted to calculate stopped delay and control delay using the field videos. The measurements were carried out on a lane-group basis for each approach of the five intersections. The procedure was performed for all three time periods.

The procedure requires identifying the approach speed. The speed limit of each approach was assumed to be its approach speed. The duration of the survey period was about one hour for each time period. The count interval of 20 seconds was selected for this study because it is an integral divisor of the 
duration of the survey period ( 1 hour), as required by the HCM. The stopped delay obtained for each lane group in the study (using the HCM field-measurement methodology) is presented in Table 5.

\subsection{QUEUE LENGTH}

The queue lengths in the field were determined using the video images of the approaches. They are compared to their estimations (discussed in the next chapter).

The queue length of a through lane group in each cycle was determined by manually counting the number of stopped vehicles at the beginning of the green light for that direction. This counting also included vehicles that joined the queue after the end of the red light and came to a complete stop. The average queue lengths for the TBC 2017 condition are compared to those under the ASCT 2017 condition. The average queue length data are shown in Table 5 for TBC 2017 and ASCT 2017. 


\section{CHAPTER 4: DATA ANALYSIS}

This chapter explains three steps of data analysis: average volumes comparison of TBC 2017 and ASCT 2017 conditions, field stopped delays comparison of TBC 2017 and ASCT 2017, and field queue lengths comparison of TBC 2017 and ASCT 2017. It also includes the discussions about the findings of these comparisons. First, the methodology for the analyses is explained. Then, the comparisons for all approaches combined (corridor level) are discussed. Finally, the results at the intersection level are analyzed.

\subsection{METHODOLOGY}

Statistical comparisons were performed using two-sided t-tests (unpaired) at 0.03-significance levels ( $97 \%$ confidence level). The null hypothesis of the test is that the field measurements under the TBC 2017 and ASCT 2017 conditions are not significantly different. The t values were computed using the means and variances of the data:

$$
\mathrm{t}=\frac{\overline{\mathrm{X}_{1}}-\overline{\mathrm{X}_{2}}}{\mathrm{~s}_{\mathrm{p}}}
$$

where

$$
s_{p}= \begin{cases}\sqrt{\frac{\left(n_{1}-1\right) s_{1}^{2}+\left(n_{2}-1\right) s_{2}^{2}}{n_{1}+n_{2}-2}} & \text { if } \frac{s_{1}}{s_{2}}<2 \text { or pooled variance } \\ \sqrt{\frac{s_{1}^{2}}{n_{1}}+\frac{s_{2}^{2}}{n_{2}}} & \text { if } \frac{s_{1}}{s_{2}} \geq 2 \text { or unpooled variance }\end{cases}
$$

in Equation (1):

for the volume comparisons, $\overline{\mathbf{x}}_{1}$ and $\overline{\mathbf{x}}_{2}$ are the average volumes of the subject lane group for the TBC 2017 and ASCT 2017 conditions, respectively; $\boldsymbol{n}_{\mathbf{1}}$ and $\boldsymbol{n}_{\mathbf{2}}$ are the number of observations; and $\boldsymbol{s}_{\mathbf{1}}{ }^{2}$ and $\boldsymbol{s}_{\mathbf{2}}{ }^{2}$ are the variances.

for the field stopped comparisons, $\overline{\mathbf{x}}_{1}$ and $\overline{\mathbf{x}}_{2}$ are the average stopped delays of the subject lane group for the TBC 2017 and ASCT 2017 conditions, respectively; $\boldsymbol{n}_{\mathbf{1}}$ and $\boldsymbol{n}_{\mathbf{2}}$ are the number of observations; and $\boldsymbol{s}_{\mathbf{1}}{ }^{2}$ and $\boldsymbol{s}_{\mathbf{2}}{ }^{2}$ are the variances.

for the queue-length comparisons, $\overline{\mathbf{x}}_{\mathbf{1}}$ and $\overline{\mathbf{x}}_{\mathbf{2}}$ are the average queue lengths of the subject lane group for the TBC 2017 and ASCT 2017 conditions, respectively; $\boldsymbol{n}_{\mathbf{1}}$ and $\boldsymbol{n}_{\mathbf{2}}$ are the numbers of observations; and $\boldsymbol{s}_{\mathbf{1}}{ }^{2}$ and $\boldsymbol{s}_{\mathbf{2}}{ }^{2}$ are the variances. 


\subsubsection{For Volume Comparison}

From field data, traffic volume for each lane group in each cycle was determined. Each lane group had about 30 data points ( 30 cycles and about 60 minutes total). The average and variance of those 30 volumes were computed. Consequently, as mentioned before, in Equation (1), $\overline{X_{1}}$ and $\overline{X_{2}}$ are the average traffic volumes of the subject lane group for the TBC 2017 and ASCT 2017 conditions, respectively; $n_{1}$ and $n_{2}$ are their numbers of observations; and $s_{1}{ }^{2}$ and $s_{2}{ }^{2}$ are their variances. Thus, using this methodology, the differences are tested to determine whether they are statistically significant. The data analysis and tests were performed for a total of 57 cases (three time periods * [four * four-legged intersections] + [one * three-legged intersection]). The summary of the results is presented in section 4.2, and the detailed results are available in Appendix A.1.

\subsubsection{For Field Stopped Delay Comparison}

The delay comparison was made between the field stopped delay measured for the TBC 2017 and ASCT 2017 conditions on a lane-group basis. The data analysis procedure of this report is the same one used in report Volumes 1 (6) and 2 (7) of this research project. Comparisons are only for through lane groups, except at Neil Street and Devonshire (a T-intersection), where the comparisons are for the eastbound left-turn lane. Changes in traffic volume (increase or decrease) may affect the magnitude of stopped delay, so volumes under the TBC 2017 and ASCT 2017 conditions were taken into account.

The field variance of stopped delay of a lane group was obtained by measuring average stopped delays per cycle. Therefore, each lane group ideally had around 30 stopped delays during every hour (60 minutes); and the variance of those 30 observations is equal to the variance $\mathrm{s}^{2}$. The observation time was deliberately chosen in a way to capture traffic data of complete cycles (110 or 120 seconds) during each time interval.

Thus, using this methodology, the differences are tested to determine whether they are statistically significant. The data analysis and tests were performed for a total of 57 cases, the summary of results is presented in section 4.2, and detailed results are available in Appendix A.1.

\subsubsection{For Field Queue Length Comparison}

Similar to the delay comparison, the queue length comparison in this study was made between the average field queue length measured for the TBC 2017 and ASCT 2017 conditions, based on lane groups. Changes in the traffic volume under TBC 2017 and ASCT 2017 conditions were also considered in queue length comparisons.

Thus, using this methodology, the differences are tested to determine whether they are statistically significant. The data analysis and tests were performed for a total of 57 cases, the summary of the results is presented in section 4.2, and detailed results are available in Appendix A.1.

\subsection{COMPARISONS OF VOLUME, DELAY, AND QUEUE LENGTH (TBC 2017 VS. ASCT 2017 AT APPROACH LEVEL)}




\subsubsection{Single Variable Analysis}

For each of the 57 cases, any statistically significant change that may have occurred when comparing the TBC 2017 and ASCT 2017 conditions - such as changes in volume, delay, and queue length - was taken into consideration. The results are given in Table 5. In the table, NBT means northbound through and SBT southbound through; etc.. The p-values resulting from the tests are also given. Based on the required confidence level and by the use of the $p$-values, from now on any significant increase is indicated by "Inc" and any significant decrease by "Dec." The unchanged ones are labeled "Unch," and nonapplicable ones are labeled "NA" (in addition to shading). 
Table 5. Volume, Delay, and Queue Length of TBC 2017 and ASCT 2017 Data Comparison Results

\begin{tabular}{|c|c|c|c|c|c|c|c|c|c|c|c|}
\hline Intersection & Time Period & Approach & March Volume & April Volume & t-test $P$ value & March Delay & April Delay & t-test $P$ value & March Queue & April Queue & t-test $P$ value \\
\hline \multirow{12}{*}{ Stadium } & \multirow{4}{*}{ AM } & NBT & 8.659 & 7.776 & 0.39412557 & 1.827 & 6.776 & 0.00674307 & 1.138 & 1.948 & 0.01904614 \\
\hline & & SBT & 6.584 & 5.776 & 0.22256143 & 3.605 & 7.620 & \begin{tabular}{|l|}
0.00360772 \\
\end{tabular} & 1.707 & 2.379 & 0.1037344 \\
\hline & & EBT & 5.060 & 3.621 & 0.00569158 & 7.485 & 13.753 & 0.00086216 & 1.397 & 2.328 & 0.0037214 \\
\hline & & WBT & 0.953 & 0.500 & 0.00586304 & 4.707 & 3.103 & 0.32490696 & 0.086 & 0.276 & 0.02230378 \\
\hline & \multirow{4}{*}{ NP } & NBT & 6.476 & 6.400 & 0.8999122 & 1.922 & 6.831 & $6.1818 \mathrm{E}-07$ & 0.683 & 2.446 & 7.4664E-08 \\
\hline & & SBT & 6.095 & 5.738 & 0.51085754 & 4.060 & 6.826 & 0.04413999 & 1.730 & 2.338 & 0.10955738 \\
\hline & & EBT & 1.635 & 1.000 & 0.00516742 & 4.776 & 7.569 & 0.11485334 & 0.381 & 0.708 & 0.02731159 \\
\hline & & WBT & 1.365 & 0.908 & 0.0250772 & 4.881 & 5.631 & 0.64008449 & 0.444 & 0.600 & 0.26299364 \\
\hline & \multirow{4}{*}{ PM } & NBT & 7.271 & 7.831 & 0.4468989 & 5.012 & 5.851 & 0.48627725 & 1.458 & 2.169 & 0.01614335 \\
\hline & & SBT & 8.153 & 8.339 & 0.79117967 & 2.799 & 7.664 & 0.00032562 & 1.695 & 3.305 & 0.00122081 \\
\hline & & EBT & 2.068 & 1.000 & 0.00016712 & 3.549 & 7.958 & 0.01640074 & 0.450 & 0.525 & 0.5671527 \\
\hline & & WBT & 3.678 & 3.966 & 0.55504388 & 6.497 & 14.408 & $3.206 \mathrm{E}-06$ & 1.119 & 2.576 & $5.2445 \mathrm{E}-06$ \\
\hline \multirow{12}{*}{ Kirby } & \multirow{4}{*}{ AM } & NBT & 15.562 & 16.571 & 0.39882862 & 10.000 & 14.854 & 0.01197897 & 5.214 & 8.893 & $6.6612 \mathrm{E}-05$ \\
\hline & & SBT & 11.857 & 9.357 & 0.02347278 & 12.675 & 14.278 & 0.37003018 & 4.464 & 4.929 & 0.50675509 \\
\hline & & EBT & 12.859 & 13.107 & 0.79197951 & 15.282 & 31.335 & $8.1749 \mathrm{E}-07$ & 3.714 & 8.357 & $1.2262 \mathrm{E}-08$ \\
\hline & & WBT & 9.325 & 5.214 & $2.0722 \mathrm{E}-05$ & 23.189 & 21.865 & 0.77149312 & 2.920 & 2.821 & 0.87642959 \\
\hline & \multirow{4}{*}{ NP } & NBT & 11.097 & 11.258 & 0.85699282 & 19.592 & 13.745 & 0.01762097 & 7.323 & 6.806 & 0.40982477 \\
\hline & & SBT & 10.129 & 9.161 & 0.23133219 & 17.139 & 22.607 & 0.11714126 & 5.516 & 4.935 & 0.36328357 \\
\hline & & EBT & 5.968 & 7.000 & 0.16557692 & 24.504 & 61.769 & $3.77 \mathrm{E}-08$ & 4.258 & 5.032 & 0.21878243 \\
\hline & & WBT & 7.677 & 6.258 & 0.03243753 & 14.890 & 32.116 & $5.3461 \mathrm{E}-05$ & 3.290 & 3.032 & 0.65822167 \\
\hline & \multirow{4}{*}{ PM } & NBT & 12.379 & 13.583 & 0.19832115 & 29.155 & 21.192 & 0.00705806 & 7.655 & 8.792 & 0.05293245 \\
\hline & & SBT & 16.759 & 14.862 & 0.09661101 & 19.605 & 26.536 & 0.01216578 & 7.345 & 10.345 & 0.00104622 \\
\hline & & EBT & 7.276 & 7.161 & 0.87562077 & 20.916 & 20.726 & 0.95992685 & 3.207 & 3.552 & 0.52496557 \\
\hline & & WBT & 15.897 & 11.241 & 0.00013951 & 25.566 & 30.400 & 0.22500748 & 7.310 & 6.966 & 0.48251019 \\
\hline \multirow{12}{*}{ St. Mary's } & \multirow{4}{*}{ AM } & NBT & 19.219 & 17.483 & 0.2498226 & 4.291 & 6.522 & 0.07640859 & 3.034 & 3.828 & 0.18918118 \\
\hline & & SBT & 8.514 & 7.897 & 0.47477662 & 7.563 & 7.861 & 0.84999212 & 3.034 & 3.103 & 0.8813062 \\
\hline & & EBT & 5.166 & 4.759 & 0.52917522 & 32.860 & 31.101 & 0.73616585 & 2.759 & 3.517 & 0.17062407 \\
\hline & & WBT & 3.059 & 1.172 & 0.00024889 & 20.356 & 16.034 & 0.3689176 & 1.103 & 0.931 & 0.62260657 \\
\hline & \multirow{4}{*}{ NP } & NBT & 14.313 & 16.469 & 0.02782481 & 6.600 & 8.339 & 0.10258036 & 3.375 & 5.531 & 0.00028385 \\
\hline & & SBT & 11.500 & 13.719 & 0.01310986 & 2.682 & 5.939 & 0.000195 & 1.500 & 4.313 & $1.9245 \mathrm{E}-09$ \\
\hline & & EBT & 4.156 & 3.219 & 0.09627411 & 22.133 & 31.508 & \begin{tabular}{|l|}
0.04570057 \\
\end{tabular} & 2.094 & 2.438 & 0.42856488 \\
\hline & & WBT & 3.969 & 1.531 & $1.0526 \mathrm{E}-07$ & 19.207 & 17.484 & 0.73951973 & 1.688 & 1.000 & 0.08682897 \\
\hline & \multirow{4}{*}{ PM } & NBT & 14.621 & 15.241 & 0.5270375 & 7.555 & 5.460 & 0.07381417 & 4.103 & 3.034 & 0.08694377 \\
\hline & & SBT & 19.276 & 18.931 & 0.77964758 & 6.146 & 4.619 & 0.07360804 & 3.207 & 4.310 & 0.03467799 \\
\hline & & EBT & 3.931 & 2.552 & 0.03935207 & 15.378 & 23.208 & \begin{tabular}{|l|}
0.06779658 \\
\end{tabular} & 1.207 & 1.724 & 0.19547741 \\
\hline & & WBT & 10.761 & 5.483 & 5.4669E-09 & 17.138 & 25.961 & 0.01991103 & 2.759 & 3.966 & \begin{tabular}{|l|l|}
0.06986392 \\
\end{tabular} \\
\hline \multirow{9}{*}{ Devonshire } & \multirow{3}{*}{ AM } & NBT & 21.577 & 19.350 & 0.19577121 & 1.071 & 2.036 & 0.02419261 & 1.643 & 3.607 & 0.00017299 \\
\hline & & SBT & 7.835 & 7.500 & 0.69511998 & 0.864 & 1.120 & \begin{tabular}{|l|}
0.63744139 \\
\end{tabular} & 0.464 & 0.670 & 0.32972053 \\
\hline & & EBL & 3.639 & 3.320 & 0.56302541 & 43.153 & 45.640 & 0.6508074 & 2.536 & 3.070 & 0.21123639 \\
\hline & & NBT & 13.120 & 15.375 & 0.01653586 & 1.550 & 2.140 & 0.21853083 & 1.590 & 2.650 & 0.01690812 \\
\hline & NP & SBT & 12.340 & 13.310 & 0.21092099 & 1.750 & 6.170 & 0.00057684 & 1.281 & 3.250 & 0.00097145 \\
\hline & & EBL & 4.125 & 5.280 & 0.04759346 & 41.070 & 35.720 & 0.12093307 & 3.650 & 4.400 & 0.145627 \\
\hline & & NBT & 12.890 & 12.821 & 0.94099443 & 0.910 & 1.595 & 0.15386009 & 0.780 & 1.643 & 0.02582909 \\
\hline & PM & SBT & 21.070 & 21.714 & 0.64291091 & 1.355 & 3.766 & 0.00016296 & 2.250 & 4.429 & 0.00073814 \\
\hline & & EBL & 2.780 & 4.286 & 0.00224166 & 53.880 & 46.860 & 0.24743924 & 2.570 & 3.714 & 0.02150805 \\
\hline & & NBT & 19.056 & 17.000 & 0.19265764 & 10.395 & 19.722 & 0.00303326 & 5.704 & 10.037 & 0.00011839 \\
\hline & $A M$ & SBT & 4.965 & 3.444 & 0.00784716 & 5.732 & 9.244 & 0.1898932 & 0.926 & 1.519 & 0.10505367 \\
\hline & AIVI & EBT & 13.017 & 11.741 & 0.21773395 & 22.547 & 38.711 & 0.00077755 & 7.778 & 9.444 & 0.07610339 \\
\hline & & WBT & 7.113 & 5.852 & 0.14458357 & 30.797 & 33.963 & 0.54547496 & 4.111 & 4.852 & 0.3237321 \\
\hline & & NBT & 10.100 & 10.645 & 0.58473734 & 12.483 & 23.199 & 0.00213803 & 5.333 & 5.806 & 0.57323471 \\
\hline Windsor & NP & SBT & 7.600 & 7.581 & 0.97793252 & 7.086 & 10.231 & \begin{tabular}{|l|}
0.07476182 \\
\end{tabular} & 2.033 & 2.839 & 0.15810721 \\
\hline & INP & EBT & 5.700 & 6.452 & 0.30273642 & 30.080 & 35.701 & \begin{tabular}{|l|}
0.22337379 \\
\end{tabular} & 4.000 & 5.290 & 0.05973661 \\
\hline & & WBT & 4.300 & 4.290 & 0.98628787 & 27.726 & 37.434 & 0.04649338 & 2.900 & 3.867 & 0.06326605 \\
\hline & & NBT & 8.867 & 8.067 & 0.28259059 & 19.419 & 25.270 & 0.0853706 & 5.333 & 5.000 & 0.57541411 \\
\hline & PM & SBT & 15.400 & 13.767 & 0.20752316 & 12.906 & 19.450 & 0.00785558 & 5.300 & 7.233 & 0.04461025 \\
\hline & rivi & EBT & 6.867 & 6.167 & 0.22354658 & 20.165 & 29.487 & 0.00616664 & 5.433 & 4.933 & 0.31445129 \\
\hline & & WBT & 11.267 & 10.333 & 0.33097932 & 21.540 & 39.104 & $6.8352 \mathrm{E}-06$ & 7.400 & 8.000 & 0.47623979 \\
\hline
\end{tabular}


Based on the statistical tests, the results of volume, delay, and queue length comparisons are presented in Table 5. They can be grouped into three categories: (a) lane groups with no significant changes in delay or volume (Unch); (2) lane groups with significant increases in delay or volume (Inc); and (3) lane groups with significant decreases in delay or volume (Dec). Table 6 shows the number and percent of lane groups in each group. The column with heading "\%" gives the ratio of the number of lane groups divided by the total number of lane groups, which is 57 .

Table 6. Summary of t-test Results at $\mathbf{9 0 \%}$ and $\mathbf{9 7 \%}$ Confidence Levels

\begin{tabular}{|c|c|c|c|c|}
\hline Categories & No. of lane groups $\left(90 \% \mathrm{CL}^{*}\right)$ & $\%$ & No. of lane groups $(97 \% \mathrm{CL})$ & $\%$ \\
\hline \multicolumn{5}{|c|}{ VOLUME } \\
\hline Total & 57 & & 57 & \\
\hline Unchanged (Unch) & 36 & $63 \%$ & 41 & $72 \%$ \\
\hline Significantly increased (Inc) & 5 & $9 \%$ & 4 & $7 \%$ \\
\hline Significantly decreased (Dec) & 16 & $28 \%$ & 12 & $21 \%$ \\
\hline \multicolumn{5}{|c|}{ DELAY } \\
\hline Total & 57 & & 57 & \\
\hline Unchanged (Unch) & 23 & $40 \%$ & 32 & $56 \%$ \\
\hline Significantly increased (Inc) & 30 & $53 \%$ & 23 & $40 \%$ \\
\hline Significantly decreased (Dec) & 4 & $7 \%$ & 2 & $4 \%$ \\
\hline \multicolumn{5}{|c|}{ QUEUE LENGTH } \\
\hline Total & 57 & & 57 & \\
\hline Unchanged (Unch) & 28 & $49 \%$ & 37 & $65 \%$ \\
\hline Significantly increased (Inc) & 27 & $47 \%$ & 20 & $35 \%$ \\
\hline Significantly decreased (Dec) & 2 & $4 \%$ & 0 & $0 \%$ \\
\hline
\end{tabular}

${ }^{*} \mathrm{CL}$ : Confidence level.

To maintain a $91 \%$ confidence level for the combined analyses (volume, delay, and queue all together) that is discussed in the next sections, a confidence level of $97 \%$ for the single variable comparisons (volume to volume, delay to delay, etc.) is used. In general, for comparison of individual variables (volume, delay, or queue length alone), confidence levels of $90 \%$ or $95 \%$ is used.

With a $97 \%$ confidence level:

- Out of the 57 lane-group-volume comparisons, 41 lane groups (72\%) showed no significant change in volume; however, 4 (7\%) had a significant increase, and $12(21 \%)$ had a significant decrease.

- Out of the 57 lane-group-delay comparisons, 32 lane groups (56\%) had no significant change in delay; however, 23 (40\%) showed a significant increase, and 2 (4\%) showed significant decrease.

- Out of the 57 lane-group-queue-length comparisons, 37 (65\%) had no significant change in queue length; however, 20 (35\%) showed a significant increase, and none had a significant decrease.

- Volume significantly increased in $7 \%$ of the lane groups, delay significantly increased in $40 \%$, and queue significantly increased in $35 \%$. Similarly, volume decreased significantly in $21 \%$ of the lane groups, but delay significantly decreased in $4 \%$ of the lane groups and there was no queue length decrease. These findings are indications that the ASCT was not improving traffic operation conditions for the cases where volume was significantly increased. 


\subsubsection{Delay and Volume Combination Analysis}

Looking at the changes in delay without paying attention to the changes in traffic volume may not reveal the impact of ASCT on traffic operation. Delay may increase due to the volume increase, and ASCT may also show an increase in delay; but this pattern is not an indication that ACST is not working properly. To consider the influence of volume changes on the delay changes, a combined-analysis approach is used, where the delay-volume, $D_{v}$, performance measure is analyzed. As Table 7 shows,

- In the 41 lane groups for which volume remained unchanged, delay significantly increased in 19, remained unchanged in 20, and decreased in 2.

- In the 4 lane groups for which volume significantly increased, delay significantly increased in only 1 , and remained unchanged in 3.

- In the 12 lane groups for which volume significantly decreased, delay remained unchanged in 9 and significantly increased in 3.

Table 7. Summary of Volume and Delay Combination Analysis at $94 \%$ Confidence Level $(0.97 * 0.97$ Individual Confidence Levels)

\begin{tabular}{|l|c|c|c|c|c|}
\hline \multicolumn{1}{|c|}{ Categories } & $\begin{array}{c}\text { Delay } \\
\text { increased }\end{array}$ & $\begin{array}{c}\text { Delay } \\
\text { unchanged }\end{array}$ & $\begin{array}{c}\text { Delay } \\
\text { decreased }\end{array}$ & Total & $\%$ \\
\hline $\begin{array}{l}\text { Volume } \\
\text { increased }\end{array}$ & 1 & 3 & 0 & 4 & $7 \%$ \\
\hline $\begin{array}{l}\text { Volume } \\
\text { unchanged }\end{array}$ & 19 & 20 & 2 & 41 & $72 \%$ \\
\hline $\begin{array}{l}\text { Volume } \\
\text { decreased }\end{array}$ & 3 & 9 & 0 & 12 & $21 \%$ \\
\hline \multicolumn{7}{|c|}{ Total } \\
\hline
\end{tabular}

- The final decision as to whether these changes should be considered improvement or deterioration will be made when all three variables (volume, delay, and queue length) are considered. Based on the volume and delay combination (only two variables), the results can be grouped into three groups, e.g., categories (this is not a complete picture): (1) in 20 lane groups, both delay and volume were unchanged (white cell in Table 7); (2) in 3 lane groups, delay remained unchanged while volume increased; and there was no lane group with delay decrease and volume increase; but in 1 case, delay decreased while volume remained unchanged (green cells in Table 7); (3) in 19 lane groups, delay increased while volume remained unchanged; in 9, delay remained unchanged while volume significantly decreased; and in 3 , delay significantly increased and volume decreased significantly (blue cells in Table 7). For the lane groups where both delay and volume significantly increased/decreased (yellow cells), HCS 2010 (9) was used to estimate the expected delay increase/decrease due to the volume change. More detailed information on these special cases, as well as intersection-level delay and volume combination analysis, is given in Appendix A.2 


\subsubsection{Queue Length and Volume Combination Analysis}

To consider the influence of volume changes on queue length changes, similar to the delay and volume combined analysis, a combined analysis approach is used in which the queue length-volume, $Q_{v}$, performance measure is analyzed. Table 8 , shows the summary of the volume and queue length conditions for all cases in the study.

- In the 41 lane groups for which volume remained unchanged, queue length significantly increased in 13 , remained unchanged in 28 , and decreased in none.

- In the 4 lane groups for which volume significantly increased, queue length significantly increased in all 4.

- In the 12 lane groups for which volume significantly decreased, queue length remained unchanged in 8 , significantly decreased in 1 , and significantly increased in 4.

Table 8. Summary of Volume and Queue-Length Combination Analysis, 0.94 Confidence Levels

\begin{tabular}{|l|c|c|c|c|c|}
\hline \multicolumn{7}{|c|}{ Number of lane groups } & Total \\
\hline & $\begin{array}{c}\text { Queue } \\
\text { increased }\end{array}$ & $\begin{array}{c}\text { Queue } \\
\text { unchanged }\end{array}$ & $\begin{array}{c}\text { Queue } \\
\text { decreased }\end{array}$ & Tol \\
\hline $\begin{array}{l}\text { Volume } \\
\text { increased }\end{array}$ & 4 & 0 & 0 & 4 & $7 \%$ \\
\hline $\begin{array}{l}\text { Volume } \\
\text { unchanged }\end{array}$ & 13 & 28 & 0 & $12 \%$ \\
\hline $\begin{array}{l}\text { Volume } \\
\text { decreased }\end{array}$ & 3 & 9 & 0 & $\mathbf{2 1 \%}$ \\
\hline \multicolumn{7}{|c|}{ Total } \\
\hline
\end{tabular}

- As mentioned before, the final decision as to whether these changes should be considered improvement or deterioration will be made when all three variables (volume, delay, and queue length) are considered. Based on the volume and queue length combination (only two variables), the results can be grouped into three categories (even though this analysis does not give a complete picture): (1) in 28 lane groups, both queue length and volume remained unchanged (white cell in Table 8); (2) in no lane group did queue length remain unchanged while volume increased, and in no case did queue length decrease while volume remained unchanged or significantly increased (green cells in Table 8); (3) in 13 lane groups, queue length increased while volume remained unchanged; in 2 , queue length significantly increased while volume significantly decreased; and in 9, queue length remained unchanged while volume decreased significantly (blue cells in Table 8). For the lane groups in which both queue length and volume significantly increased/decreased (yellow cells), HCS 2010 was used to estimate the expected queue length increases/decreases due to the volume changes. More detailed information on these special cases, as well as intersection level queue length and volume combination analysis, is given in Appendix A.2.

\subsection{ANALYSIS OF THE ASCT PERFORMANCE}


Considering the volume, delay, and queue length changes combined, an overall performance indicator (PI) was determined for each lane group, for each intersection, and for each time period. Almost all of the lane groups could easily be assigned to one of three PI categories (classes): Imp (Improved), Unch (Unchanged), or Det (Deteriorated). For example, the class for which volume increased significantly while delay and queue length significantly decreased: that approach was placed in Imp category. The Unch category is assigned to an approach when volume, delay, and queue length remained unchanged. Finally, the Det category is assigned to an approach for which volume did not change significantly; but delay and queue length significantly increased. However, for a very small number of lane groups, careful consideration is needed to determine their category. On the rare occasion that the lane group could not be assigned into one of the three categories, it was labeled as "Mixed" results. The results of such determinations are summarized in Table 9.

\subsubsection{Number of Cases Involved in Performance Analysis}

According to Table 5, further investigation was done for the cases with average volumes of more than 2 cars. According to the frequency at which the signal was called for a green-time allocation to a specific phase, for a specific case, if in $50 \%$ or more of the cycles during the analysis period, the corresponding phase called the signal, we took that case into consideration; but if the signal was called less frequently (less than 50\%), we did not take that case into account any more. As a result, one case was removed from the list of cases for further analysis: Neil and Stadium, WB, during the AM peak, with an average volume of 0.7 car under TBC 2017 and 0.5 car under ASCT 2017. Thus, the number of cases analyzed is 56 in the following sections. 
Table 9. PI for Three Volume Groups, Considering Delay and Queue, at $91 \%$ Confidence Level

(a) when VOLUME INCREASED SIGNIFICANTLY (on 4 approaches)

\begin{tabular}{|l|c|c|c|}
\hline Queue & Inclay & Unchanged & Decreased \\
\hline Increased & Det* (1) $^{*}$ & Imp* (1), Det* (2) & - \\
\hline Unchanged & - & - & - \\
\hline Decreased & - & - & - \\
\hline
\end{tabular}

(b) when VOLUME DECREASED SIGNIFICANTLY (on 11 approaches)

\begin{tabular}{|l|c|c|c|}
\hline Queue & Inclay & Unchanged & Decreased \\
\hline Increased & Det *(1) & $\operatorname{Det}(1)$ & - \\
\hline Unchanged & $\operatorname{Det}(2)$ & $\operatorname{Det}(7)$ & - \\
\hline Decreased & - & - & - \\
\hline
\end{tabular}

(c ) when VOLUME DID NOT CHANGE SIGNIFICANTLY (on 41 approaches)

\begin{tabular}{|l|c|c|c|}
\hline \multicolumn{1}{|c|}{ Delay } & Increased & Unchanged & Decreased \\
\hline Increased & Det (11) & Det (2) & - \\
\hline Unchanged & Det (8) & Unch (18) & Imp (2) \\
\hline Decreased & - & - & - \\
\hline
\end{tabular}

Note: The Imp* and Det indicate that some of the PIs are a result of the HCS runs mentioned in previous sections.

Now that the PI for each lane group is determined, Table 10 summarizes the outcome of the analyses for each lane group during the three time periods (AM peak, off peak, and PM peak). The NA entry indicates that the Stadium intersection on WB, AM, is removed from the analysis due to the low volume, leaving 56 cases. 
Table 10. Performance Indicator (PI) for Each Lane Group at 91\% Confidence Level

\begin{tabular}{|c|c|c|c|c|}
\hline Intersections & Approach & AM Peak & Noon Peak & PM Peak \\
\hline \multirow{4}{*}{ Stadium } & NBT & Det & Det & Det \\
\hline & SBT & Det & Unch & Det \\
\hline & EBT & Det & Det & Det \\
\hline & WBT & $N A$ & Det & Det \\
\hline \multirow{4}{*}{ Kirby } & NBT & Det & Imp & Imp \\
\hline & SBT & Det & Unch & Det \\
\hline & EBT & Det & Det & Unch \\
\hline & WBT & Det & Det & Det \\
\hline \multirow{4}{*}{ St. Mary's } & NBT & Unch & Det & Unch \\
\hline & SBT & Unch & Det & Unch \\
\hline & EBT & Unch & Unch & Unch \\
\hline & WBT & Det & Det & Det \\
\hline \multirow{3}{*}{ Devonshire } & NBT & Det & Det & Det \\
\hline & SBT & Unch & Det & Det \\
\hline & EBL & Unch & Unch & Imp \\
\hline \multirow{4}{*}{ Windsor } & NBT & Det & Det & Unch \\
\hline & SBT & Det & Unch & Det \\
\hline & EBT & Det & Unch & Det \\
\hline & WBT & Unch & Unch & Det \\
\hline
\end{tabular}

Table 11 gives the ratio of the number of lane groups in a category to the total number of lane groups analyzed at that intersection. In the last row of Table 11, the ratios for the corridor level are given.

Table 11. Performance Indicator (PI) at Intersection and Corridor Levels at $91 \%$ Confidence Level

\begin{tabular}{|l|l|l|l|}
\hline Intersections & Improved & Deteriorated & Unchanged \\
\hline Stadium & $0 / 11$ & $10 / 11$ & $1 / 11$ \\
\hline Kirby & $2 / 12$ & $8 / 12$ & $2 / 12$ \\
\hline St. Mary's & $0 / 12$ & $5 / 12$ & $7 / 12$ \\
\hline Devonshire & $1 / 9$ & $5 / 9$ & $3 / 9$ \\
\hline Windsor & $0 / 12$ & $7 / 12$ & $5 / 12$ \\
\hline Total at corridor level (\%) & $3 / 56(5 \%)$ & $35 / 56(63 \%)$ & $18 / 56(32 \%)$ \\
\hline
\end{tabular}

Out of the 56 lane groups, PI improved in 3 lane groups (5\%), remained unchanged in 18 (32\%), and deteriorated in 35 (63\%)-as shown in Table 11.

Overall, PI either improved or remained unchanged in $37 \%$ of the lane groups. However, in $63 \%, \mathrm{PI}$ deteriorated. Out of the 35 deteriorated cases (the 63\%), volume significantly increased in 3, did not change significantly in 21 , and significantly decreased in 11 . The deterioration in the 3 cases can be attributed to the volume increase, which indicates the system's inability to respond adequately to the 
volume increase. However, in the 21 lane groups for which volume did not change significantly, the deterioration in $\mathrm{PI}$ is not expected.

Schematically, Figure 8 reflects the improvements and deteriorations at each intersection.

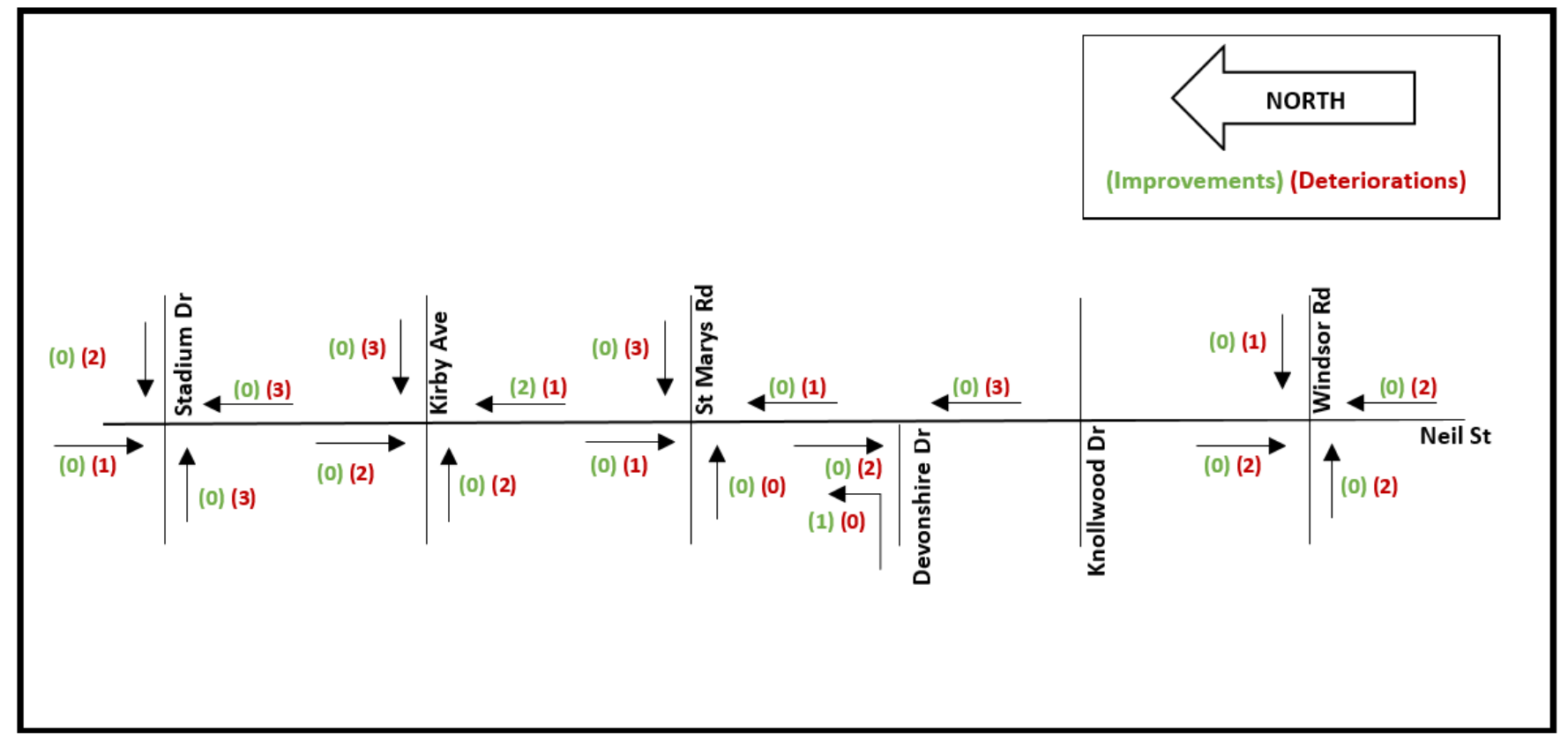

Figure 8. Number of improvements and deteriorations at intersections on Neil Street.

In the next section, the changes of $\mathrm{PI}$ at each intersection is discussed.

\subsection{DETAILED ANALYSIS OF PI AT INTERSECTION LEVEL}

In the following section, the ASCT performance at each intersection for each time period is further analyzed, considering volume, delay, and queue length combined. Thus, we will use the words "improved," "deteriorated," "unchanged," and "mixed results" as the performance indicator (PI) for each approach of each intersection.

\subsubsection{Neil Street and Stadium Drive}

AM peak (AM): Generally, there was deterioration on all approaches analyzed.

Major street: During this period, even though the through volumes on two approaches (NB, SB) remained unchanged, queue and delay significantly increased. Thus, performance deteriorated on the NB and SB approaches.

Minor street: Volume on EB approach significantly decreased; delay and queue length significantly increased. Thus, ASCT performance deteriorated on EB. WB is removed from further analysis due to low volume. 
Noon peak (NP): Generally, there was deterioration on all approaches except for SB, which had unchanged performance.

Major street: Although volume on NB remained unchanged, delay and queue length increased significantly. Volume, delay, and queue length remained unchanged on SB. Thus, performance deteriorated on NB and remained unchanged on SB.

Minor street: Although volume decreased significantly on EB and WB approaches, delay remained unchanged on both. Queue length increased significantly on EB and remained unchanged on WB. Thus, the intersection performance deteriorated on EB and WB approaches.

PM peak (PM): Generally, there was deterioration on all approaches.

Major street: On NB and SB, volume did not changed significantly; delay remained unchanged on NB and increased significantly on SB. Queue length significantly increased on both NB and SB approaches. Thus, performance deteriorated on NB and SB approaches.

Minor street: Volume decreased significantly on EB and remained unchanged on WB. Delay increased significantly on both EB and WB approaches. Queue length remained unchanged on EB and increased significantly on WB. Thus, performance deteriorated on EB and WB approaches.

Summary: At the intersection of Neil and Stadium, for all 11 analyzed approaches during all three time periods, system performance did not improve on any approach, remained unchanged on one, and deteriorated on 10.

\subsubsection{Neil Street and Kirby Avenue}

AM peak (AM): Generally, ASCT performance deteriorated on all approaches.

Major street: Volume remained unchanged, and both delay and queue length increased significantly on NB; therefore, performance deteriorated on NB. On SB, volume decreased significantly; delay and queue length remained unchanged; therefore, performance deteriorated on SB.

Minor street: Volume remained unchanged, and both delay and queue length increased significantly on EB; therefore, performance deteriorated on EB. On WB, although volume decreased significantly, delay and queue length remained unchanged.

Noon peak (NP): Generally, performance improved on NB, remained unchanged on SB, and deteriorated on $E B$ and WB.

Major street: Volume and queue length remained unchanged on NB and SB. Delay decreased significantly on NB and remained unchanged on SB.

Minor street: Although volume and queue length remained unchanged on EB, delay increased significantly. On WB, volume decreased significantly; delay increased significantly; and queue length remained unchanged. 
PM peak (PM): Generally, performance improved on NB, deteriorated on SB, remained unchanged on $E B$, and deteriorated on WB.

Major street: On NB, although volume and queue length remained unchanged, delay decreased significantly; therefore, performance improved on NB. On SB, volume decreased significantly, but delay and queue length increased significantly; therefore, performance deteriorated on SB.

Minor street: On EB, volume, delay, and queue length did not change significantly. On WB, volume decreased significantly; but delay and queue length remained unchanged. Thus, system performance remained unchanged on EB and deteriorated on WB.

Summary: At the intersection of Neil and Kirby, for all 12 approaches during all three time periods, system performance improved on 2 approaches, remained unchanged on 2, and deteriorated on 8.

\subsubsection{Neil Street and St. Mary's Road}

AM peak (AM): Generally, performance remained unchanged on NB, SB, and EB, and deteriorated on WB.

Volume, delay, and queue length remained unchanged on NB, SB, and EB approaches. On WB, although volume decreased significantly, delay and queue length remained unchanged. Thus, performance deteriorated on WB.

Noon peak (NP): Generally, performance deteriorated on NB, SB, and WB, and remained unchanged on EB.

Major street: On NB, volume and queue length increased significantly; and delay remained unchanged. The queue length increase was more than expected due to the volume increase (based on the HCS runs, see A.2). Thus, performance deteriorated on NB. On SB, volume, delay, and queue length increased significantly. The increase in both delay and queue length was more than expected due to the volume increase (based on the HCS runs, see A.2). Thus, the performance deteriorated on SB.

Minor street: On EB, volume, delay, and queue length remained unchanged. On WB, although volume decreased significantly, delay and queue length remained unchanged. Thus, performance remained unchanged on EB and deteriorated on WB.

PM peak (PM): Generally, performance remained unchanged on NB, SB, and EB. Performance deteriorated on WB.

Volume, delay, and queue length remained unchanged on NB, SB, and EB. On WB, although volume decreased significantly, delay increased significantly; and queue length remained unchanged. Thus, performance deteriorated on WB.

Summary: At the intersection of Neil and St. Mary's, for all 12 approaches during all three time periods, system performance improved on no approaches, remained unchanged on 7 , and deteriorated on 5. 


\subsubsection{Neil Street and Devonshire Drive}

Note that the minor-street analysis at this intersection is for EBL (eastbound left) approach only.

AM peak (AM): Generally, performance deteriorated on NB and remained unchanged on SB and EBL.

Volume remained unchanged on all three approaches. On NB, delay and queue length increased significantly. On SB and EBL, delay and queue length did not change significantly.

Noon peak (NP): Generally, during this period, performance deteriorated on NB and SB, and remained unchanged on EBL.

On NB, volume and queue length increased significantly; and delay remained unchanged. The queuelength increase was more than expected due to the volume increase (based on the HCS runs, see A.2). Thus, the performance deteriorated on NB.

On SB, volume did not change significantly although delay and queue length increased significantly.

On EBL, volume, queue length, and delay did not change significantly. Thus, the performance remained unchanged on EBL.

PM peak (PM): Generally, performance deteriorated on NB and SB, and improved on EBL.

On NB, volume and delay remained unchanged although queue length increased significantly.

On SB, volume did not change significantly; but both delay and queue increased significantly.

On EBL, volume and queue length increased significantly; but delay did not change significantly. The queue-length increase was less than expected due to the volume increase (based on the HCS runs, see A.2). Thus, the performance improved on EBL.

Summary: At the intersection of Neil and Devonshire, for the 9 approaches during three time periods, system performance improved on 1 approach, remained unchanged on 3, and deteriorated on 5.

\subsubsection{Neil Street and Windsor Road}

AM peak (AM): Generally, performance deteriorated on NB, SB, and EB and remained unchanged on WB.

Volume decreased significantly on SB and remained unchanged on all other approaches. On NB, SB, and $E B$, queue length increased significantly; and it remained unchanged on WB. Delay increased significantly on NB and EB, and remained unchanged on SB and WB.

Noon peak (NP): Generally, performance deteriorated on NB and remained unchanged on SB, EB, and WB. 
Volume and queue length remained unchanged on NB, and delay increased significantly. Thus, performance deteriorated on NB. On all other approaches, volume, delay, and queue length remained unchanged; therefore, performance remained unchanged on SB, EB, and WB.

PM peak (PM): Generally, performance remained unchanged on NB and deteriorated on SB, EB, and WB. Volume, delay, and queue length remained unchanged on NB.

On $\mathrm{SB}, \mathrm{EB}$, and $\mathrm{WB}$, volume and queue length remained unchanged; delay significantly increased. Thus, performance deteriorated on $\mathrm{SB}, \mathrm{EB}$, and $\mathrm{WB}$.

Summary: At the intersection of Neil and Windsor, for the 12 approaches during three time periods, system performance did not improve on any approach, remained unchanged on 5 , and deteriorated on 7.

\subsection{DETERIORATION ANALYSIS}

The results showed a 63\% deterioration (35 cases) in performance at the intersections along Neil Street. Further analysis was performed to investigate possible causes for the deterioration.

\subsubsection{Deterioration due to Arrival Type Changes under ASCT 2017}

Quality of progression at signalized intersections along a coordinated corridor is decided based on the arrival type (AT) (10). The AT parameter is based upon the percentage of vehicles arriving during the green indication, when they arrive during the green interval, and the density of the arriving platoon.

Currently, two common methods are available to determine arrival types at a signalized intersection, on a cycle-by-cycle basis: the HCM method and a visual method. In the visual method, the procedure involves matching the observed traffic conditions (through videos) to one of the detailed definitions of quality of progression and arrival types. These definitions are based on platoon arrival time during the cycle. Depending on a platoon arrival time, the observer assigns an arrival type of 1 to 5 for each approach during a signal cycle. No arrival type 6 was observed. During data reduction, it was observed that a platoon arrives during a span of time that practically can be considered a "point." For example, a platoon with very favorable progression (arrival type 5) can arrive around the beginning of green but does not need to be exactly at the beginning of green. A reasonable range was established for datareduction purposes. These ranges are shown in Table 12 and schematically shown in Figure 9. 
Table 12. Relationship between Arrival Type and Platoon-Arrival Time

\begin{tabular}{|c|c|c|}
\hline Arrival type & Arrival time of the platoon & Progression quality \\
\hline $\mathbf{1}$ & $95 \%$ of the green elapsed-25\% of the red elapsed & Very poor \\
\hline $\mathbf{2}$ & $25 \%$ of the red elapsed-95\% of the red elapsed & Poor \\
\hline $\mathbf{3}$ & Random arrivals did not platoon anytime during a cycle. & No platooning \\
\hline \multirow{2}{*}{$\mathbf{5}$} & $25 \%$ of the green elapsed-75\% of the green elapsed & Good \\
\cline { 2 - 3 } & 75\% of the green elapsed-95\% of the green elapsed & Not good \\
\hline
\end{tabular}

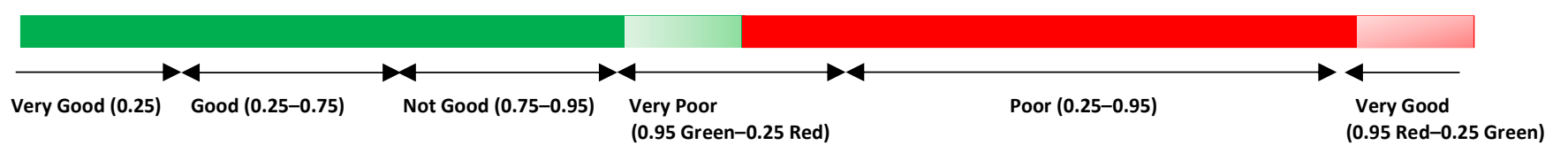

Figure 9. Relationship between the relative platoon-arrival time and progression quality.

We have determined cycle-by-cycle arrival types for the deteriorated cases, using March and April 2017 videos. This way, we compared the arrival types in March and those in April for the cases with deteriorated performances.

In the cases for which arrival types where mostly very good or good in March and very poor or poor in April, we can conclude that unfavorable arrival types in April could be the reason for the deterioration. Cases with the condition mentioned are highlighted in Table 13. In 10 cases, the arrival type worsened. In all 10 cases, the PI also deteriorated. 
Table 13. Cases with Deteriorated Performance under ASCT 2017 and with More Frequent Unfavorable Arrival Types, as Compared to TBC 2017

\begin{tabular}{|c|c|c|c|c|}
\hline Intersections & Approach & AM Peak & Noon Peak & PM Peak \\
\hline \multirow{4}{*}{ Stadium } & NBT & Det $^{1}$ & Det & Det \\
\hline & SBT & Det & Unch & $\mathrm{Det}^{2}$ \\
\hline & EBT & Det & Det & Det \\
\hline & WBT & $N A$ & Det & Det \\
\hline \multirow{4}{*}{ Kirby } & NBT & Det & Imp & Imp \\
\hline & SBT & Det & Unch & Det \\
\hline & EBT & Det & Det & Unch \\
\hline & WBT & Det & Det & Det \\
\hline \multirow{4}{*}{ St. Mary's } & NBT & Unch & Det & Unch \\
\hline & SBT & Unch & Det & Unch \\
\hline & EBT & Unch & Unch & Unch \\
\hline & WBT & Det & Det & Det \\
\hline \multirow{3}{*}{ Devonshire } & NBT & $\operatorname{Det}^{3}$ & Det & Det $^{4}$ \\
\hline & SBT & Unch & Det & Det $^{5}$ \\
\hline & EBL & Unch & Unch & Imp \\
\hline \multirow{4}{*}{ Windsor } & NBT & $\operatorname{Det}^{6}$ & Det & Unch \\
\hline & SBT & $\mathrm{Det}^{7}$ & Unch & $\mathrm{Det}^{8}$ \\
\hline & EBT & Det & Unch & Det \\
\hline & WBT & Unch & Unch & Det \\
\hline
\end{tabular}

Based on the highlighted and numbered cases above, an analysis of the detailed cycle-by-cycle arrivaltype conditions is presented in the following:

1. Stadium, AM, NB:

Table 14. Distribution of Arrival Types for TBC 2017 vs. ASCT 2017 Conditions

\begin{tabular}{|l|c|c|}
\hline Stadium, AM, NB & TBC 2017 & ASCT 2017 \\
\hline Cycles & 58 & 58 \\
\hline Very good or good & $53 \%$ & $34 \%$ \\
\hline Poor or very poor & $2 \%$ & $19 \%$ \\
\hline Not good & $0 \%$ & $12 \%$ \\
\hline No platooning & $45 \%$ & $34 \%$ \\
\hline
\end{tabular}

Based on Table 14, during the AM peak at Stadium NB under TBC 2017, 53\% of the cycles had very good or good ATs; and only $2 \%$ had poor or very poor. Under ASCT $2017,34 \%$ of the cycles had very good or good ATs; and $19 \%$ had poor or very poor. Also, the ATs in the not-good category were more frequent during ASCT 2017. These findings show that the ATs were relatively worsened under ASCT 2017; and Stadium, AM, NB was in a better condition during TBC 2017, in terms of AT. 
2. Stadium, PM, SB:

Table 15. Distribution of Arrival Types for TBC 2017 vs. ASCT 2017 Conditions

\begin{tabular}{|l|r|r|}
\hline Stadium, PM, SB & \multicolumn{1}{|l|}{ TBC 2017 } & ASCT 2017 \\
\hline Cycles & 28 & 28 \\
\hline Very good or good & $77 \%$ & $25 \%$ \\
\hline Poor or very poor & $3 \%$ & $31 \%$ \\
\hline Not good & $3 \%$ & $5 \%$ \\
\hline No platooning & $17 \%$ & $39 \%$ \\
\hline
\end{tabular}

Based on Table 15, during the PM peak at Stadium SB under TBC 2017 conditions, 77\% of the cycles had very good or good ATs; and 3\% had poor or very poor. Under ASCT 2017, 25\% of the cycles had very good or good ATs; and $31 \%$ had poor and very poor. These findings show that good progression conditions were less frequent during ASCT 2017 and poor progression conditions more frequent, as compared to TBC 2017. These findings show that ATs were relatively worsened under ASCT 2017; and Stadium, PM, SB was in a better condition during TBC 2017, in terms of AT.

3. Devonshire, AM, NB:

Table 16. Distribution of Arrival Types for TBC 2017 vs. ASCT 2017 Conditions

\begin{tabular}{|l|r|r|}
\hline Devonshire, AM, NB & TBC 2017 & ASCT 2017 \\
\hline Cycles & 28 & 28 \\
\hline Very good or good & $82 \%$ & $29 \%$ \\
\hline Poor or very poor & $11 \%$ & $57 \%$ \\
\hline Not good & $0 \%$ & $0 \%$ \\
\hline No platooning & $32 \%$ & $11 \%$ \\
\hline
\end{tabular}

Based on Table 16, during the AM peak at Devonshire NB under TBC 2017 conditions, 82\% of the cycles had very good or good ATs; and $11 \%$ had poor or very poor. Under ASCT $2017,29 \%$ of the cycles had very good or good ATs; and $57 \%$ had poor or very poor. These findings show that good progression conditions were less frequent during ASCT 2017 and poor progression conditions more frequent, as compared to TBC 2017. These findings show that the ATs were relatively worsened under ASCT 2017; and Devonshire, AM, NB was in a better condition during TBC 2017, in terms of AT. 
4. Devonshire, PM, NB:

Table 17. Distribution of Arrival Types for TBC 2017 vs. ASCT 2017 Conditions

\begin{tabular}{|l|r|r|}
\hline Devonshire, PM, NB & TBC 2017 & ASCT 2017 \\
\hline Cycles & 28 & 28 \\
\hline Very good or good & $63 \%$ & $50 \%$ \\
\hline Poor or very poor & $3 \%$ & $23 \%$ \\
\hline Not good & $0 \%$ & $0 \%$ \\
\hline No platooning & $30 \%$ & $27 \%$ \\
\hline
\end{tabular}

Based on Table 17, during the PM peak at Devonshire NB under TBC 2017 conditions, 63\% of the cycles had very good or good ATs; and 3\% had poor or very poor. Under ASCT 2017, 50\% of the cycles had very good or good ATs; and $23 \%$ had poor or very poor. These findings show that good progression conditions were less frequent during ASCT 2017 and poor progression conditions more frequent, as compared to TBC 2017. These findings show that the ATs were relatively worsened under ASCT 2017; and Devonshire, PM, NB was in a better condition during TBC 2017, in terms of AT.

5. Devonshire, PM, SB:

Table 18. Distribution of the Arrival Types for TBC 2017 vs. ASCT 2017 Conditions

\begin{tabular}{|l|r|r|}
\hline Devonshire, PM, SB & TBC 2017 & ASCT 2017 \\
\hline Cycles & 28 & 28 \\
\hline Very good or good & $89 \%$ & $33 \%$ \\
\hline Poor or very poor & $0 \%$ & $37 \%$ \\
\hline Not good & $0 \%$ & $0 \%$ \\
\hline No platooning & $32 \%$ & $10 \%$ \\
\hline
\end{tabular}

Based on Table 18, during the PM peak at Devonshire SB under TBC 2017 conditions, 89\% of the cycles had very good or good ATs; and none had poor or very poor. Under ASCT 2017, 33\% of the cycles had very good or good ATs; and $37 \%$ had poor or very poor. These findings show that good progression conditions were less frequent during ASCT 2017 and poor progression conditions more frequent, as compared to the TBC 2017 conditions. These findings show that the ATs are relatively worsened under ASCT 2017; and Devonshire, PM, SB was in a better condition under TBC 2017, in terms of AT. 
6. Windsor, AM, NB:

Table 19. Distribution of the Arrival Types for TBC 2017 vs. ASCT 2017 Conditions

\begin{tabular}{|l|r|r|}
\hline Windsor, AM, NB & \multicolumn{1}{|l|}{ TBC 2017 } & ASCT 2017 \\
\hline Cycles & 28 & 28 \\
\hline Very good or good & $61 \%$ & $18 \%$ \\
\hline Poor or very poor & $14 \%$ & $54 \%$ \\
\hline Not good & $4 \%$ & $11 \%$ \\
\hline No platooning & $21 \%$ & $18 \%$ \\
\hline
\end{tabular}

Based on Table 19, during the AM peak at Windsor NB under TBC 2017 conditions, 61\% of the cycles had very good or good ATs; and $14 \%$ had poor or very poor. Under ASCT 2017, $18 \%$ of the cycles had very good or good ATs; and $54 \%$ had poor or very poor. These findings show that good progression conditions were less frequent during ASCT 2017 and poor progression conditions more frequent, as compared to TBC 2017 conditions. These findings show that ATs were relatively worsened under ASCT 2017; and Windsor, AM, NB was in a better condition during TBC 2017, in terms of AT.

7. Windsor, AM, SB:

Table 20. Distribution of Arrival Types for TBC 2017 vs. ASCT 2017 Conditions

\begin{tabular}{|l|r|r|}
\hline Windsor, AM, SB & \multicolumn{1}{|l|}{ TBC 2017 } & ASCT 2017 \\
\hline Cycles & 28 & 28 \\
\hline Very good or good & $43 \%$ & $33 \%$ \\
\hline Poor or very poor & $7 \%$ & $15 \%$ \\
\hline Not good & $0 \%$ & $0 \%$ \\
\hline No platooning & $50 \%$ & $52 \%$ \\
\hline
\end{tabular}

Based on Table 20, during the AM peak at Windsor SB under TBC 2017 conditions, 43\% of the cycles had very good or good ATs; and 7\% had poor or very poor. Under ASCT 2017, 33\% of the cycles had very good or good ATs; and $15 \%$ had poor or very poor. These findings show that the ATs were relatively worsened under ASCT 2017; and Windsor, AM, SB was in a better condition during TBC 2017, in terms of AT.

8. Windsor, PM, SB:

Table 21. Distribution of Arrival Types for TBC 2017 vs. ASCT 2017 Conditions

\begin{tabular}{|l|r|r|}
\hline Windsor, PM, SB & \multicolumn{1}{|l|}{ TBC 2017 } & ASCT 2017 \\
\hline Cycles & 28 & 28 \\
\hline Very good or good & $90 \%$ & $43 \%$ \\
\hline Poor or very poor & $7 \%$ & $40 \%$ \\
\hline
\end{tabular}




\begin{tabular}{|l|r|r|} 
Not good & $0 \%$ & $13 \%$ \\
\hline No platooning & $3 \%$ & $3 \%$ \\
\hline
\end{tabular}

Based on Table 21, during the PM peak at Windsor SB under TBC 2017 conditions, 90\% of the cycles had very good or good ATs; and $7 \%$ had poor or very poor. Under ASCT $2017,43 \%$ of the cycles had very good or good ATs; but $40 \%$ had poor or very poor. Also, the percent for the "not good" arrivaltype category was 13\% for ASCT 2017, as compared to 0\% for TBC 2017. These findings show that good progression conditions were less frequent during ASCT 2017 and poor progression conditions more frequent, as compared to TBC 2017. These findings show that ATs were relatively worsened under ASCT 2017; and Windsor, PM, SB was in a better condition during TBC 2017, in terms of AT.

\subsubsection{Deterioration due to Insufficient System Response to Volume Increase}

Among the 56 cases, 3 had significant volume increase. In all 3 cases, volume increase resulted in deterioration in system performance, showing the system response was insufficient for the volume increase. Based on the volume increase, some adjustments to the signal timing is to be expected, such as increase in the green time or cycle length for the subject lane group. The system's failure to adapt the signal timing to the volume changes could be the cause of the deterioration. These cases are highlighted in Table 22: NB and SB at St. Mary's during the noon peak and NB at Devonshire during the noon peak.

Table 22. Cases in Which the System Response Is Insufficient to the Volume Increase

\begin{tabular}{|c|c|c|c|c|}
\hline Intersections & Approach & AM Peak & Noon Peak & PM Peak \\
\hline \multirow{4}{*}{ Stadium } & NBT & Det & Det & Det \\
\hline & SBT & Det & Unch & Det \\
\hline & EBT & Det & Det & Det \\
\hline & WBT & $N A$ & Det & Det \\
\hline \multirow{4}{*}{ Kirby } & NBT & Det & Imp & $\operatorname{Imp}$ \\
\hline & SBT & Det & Unch & Det \\
\hline & EBT & Det & Det & Unch \\
\hline & WBT & Det & Det & Det \\
\hline \multirow{4}{*}{ St. Mary's } & NBT & Unch & Det $^{1}$ & Unch \\
\hline & SBT & Unch & $\mathrm{Det}^{2}$ & Unch \\
\hline & EBT & Unch & Unch & Unch \\
\hline & WBT & Det & Det & Det \\
\hline \multirow{3}{*}{ Devonshire } & NBT & Det & Det $^{3}$ & Det \\
\hline & SBT & Unch & Det & Det \\
\hline & EBL & Unch & Unch & Imp \\
\hline \multirow{4}{*}{ Windsor } & NBT & Det & Det & Unch \\
\hline & SBT & Det & Unch & Det \\
\hline & EBT & Det & Unch & Det \\
\hline & WBT & Unch & Unch & Det \\
\hline
\end{tabular}




\subsubsection{Deterioration due to Signal Timing Changes}

We examined the cycle length changes, the "Average Effective Green Time" change, and "the g/C Ratio" changes between TBC 2017 and ASCT 2017 to find potential factors contributing to the deterioration. The details are given in Appendix A.3 and a brief summary in the following sections.

To investigate the changes in the signal timing between TBC 2017 and ASCT 2017, t-tests were conducted to compare the average effective greens, average $\mathrm{g} / \mathrm{C}$ ratios, and average cycle lengths. Specific test results are presented in Table 23. 
Table 23. Signal Timing Change Comparisons between TBC 2017 and ASCT 2017

\begin{tabular}{|c|c|c|c|c|c|c|c|c|c|c|c|c|c|c|c|c|c|}
\hline \multirow[b]{3}{*}{ Intersection } & \multirow[b]{3}{*}{$\begin{array}{c}\text { Time } \\
\text { period }\end{array}$} & \multirow[b]{3}{*}{ Approach } & \multirow{2}{*}{\multicolumn{3}{|c|}{ Previous results }} & \multicolumn{12}{|c|}{ Signal timing changes } \\
\hline & & & & & & \multicolumn{4}{|c|}{ Average cycle length changes } & \multicolumn{4}{|c|}{$\begin{array}{c}\text { Average effective green time } \\
\text { changes }\end{array}$} & \multicolumn{4}{|c|}{ Average $\mathrm{g} / \mathrm{C}$ changes } \\
\hline & & & $\begin{array}{c}\text { Delay } \\
\text { change } \\
\text { (Apr- } \\
\text { Mar) }\end{array}$ & $\begin{array}{c}\text { Queue } \\
\text { length } \\
\text { change } \\
\text { (Apr- } \\
\text { Mar) }\end{array}$ & PI & $\begin{array}{c}\text { April } \\
\text { cycle } \\
\text { length } \\
\text { average }\end{array}$ & $\begin{array}{l}\text { March } \\
\text { cycle } \\
\text { length } \\
\text { average }\end{array}$ & p-value & $\begin{array}{c}\text { Cycle } \\
\text { length } \\
\text { change } \\
\text { (Apr- } \\
\text { Mar) }\end{array}$ & $\begin{array}{c}\text { April } \\
\text { effective } \\
\text { green } \\
\text { time } \\
\text { average }\end{array}$ & $\begin{array}{c}\text { March } \\
\text { effective } \\
\text { green } \\
\text { time } \\
\text { average }\end{array}$ & p-value & $\begin{array}{l}\text { Effective } \\
\text { green time } \\
\text { change } \\
\text { (Apr-Mar) }\end{array}$ & $\begin{array}{l}\text { April } \\
\text { average } \\
\text { g/c }\end{array}$ & $\begin{array}{l}\text { March } \\
\text { average } \\
\text { g/C }\end{array}$ & p-value & $\begin{array}{c}\mathrm{g} / \mathrm{C} \\
\text { change } \\
\text { (Apr- } \\
\text { Mar) }\end{array}$ \\
\hline \multirow{12}{*}{ Stadium } & \multirow{4}{*}{ AM } & NBT & Inc & Inc & Det & \multirow{4}{*}{60.862} & \multirow{4}{*}{54.985} & \multirow{4}{*}{$1.367 \mathrm{E}-18$} & \multirow{4}{*}{ Inc } & 32.06 & 28.32 & $1.08 \mathrm{E}-08$ & Inc & 0.53 & 0.52 & 0.2718 & Unch \\
\hline & & SBT & Inc & Unch & Det & & & & & 32.06 & 28.32 & $1.08 \mathrm{E}-08$ & Inc & 0.53 & 0.52 & 0.2718 & Unch \\
\hline & & EBT & Inc & Inc & Det & & & & & 17.01 & 14.85 & 0.0007 & Inc & 0.28 & 0.27 & 0.3372 & Unch \\
\hline & & WBT & Unch & Inc & - & & & & & 17.01 & 14.85 & 0.0007 & Inc & 0.28 & 0.27 & 0.3372 & Unch \\
\hline & \multirow{4}{*}{ NP } & NBT & Inc & Inc & Det & \multirow{4}{*}{55.092} & \multirow{4}{*}{56.698} & \multirow{4}{*}{0.0049} & \multirow{4}{*}{ Dec } & 28.55 & 31.60 & $6.05 E-06$ & Dec & 0.52 & 0.56 & 0.0003 & Dec \\
\hline & & SBT & Unch & Unch & Unch & & & & & 28.55 & 31.60 & $6.05 \mathrm{E}-06$ & Dec & 0.52 & 0.56 & 0.0003 & Dec \\
\hline & & EBT & Unch & Inc & Det & & & & & 14.75 & 13.30 & 0.0301 & Unch & 0.27 & 0.23 & 0.0023 & Inc \\
\hline & & WBT & Unch & Unch & Det & & & & & 14.75 & 13.30 & 0.0301 & Unch & 0.27 & 0.23 & 0.0023 & Inc \\
\hline & \multirow{4}{*}{ PM } & NBT & Unch & Inc & Det & \multirow{4}{*}{60.339} & \multirow{4}{*}{60} & \multirow{4}{*}{0.4669} & \multirow{4}{*}{ Unch } & 31.07 & 31.19 & 0.7791 & Unch & 0.51 & 0.52 & 0.5500 & Unch \\
\hline & & SBT & $\operatorname{Inc}$ & Inc & Det & & & & & 31.07 & 31.19 & 0.7791 & Unch & 0.51 & 0.52 & 0.5500 & Unch \\
\hline & & EBT & Inc & Unch & Det & & & & & 17.47 & 17.01 & 0.5221 & Unch & 0.29 & 0.28 & 0.6170 & Unch \\
\hline & & WBT & Inc & Inc & Det & & & & & 17.47 & 17.01 & 0.5221 & Unch & 0.29 & 0.28 & 0.6170 & Unch \\
\hline \multirow{12}{*}{ Kirby } & \multirow{4}{*}{ AM } & NBT & Inc & Inc & Det & \multirow{4}{*}{121.5} & & & & 42.74 & 37.87 & 0.0002 & Inc & 0.35 & 0.34 & 0.4424 & Unch \\
\hline & & SBT & Unch & Unch & Det & & 110 & $2398 \mathrm{~F}-15$ & $\operatorname{Inc}$ & 53.37 & 46.50 & 0.0032 & Inc & 0.44 & 0.42 & 0.3693 & Unch \\
\hline & & EBT & Inc & Inc & Det & & 110 & $2.398 \mathrm{t}-15$ & Inc & 34.73 & 37.63 & $3.22 \mathrm{E}-03$ & Dec & 0.29 & 0.34 & $6.35 \mathrm{E}-08$ & Dec \\
\hline & & WBT & Unch & Unch & Det & & & & & 38.62 & 38.21 & 0.7877 & Unch & 0.32 & 0.35 & 0.0386 & Unch \\
\hline & & NBT & Dec & Unch & Imp & & & & & 45.03 & 41.35 & 0.0346 & Unch & 0.41 & 0.38 & 0.0350 & Unch \\
\hline & $N P$ & SBT & Unch & Unch & Unch & 110.032 & 110 & 0.9785 & Unch & 43.90 & 41.10 & 0.1110 & Unch & 0.40 & 0.37 & 0.1053 & Unch \\
\hline & NP & EBT & Inc & Unch & Det & 110.032 & 110 & $0.9 / 85$ & Unch & 22.62 & 34.00 & $4.82 \mathrm{E}-08$ & Dec & 0.20 & 0.31 & $2.39 \mathrm{E}-09$ & Dec \\
\hline & & WBT & Inc & Unch & Det & & & & & 27.42 & 36.52 & 4.46E-08 & Dec & 0.25 & 0.33 & $6.19 \mathrm{E}-09$ & Dec \\
\hline & & NBT & Dec & Unch & $\operatorname{Imp}$ & & & & & 48.69 & 49.27 & 0.7474 & Unch & 0.41 & 0.41 & 0.8764 & Unch \\
\hline & PM & SBT & $\operatorname{Inc}$ & Inc & Det & 118231 & 120 & 01926 & Unch & 44.24 & 44.66 & 0.7450 & Unch & 0.37 & 0.37 & 0.5220 & Unch \\
\hline & PIVI & EBT & Unch & Unch & Unch & 118.231 & 120 & 0.1926 & Unch & 30.27 & 31.27 & 0.2995 & Unch & 0.25 & 0.26 & 0.1499 & Unch \\
\hline & & WBT & Unch & Unch & Det & & & & & 35.17 & 36.96 & 0.2181 & Unch & 0.29 & 0.31 & 0.1351 & Unch \\
\hline
\end{tabular}

Note: Highlighted cells are explained in the text. 
Table 23. Signal Timing Change Comparisons between TBC 2017 and ASCT 2017 (Cont.)

\begin{tabular}{|c|c|c|c|c|c|c|c|c|c|c|c|c|c|c|c|c|c|}
\hline & & & \multirow{2}{*}{\multicolumn{3}{|c|}{ Previous results }} & \multicolumn{12}{|c|}{ Signal timing changes } \\
\hline & & & & & & \multicolumn{4}{|c|}{ Average cycle length changes } & \multicolumn{4}{|c|}{$\begin{array}{c}\text { Average effective green time } \\
\text { changes }\end{array}$} & \multicolumn{4}{|c|}{ Average $\mathrm{g} / \mathrm{C}$ changes } \\
\hline Intersection & $\begin{array}{c}\text { Time } \\
\text { period }\end{array}$ & Approach & $\begin{array}{c}\text { Delay } \\
\text { change } \\
\text { (Apr- } \\
\text { Mar) }\end{array}$ & $\begin{array}{c}\text { Queue } \\
\text { length } \\
\text { change } \\
\text { (Apr- } \\
\text { Mar) }\end{array}$ & PI & $\begin{array}{c}\text { April } \\
\text { cycle } \\
\text { length } \\
\text { average }\end{array}$ & $\begin{array}{c}\text { March } \\
\text { cycle } \\
\text { length } \\
\text { average }\end{array}$ & $p$-value & $\begin{array}{c}\text { Cycle } \\
\text { length } \\
\text { change } \\
\text { (Apr- } \\
\text { Mar) }\end{array}$ & $\begin{array}{c}\text { April } \\
\text { effective } \\
\text { green } \\
\text { time } \\
\text { average }\end{array}$ & $\begin{array}{c}\text { March } \\
\text { effective } \\
\text { green } \\
\text { time } \\
\text { average }\end{array}$ & p-value & $\begin{array}{c}\text { Effective } \\
\text { green time } \\
\text { change } \\
\text { (Apr-Mar) }\end{array}$ & $\begin{array}{l}\text { April } \\
\text { average } \\
\text { g/C }\end{array}$ & $\begin{array}{l}\text { March } \\
\text { average } \\
\text { g/C }\end{array}$ & p-value & $\begin{array}{c}\mathrm{g} / \mathrm{C} \\
\text { change } \\
\text { (Apr- } \\
\text { Mar) }\end{array}$ \\
\hline \multirow{12}{*}{ St. Mary's } & \multirow{4}{*}{ AM } & NBT & Unch & Unch & Unch & \multirow{4}{*}{120.414} & \multirow{4}{*}{110} & \multirow{4}{*}{$6.263 \mathrm{E}-16$} & \multirow{4}{*}{ Inc } & 65.42 & 61.59 & 0.0779 & Unch & 0.54 & 0.56 & 0.3193 & Unch \\
\hline & & SBT & Unch & Unch & Unch & & & & & 78.00 & 74.15 & 0.0649 & Unch & 0.65 & 0.67 & 0.0971 & Unch \\
\hline & & EBT & Unch & Unch & Unch & & & & & 22.11 & 18.14 & 0.0109 & Inc & 0.18 & 0.16 & 0.1547 & Unch \\
\hline & & WBT & Unch & Unch & Det & & & & & 24.01 & 18.17 & $1.13 \mathrm{E}-05$ & Inc & 0.20 & 0.17 & 0.0032 & Inc \\
\hline & \multirow{4}{*}{ NP } & NBT & Unch & $\operatorname{Inc}$ & Det & \multirow{4}{*}{110.375} & \multirow{4}{*}{110} & \multirow{4}{*}{0.1099} & \multirow{4}{*}{ Unch } & 55.12 & 61.21 & 0.0024 & Dec & 0.50 & 0.56 & 0.0016 & Dec \\
\hline & & SBT & Inc & Inc & Det & & & & & 63.40 & 67.37 & 0.0385 & Unch & 0.57 & 0.61 & 0.0265 & Dec \\
\hline & & EBT & Unch & Unch & Unch & & & & & 20.58 & 19.45 & 0.4482 & Unch & 0.19 & 0.18 & 0.4661 & Unch \\
\hline & & WBT & Unch & Unch & Det & & & & & 23.23 & 21.92 & 0.2329 & Unch & 0.21 & 0.20 & 0.2617 & Unch \\
\hline & \multirow{4}{*}{ PM } & NBT & Unch & Unch & Unch & \multirow{4}{*}{119.414} & \multirow{4}{*}{120} & \multirow{4}{*}{0.6254} & \multirow{4}{*}{ Unch } & 69.38 & 60.87 & 0.0005 & Inc & 0.58 & 0.51 & 0.0001 & Inc \\
\hline & & SBT & Unch & Unch & Unch & & & & & 69.11 & 62.69 & 0.0086 & Inc & 0.58 & 0.52 & 0.0022 & Inc \\
\hline & & EBT & Unch & Unch & Unch & & & & & 15.67 & 22.46 & $1.93 \mathrm{E}-09$ & Dec & 0.13 & 0.19 & $2.34 \mathrm{E}-08$ & Dec \\
\hline & & WBT & Inc & Unch & Det & & & & & 29.04 & 35.60 & $7.88 \mathrm{E}-06$ & Dec & 0.24 & 0.30 & $2.12 \mathrm{E}-05$ & Dec \\
\hline \multirow{9}{*}{ Devonshire } & \multirow{3}{*}{ AM } & NBT & Inc & Inc & Det & \multirow{3}{*}{120.464} & \multirow{3}{*}{110.031} & \multirow{3}{*}{$2.658 \mathrm{E}-15$} & \multirow{3}{*}{ Inc } & 96.49 & 86.92 & $8.34 \mathrm{E}-11$ & Inc & 0.80 & 0.79 & 0.2573 & Unch \\
\hline & & SBT & Unch & Unch & Unch & & & & & 91.35 & 83.37 & 0.0022 & Inc & 0.76 & 0.76 & 0.9619 & Unch \\
\hline & & EBL & Unch & Unch & Unch & & & & & 12.87 & 12.01 & 0.4434 & Unch & 0.11 & 0.11 & 0.8036 & Unch \\
\hline & \multirow{3}{*}{ NP } & NBT & Unch & Inc & Det & & & & & 82.46 & 84.38 & 0.2018 & Unch & 0.75 & 0.77 & 0.1365 & Unch \\
\hline & & SBT & Inc & Inc & Det & 110.4 & 110 & 0.11 & Unch & 73.99 & 78.35 & 0.0889 & Unch & 0.67 & 0.71 & 0.0669 & Unch \\
\hline & & EBL & Unch & Unch & Unch & & & & & 17.17 & 14.52 & 0.0424 & Unch & 0.16 & 0.13 & 0.0468 & Unch \\
\hline & & NBT & Unch & Inc & Det & & & & & 94.10 & 96.92 & 0.0951 & Unch & 0.79 & 0.81 & 0.0264 & Dec \\
\hline & PM & SBT & Inc & Inc & Det & 119.333 & 120 & 0.5666 & Unch & 90.42 & 91.28 & 0.7440 & Unch & 0.76 & 0.76 & 0.8028 & Unch \\
\hline & & EBL & Unch & Inc & Imp & & & & & 14.41 & 11.98 & 0.0321 & Unch & 0.12 & 0.10 & 0.0275 & Inc \\
\hline
\end{tabular}

Note: Highlighted cells are explained in the text. 
Table 23. Signal Timing Change Comparisons between TBC 2017 and ASCT 2017 (Cont.)

\begin{tabular}{|c|c|c|c|c|c|c|c|c|c|c|c|c|c|c|c|c|c|}
\hline & & & \multirow{2}{*}{\multicolumn{3}{|c|}{ Previous results }} & \multicolumn{12}{|c|}{ Signal timing changes } \\
\hline & & & & & & \multicolumn{4}{|c|}{ Average cycle length changes } & \multicolumn{4}{|c|}{$\begin{array}{c}\text { Average effective green time } \\
\text { changes }\end{array}$} & \multicolumn{4}{|c|}{ Average $\mathrm{g} / \mathrm{C}$ changes } \\
\hline Intersection & $\begin{array}{c}\text { Time } \\
\text { period }\end{array}$ & Approach & $\begin{array}{c}\text { Delay } \\
\text { change } \\
\text { (Apr- } \\
\text { Mar) }\end{array}$ & $\begin{array}{l}\text { Queue } \\
\text { length } \\
\text { change } \\
\text { (Apr- } \\
\text { Mar) }\end{array}$ & PI & $\begin{array}{l}\text { April } \\
\text { cycle } \\
\text { length } \\
\text { average }\end{array}$ & $\begin{array}{l}\text { March } \\
\text { cycle } \\
\text { length } \\
\text { average }\end{array}$ & p-value & $\begin{array}{c}\text { Cycle } \\
\text { length } \\
\text { change } \\
\text { (Apr- } \\
\text { Mar) }\end{array}$ & $\begin{array}{c}\text { April } \\
\text { effective } \\
\text { green } \\
\text { time } \\
\text { average }\end{array}$ & $\begin{array}{l}\text { March } \\
\text { effective } \\
\text { green } \\
\text { time } \\
\text { average }\end{array}$ & p-value & $\begin{array}{l}\text { Effective } \\
\text { green time } \\
\text { change } \\
\text { (Apr-Mar) }\end{array}$ & $\begin{array}{l}\text { April } \\
\text { average } \\
\text { g/C }\end{array}$ & $\begin{array}{l}\text { March } \\
\text { average } \\
\text { g/C }\end{array}$ & p-value & $\begin{array}{c}\text { g/C } \\
\text { change } \\
\text { (Apr- } \\
\text { Mar) }\end{array}$ \\
\hline \multirow{12}{*}{ Windsor } & \multirow{4}{*}{ AM } & NBT & Inc & $\operatorname{Inc}$ & Det & \multirow{4}{*}{119.714} & \multirow{4}{*}{110} & \multirow{4}{*}{$4.74 E-08$} & \multirow{4}{*}{ Inc } & 50.71 & 49.23 & 0.6167 & Unch & 0.42 & 0.45 & 0.2646 & Unch \\
\hline & & SBT & Unch & Unch & Det & & & & & 52.89 & 52.93 & 0.9862 & Unch & 0.44 & 0.48 & 0.0644 & Unch \\
\hline & & EBT & Inc & Unch & Det & & & & & 31.58 & 30.47 & 0.5865 & Unch & 0.26 & 0.28 & 0.4769 & Unch \\
\hline & & WBT & Unch & Unch & Unch & & & & & 26.19 & 20.47 & 2.09E-05 & $\operatorname{lnc}$ & 0.22 & 0.19 & 0.0046 & $\operatorname{Inc}$ \\
\hline & \multirow{4}{*}{ NP } & NBT & Inc & Unch & Det & \multirow{4}{*}{109.258} & \multirow{4}{*}{113.516} & \multirow{4}{*}{0.0106} & \multirow{4}{*}{ Dec } & 45.21 & 49.40 & 0.0617 & Unch & 0.41 & 0.43 & 0.2544 & Unch \\
\hline & & SBT & Unch & Unch & Unch & & & & & 49.79 & 54.77 & 0.0507 & Unch & 0.46 & 0.48 & 0.2250 & Unch \\
\hline & & EBT & Unch & Unch & Unch & & & & & 20.71 & 27.67 & $2.75 \mathrm{E}-07$ & Dec & 0.19 & 0.24 & $6.49 \mathrm{E}-06$ & Dec \\
\hline & & WBT & Unch & Unch & Unch & & & & & 23.19 & 28.03 & 0.0078 & Dec & 0.21 & 0.25 & 0.0318 & Unch \\
\hline & \multirow{4}{*}{ PM } & NBT & Unch & Unch & Unch & \multirow{4}{*}{118.367} & \multirow{4}{*}{120} & \multirow{4}{*}{0.2738} & \multirow{4}{*}{ Unch } & 38.03 & 40.17 & 0.2428 & Unch & 0.32 & 0.33 & 0.3970 & Unch \\
\hline & & SBT & Inc & Unch & Det & & & & & 42.23 & 50.07 & 0.0003 & Dec & 0.36 & 0.42 & 0.0004 & Dec \\
\hline & & EBT & Inc & Unch & Det & & & & & 29.97 & 30.27 & 0.7794 & Unch & 0.25 & 0.25 & 0.8542 & Unch \\
\hline & & WBT & Inc & Unch & Det & & & & & 30.87 & 32.63 & 0.1616 & Unch & 0.26 & 0.27 & 0.1684 & Unch \\
\hline
\end{tabular}

Note: Highlighted cells are explained in the text. 
When cycle lengths were not significantly changed, any decrease in the average effective green time caused their red time increase, which then contributed to delay and/or queue length increases. The increased queue lengths or delays finally resulted in deterioration of the ASCT system performance during ASCT 2017. Under this circumstance, 6 deteriorated cases highlighted in Table 23 were explained. In contrast, any decrease in the $\mathrm{g} / \mathrm{C}$ may not explain the deteriorations, because $\mathrm{g}$ and $\mathrm{C}$ can change simultaneously or both unchanged $\mathrm{g}$ and $\mathrm{C}$ can result in $\mathrm{g} / \mathrm{C}$ decrease.

A summary of the cases explained is presented in Table 24; in which 6 cases explained by the decrease of average effective green time are highlighted. These explained cases accounted for $17 \%$ of the total of 35 deteriorated cases.

Table 24. Summary of Cases Explained by Signal Timing Change

\begin{tabular}{|c|c|c|c|c|}
\hline Intersections & Approach & AM Peak & Noon Peak & PM Peak \\
\hline \multirow{4}{*}{ Stadium } & NBT & Det & Det & Det \\
\hline & SBT & Det & Unch & Det \\
\hline & EBT & Det & Det & Det \\
\hline & WBT & $N A$ & Det & Det \\
\hline \multirow{4}{*}{ Kirby } & NBT & Det & Imp & Imp \\
\hline & SBT & Det & Unch & Det \\
\hline & EBT & Det & Det & Unch \\
\hline & WBT & Det & Det & Det \\
\hline \multirow{4}{*}{ St. Mary's } & NBT & Unch & Det & Unch \\
\hline & SBT & Unch & Det & Unch \\
\hline & EBT & Unch & Unch & Unch \\
\hline & WBT & Det & Det & Det \\
\hline \multirow{3}{*}{ Devonshire } & NBT & Det & Det & Det \\
\hline & SBT & Unch & Det & Det \\
\hline & EBL & Unch & Unch & Imp \\
\hline \multirow{4}{*}{ Windsor } & NBT & Det & Det & Unch \\
\hline & SBT & Det & Unch & Det \\
\hline & EBT & Det & Unch & Det \\
\hline & WBT & Unch & Unch & Det \\
\hline
\end{tabular}

Note: Highlighted cells indicate cases are explained in the text. 


\subsubsection{Deterioration due to Pedestrian Effects at Stadium Drive}

At Stadium Drive, all lane groups except one showed deterioration. Also, 15 cycle lengths under TBC 2017 conditions had high values. We suspected pedestrian activities to be the cause of the deterioration. As shown in Table 25, 52 out of 183 cycles under ASCT and 54 out of 187 under TBC showed the pedestrian signal was on, with pedestrians crossing the major street. In contrast, 7 out of 183 cycles under ASCT 2017 and 4 out of 187 cycles under TBC 2017 showed the pedestrian signal was on, with pedestrians crossing the minor street. Hence, pedestrians crossing the major street were more prevalent than pedestrians crossing the minor street.

Table 25. Pedestrian Activities at Stadium Drive under ASCT 2017 and TBC 2017

\begin{tabular}{|c|c|c|c|c|c|}
\hline \multirow{7}{*}{} & & $\begin{array}{c}\text { Pedestrian } \\
\text { crossed } \\
\text { major street }\end{array}$ & $\begin{array}{c}\text { Pedestrian } \\
\text { crossed } \\
\text { minor } \\
\text { street }\end{array}$ & $\begin{array}{c}\text { No } \\
\text { pedestrian } \\
\text { cycles }\end{array}$ & Total \\
\hline \multirow{3}{*}{ ASCT } & AM & 16 & 1 & 41 & 58 \\
\cline { 2 - 6 } & NP & 16 & 3 & 46 & 65 \\
\cline { 2 - 7 } & PM & 20 & 3 & 37 & $60^{*}$ \\
\hline \multicolumn{2}{|c|}{ Total cases for ASCT } & $\mathbf{5 2}$ & $\mathbf{7}$ & $\mathbf{1 2 4}$ & $\mathbf{1 8 3}$ \\
\hline \multirow{3}{*}{ TBC } & AM & 17 & 3 & 45 & $65^{*}$ \\
\cline { 2 - 7 } & NP & 15 & 0 & 48 & 63 \\
\cline { 2 - 7 } & PM & 22 & 1 & 36 & 59 \\
\hline \multicolumn{2}{|l}{ Total cases for TBC } & $\mathbf{5 4}$ & $\mathbf{4}$ & $\mathbf{1 2 9}$ & $\mathbf{1 8 7}$ \\
\hline
\end{tabular}

* For ASCT PM and TBC AM, one cycle in each showed pedestrian crossing of both major and minor streets. 


\subsubsection{Pedestrian Effects on Cycle Length and Green Time at Stadium Drive}

Figure 10 shows the minor street's green time for each cycle and the cycle length under ASCT 2017 and TBC 2017 conditions at Stadium Drive during NP. The cycles marked "P" are those with pedestrian(s) present. In general, cycle lengths were higher when pedestrians were present, as compared to cycle lengths without pedestrians.

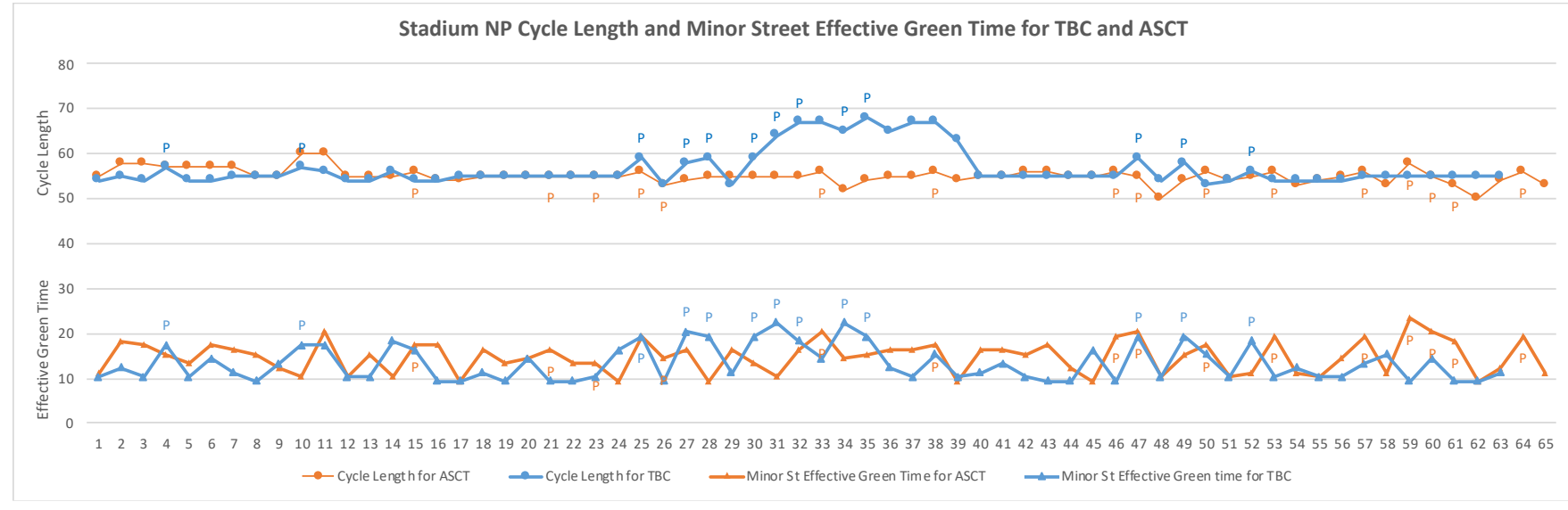

Figure 10. Cycle length and minor street's green time for TBC and ASCT conditions.

Comparisons were made between TBC and ASCT conditions with and without pedestrian presence on the minor street's average green time, major street's average green time, and cycle length, presented in Table 26. 
Table 26. Green Time and Cycle Length with and without Pedestrians Present

\begin{tabular}{|c|c|c|c|c|c|c|c|c|c|c|}
\hline \multirow{2}{*}{$\begin{array}{c}\text { Time } \\
\text { periods }\end{array}$} & \multirow{2}{*}{\multicolumn{2}{|c|}{$\begin{array}{c}\text { Green } \\
\text { time/Cycle } \\
\text { length (secs) }\end{array}$}} & \multicolumn{2}{|c|}{ No pedestrians } & \multicolumn{2}{|c|}{ Pedestrians present } & \multirow{2}{*}{$\begin{array}{l}\text { Numerical } \\
\text { difference }\end{array}$} & \multirow{2}{*}{ p value } & \multirow{2}{*}{$\begin{array}{c}\text { Results } \\
\text { with } 97 \% \\
\text { confidence } \\
\text { level }\end{array}$} & \multirow{2}{*}{$\begin{array}{c}\text { Results } \\
\text { with } 90 \% \\
\text { confidence } \\
\text { level }\end{array}$} \\
\hline & & & Averag & Variance & Average & Variance & & & & \\
\hline \multirow{6}{*}{ AM } & \multirow{3}{*}{ ASCT } & $\begin{array}{c}\text { Minor st } \\
\text { green }\end{array}$ & 16.6 & 15.2 & 18.4 & 18.4 & 1.8 & 0.0179 & yes & yes \\
\hline & & $\begin{array}{c}\text { Major st } \\
\text { green }\end{array}$ & 32.5 & 15.8 & 30.8 & 8.8 & -1.7 & 0.0895 & no & yes \\
\hline & & $\begin{array}{r}\text { Cycle } \\
\text { length }\end{array}$ & 61 & 13 & 61 & 13 & 0 & 0.8732 & no & no \\
\hline & \multirow{3}{*}{ TBC } & $\begin{array}{c}\text { Minor st } \\
\text { green }\end{array}$ & 13.7 & 9.2 & 17.5 & 6.2 & 3.8 & 2.64E-05 & yes & yes \\
\hline & & $\begin{array}{c}\text { Major st } \\
\text { green }\end{array}$ & 28.9 & 9.0 & 27.0 & 1.5 & -1.8 & 1.09E-03 & yes & yes \\
\hline & & $\begin{array}{l}\text { Cycle } \\
\text { length }\end{array}$ & 54 & 1 & 56 & 3 & 2 & 4.70E-04 & yes & yes \\
\hline \multirow{6}{*}{ NP } & \multirow{3}{*}{ ASCT } & $\begin{array}{c}\text { Minor st } \\
\text { green }\end{array}$ & 13.6 & 9.1 & 18.4 & 6.0 & 4.8 & $3.66 \mathrm{E}-07$ & yes & yes \\
\hline & & $\begin{array}{c}\text { Major st } \\
\text { green }\end{array}$ & 29.6 & 7.7 & 25.3 & 4.0 & -4.3 & 8.59E-08 & yes & yes \\
\hline & & $\begin{array}{r}\text { Cycle } \\
\text { length }\end{array}$ & 55 & 4.0 & 56 & 1.0 & 1 & 0.2121 & no & no \\
\hline & \multirow{3}{*}{ TBC } & $\begin{array}{c}\text { Minor st } \\
\text { green }\end{array}$ & 11.8 & 6.6 & 18.2 & 12.4 & 6.4 & $1.64 \mathrm{E}-10$ & yes & yes \\
\hline & & $\begin{array}{c}\text { Major st } \\
\text { green }\end{array}$ & 32.2 & 16.3 & 29.6 & 12.8 & -2.6 & 0.0303 & no & yes \\
\hline & & $\begin{array}{l}\text { Cycle } \\
\text { length }\end{array}$ & 56 & 13.0 & 60 & 19.0 & 4 & 0.001 & yes & yes \\
\hline \multirow{6}{*}{ PM } & \multirow{3}{*}{ ASCT } & $\begin{array}{c}\text { Minor st } \\
\text { green }\end{array}$ & 16.6 & 14.5 & 19.1 & 3.5 & 2.5 & 1.70E-03 & yes & yes \\
\hline & & $\begin{array}{c}\text { Major st } \\
\text { green }\end{array}$ & 32.3 & 18.1 & 28.8 & 6.2 & -3.5 & 2.47E-04 & yes & yes \\
\hline & & $\begin{array}{c}\text { Cycle } \\
\text { length }\end{array}$ & 61 & 15 & 60 & 9 & -1 & 0.3084 & no & no \\
\hline & \multirow{3}{*}{ TBC } & $\begin{array}{c}\text { Minor st } \\
\text { green }\end{array}$ & 15.83 & 20.60 & 19.3 & 5.05 & 3.47 & 2.87E-04 & yes & yes \\
\hline & & $\begin{array}{c}\text { Major st } \\
\text { green }\end{array}$ & 32.37 & 20.60 & 28.9 & 5.05 & -3.47 & 0.0003 & yes & yes \\
\hline & & $\begin{array}{c}\text { Cycle } \\
\text { length }\end{array}$ & 60 & 0 & 60 & 0 & 0 & - & - & - \\
\hline
\end{tabular}

In all three time periods, when pedestrians were present, the average green times for the minor streets were increased under both ASCT 2017 and TBC 2017 conditions, while the average green times for the major streets were reduced (with 90\% confidence). Hence, at Stadium Drive, the pedestrians 
significantly (at 90\% confidence level) reduced the major street's green time and increased the minor street's green time.

\subsubsection{Deterioration due to Volume Miscounting}

This section mainly discusses the volume-count comparisons between ASCT and field data. Table 27 shows the volume counts obtained from the ASCT system and those obtained by manually counting the vehicles in the videos taken at the sites (the field data). Comparisons between field and system hourly volume counts were made for March and April data. The March system volume was obtained from records the ASCT system had stored on the server. These volumes were not used in operating the signal during March 2017. The reason for using them here is to have matching data for the field data collected in March 2017.

Table 27. Comparisons of System Volume Count with Field Volume Count in 2017

\begin{tabular}{|c|c|c|c|c|c|c|c|c|c|c|}
\hline Intersection & $\begin{array}{l}\text { Time } \\
\text { period }\end{array}$ & Approach & $\begin{array}{c}\text { April } \\
\text { system } \\
\text { volume }\end{array}$ & $\begin{array}{c}\text { April } \\
\text { field } \\
\text { volume }\end{array}$ & $\begin{array}{l}\text { April } \\
\text { volume } \\
\text { change } \\
\text { (system- } \\
\text { field) }\end{array}$ & $\begin{array}{l}\text { April } \\
\text { percent of } \\
\text { volume } \\
\text { change } \\
\text { (field base) }\end{array}$ & $\begin{array}{l}\text { March } \\
\text { system } \\
\text { volume }\end{array}$ & $\begin{array}{c}\text { March } \\
\text { field } \\
\text { volume }\end{array}$ & $\begin{array}{l}\text { March } \\
\text { volume } \\
\text { change } \\
\text { (system- } \\
\text { field) }\end{array}$ & $\begin{array}{l}\text { March } \\
\text { percent of } \\
\text { volume } \\
\text { change } \\
\text { (field base) }\end{array}$ \\
\hline \multirow{12}{*}{ Stadium } & \multirow{4}{*}{ AM } & NBT & 401 & 460 & -59 & $-13 \%$ & 351 & 462 & -111 & $-24 \%$ \\
\hline & & SBT & 248 & 342 & -94 & $-27 \%$ & 228 & 352 & -124 & $-35 \%$ \\
\hline & & EBT & 120 & 214 & -94 & $-44 \%$ & 132 & 270 & -138 & $-51 \%$ \\
\hline & & WBT & 48 & 30 & 18 & $60 \%$ & 136 & 51 & 85 & $167 \%$ \\
\hline & \multirow{4}{*}{ NP } & NBT & 336 & 419 & -83 & $-20 \%$ & 376 & 411 & -35 & $-9 \%$ \\
\hline & & SBT & 371 & 376 & -5 & $-1 \%$ & 363 & 387 & -24 & $-6 \%$ \\
\hline & & EBT & 67 & 65 & 2 & $3 \%$ & 47 & 104 & -57 & $-55 \%$ \\
\hline & & WBT & 67 & 59 & 8 & $14 \%$ & 53 & 87 & -34 & $-39 \%$ \\
\hline & \multirow{4}{*}{ PM } & NBT & 362 & 470 & -108 & $-23 \%$ & 317 & 436 & -119 & $-27 \%$ \\
\hline & & SBT & 449 & 500 & -51 & $-10 \%$ & 413 & 489 & -76 & $-16 \%$ \\
\hline & & EBT & 54 & 60 & -6 & $-10 \%$ & 48 & 124 & -76 & $-61 \%$ \\
\hline & & WBT & 200 & 238 & -38 & $-16 \%$ & 284 & 221 & 63 & $29 \%$ \\
\hline \multirow{12}{*}{ Kirby } & \multirow{4}{*}{ AM } & NBT & 294 & 491 & -197 & $-40 \%$ & 244 & 417 & -173 & $-41 \%$ \\
\hline & & SBT & 241 & 277 & -36 & $-13 \%$ & 194 & 318 & -124 & $-39 \%$ \\
\hline & & EBT & 294 & 388 & -94 & $-24 \%$ & 273 & 345 & -72 & $-21 \%$ \\
\hline & & WBT & 119 & 154 & -35 & $-23 \%$ & 369 & 223 & 146 & $65 \%$ \\
\hline & \multirow{4}{*}{ NP } & NBT & 269 & 368 & -99 & $-27 \%$ & 306 & 363 & -57 & $-16 \%$ \\
\hline & & SBT & 319 & 300 & 19 & $6 \%$ & 245 & 331 & -86 & $-26 \%$ \\
\hline & & EBT & 141 & 229 & -88 & $-38 \%$ & 141 & 195 & -54 & $-28 \%$ \\
\hline & & WBT & 187 & 205 & -18 & $-9 \%$ & 203 & 251 & -48 & $-19 \%$ \\
\hline & \multirow{4}{*}{ PM } & NBT & 255 & 337 & -82 & $-24 \%$ & 305 & 371 & -66 & $-18 \%$ \\
\hline & & SBT & 377 & 446 & -69 & $-15 \%$ & 287 & 503 & -216 & $-43 \%$ \\
\hline & & EBT & 173 & 217 & -44 & $-20 \%$ & 158 & 218 & -60 & $-28 \%$ \\
\hline & & WBT & 289 & 337 & -48 & $-14 \%$ & 322 & 477 & -155 & $-32 \%$ \\
\hline
\end{tabular}


Table 27. Comparisons of System Volume Count with Field Volume Count in 2017 (Cont.)

\begin{tabular}{|c|c|c|c|c|c|c|c|c|c|c|}
\hline Intersection & $\begin{array}{c}\text { Time } \\
\text { period }\end{array}$ & Approach & $\begin{array}{c}\text { April } \\
\text { system } \\
\text { volume }\end{array}$ & $\begin{array}{c}\text { April } \\
\text { field } \\
\text { volume }\end{array}$ & $\begin{array}{c}\text { April } \\
\text { volume } \\
\text { change } \\
\text { (system- } \\
\text { field) } \\
\end{array}$ & $\begin{array}{c}\text { April } \\
\text { percentage } \\
\text { of volume } \\
\text { change } \\
\text { (field base) }\end{array}$ & $\begin{array}{l}\text { March } \\
\text { system } \\
\text { volume }\end{array}$ & $\begin{array}{c}\text { March } \\
\text { field } \\
\text { volume }\end{array}$ & $\begin{array}{l}\text { March } \\
\text { volume } \\
\text { change } \\
\text { (system- } \\
\text { field) }\end{array}$ & $\begin{array}{c}\text { March } \\
\text { percentage } \\
\text { of volume } \\
\text { change } \\
\text { (field base) }\end{array}$ \\
\hline \multirow{12}{*}{ St. Mary's } & \multirow{4}{*}{ AM } & NBT & 368 & 523 & -155 & $-30 \%$ & 383 & 525 & -142 & $-27 \%$ \\
\hline & & SBT & 333 & 236 & 97 & $41 \%$ & 308 & 232 & 76 & $33 \%$ \\
\hline & & EBT & 54 & 142 & -88 & $-62 \%$ & 88 & 141 & -53 & $-38 \%$ \\
\hline & & WBT & 47 & 35 & 12 & $34 \%$ & 56 & 84 & -28 & $-33 \%$ \\
\hline & \multirow{4}{*}{ NP } & NBT & 285 & 539 & -254 & $-47 \%$ & 299 & 468 & -169 & $-36 \%$ \\
\hline & & SBT & 479 & 449 & 30 & $7 \%$ & 483 & 376 & 107 & $28 \%$ \\
\hline & & EBT & 67 & 105 & -38 & $-36 \%$ & 212 & 136 & 76 & $56 \%$ \\
\hline & & WBT & 113 & 50 & 63 & $126 \%$ & 96 & 130 & -34 & $-26 \%$ \\
\hline & \multirow{4}{*}{ PM } & NBT & 249 & 461 & -212 & $-46 \%$ & 331 & 442 & -111 & $-25 \%$ \\
\hline & & SBT & 530 & 573 & -43 & $-8 \%$ & 509 & 583 & -74 & $-13 \%$ \\
\hline & & EBT & 89 & 77 & 12 & $16 \%$ & 93 & 119 & -26 & $-22 \%$ \\
\hline & & WBT & 185 & 166 & 19 & $11 \%$ & 214 & 280 & -66 & $-24 \%$ \\
\hline \multirow{9}{*}{ Devonshire } & \multirow{3}{*}{ AM } & NBT & 431 & 578 & -147 & $-25 \%$ & 458 & 589 & -131 & $-22 \%$ \\
\hline & & SBT & 266 & 224 & 42 & $19 \%$ & 227 & 214 & 13 & $6 \%$ \\
\hline & & EBL & 43 & 99 & -56 & $-57 \%$ & 45 & 99 & -54 & $-55 \%$ \\
\hline & \multirow{3}{*}{ NP } & NBT & 350 & 503 & -153 & $-30 \%$ & 325 & 430 & -105 & $-24 \%$ \\
\hline & & SBT & 370 & 436 & -66 & $-15 \%$ & 319 & 404 & -85 & $-21 \%$ \\
\hline & & EBL & 74 & 173 & -99 & $-57 \%$ & 46 & 135 & -89 & $-66 \%$ \\
\hline & \multirow{3}{*}{ PM } & NBT & 263 & 385 & -122 & $-32 \%$ & 277 & 387 & -110 & $-28 \%$ \\
\hline & & SBT & 538 & 651 & -113 & $-17 \%$ & 516 & 632 & -116 & $-18 \%$ \\
\hline & & EBL & 68 & 129 & -61 & $-47 \%$ & 39 & 84 & -45 & $-54 \%$ \\
\hline \multirow{12}{*}{ Windsor } & \multirow{4}{*}{ AM } & NBT & 240 & 518 & -278 & $-54 \%$ & 241 & 516 & -275 & $-53 \%$ \\
\hline & & SBT & 188 & 106 & 82 & $77 \%$ & 229 & 135 & 94 & $70 \%$ \\
\hline & & EBT & 278 & 355 & -77 & $-22 \%$ & 235 & 353 & -118 & $-33 \%$ \\
\hline & & WBT & 124 & 184 & -60 & $-33 \%$ & 149 & 193 & -44 & $-23 \%$ \\
\hline & \multirow{4}{*}{ NP } & NBT & 188 & 351 & -163 & $-46 \%$ & 156 & 320 & -164 & $-51 \%$ \\
\hline & & SBT & 344 & 250 & 94 & $38 \%$ & 394 & 241 & 153 & $63 \%$ \\
\hline & & EBT & 163 & 213 & -50 & $-23 \%$ & 112 & 181 & -69 & $-38 \%$ \\
\hline & & WBT & 140 & 141 & -1 & $-1 \%$ & 101 & 136 & -35 & $-26 \%$ \\
\hline & \multirow{4}{*}{ PM } & NBT & 116 & 245 & -129 & $-53 \%$ & 180 & 270 & -90 & $-33 \%$ \\
\hline & & SBT & 314 & 419 & -105 & $-25 \%$ & 364 & 468 & -104 & $-22 \%$ \\
\hline & & EBT & 120 & 188 & -68 & $-36 \%$ & 173 & 209 & -36 & $-17 \%$ \\
\hline & & WBT & 289 & 314 & -25 & $-8 \%$ & 297 & 343 & -46 & $-13 \%$ \\
\hline
\end{tabular}

Highlights: Red cell, overcounted; blue cell, undercounted; white cell, unchanged. 
For March data, the system overcounted in 9 cases and undercounted in 48. Similarly, for April, the system overcounted in 12 cases and undercounted in 42. The average undercount for March and April was $31 \%$ and $29 \%$, respectively. The average overcount for March and April was $57 \%$ and $37 \%$, respectively. If we consider undercounts or overcounts of up to $5 \%$ as "similar," Figure 11 shows the frequency of under- or overcounting on major and minor streets.

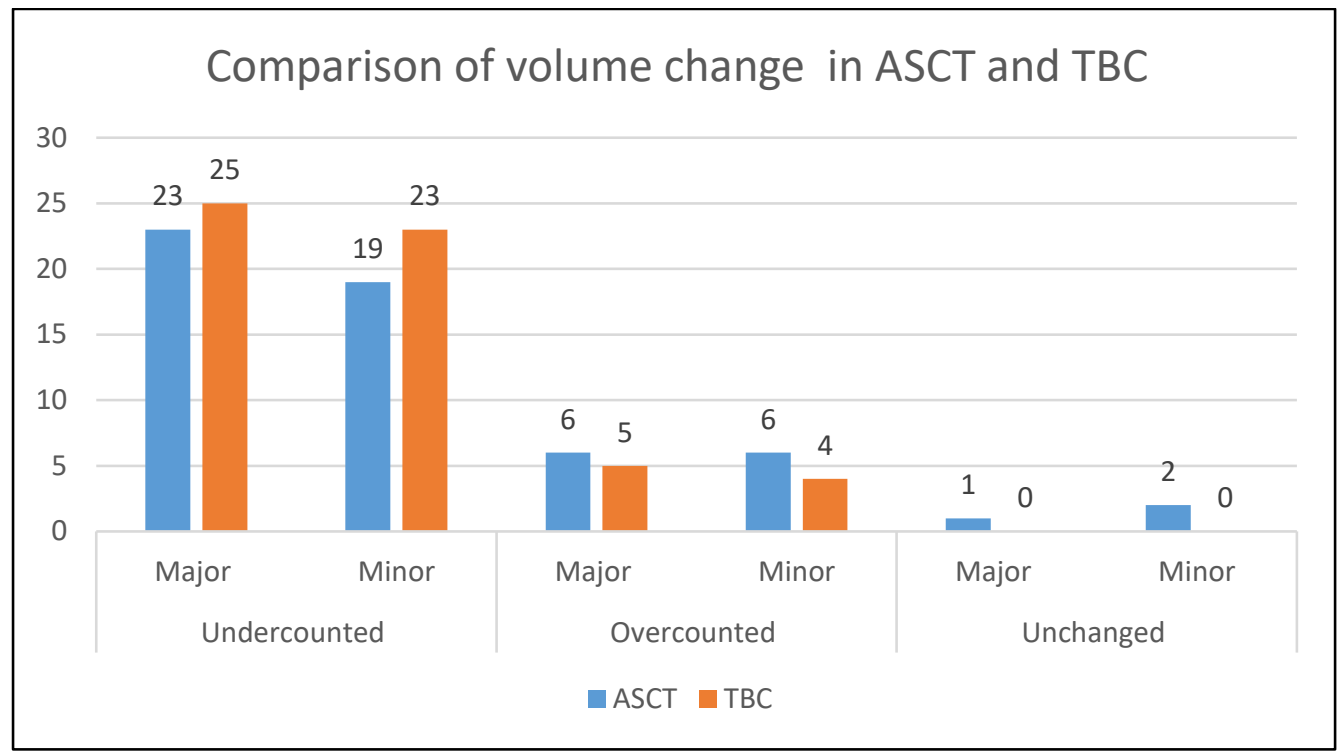

Figure 11. Comparison of the volume count under ASCT 2017 and TBC 2017.

One reason we observed for the system's overcounting could be that vehicles on the major street activated the minor street's detectors. Thus, it resulted in overcounting vehicles on the minor street. A specific example at Stadium Drive and Neil Street AM, with screen snapshots and video recorded times is provided in Appendix A.6. This kind of event can explain the overcounted volume on WBT at Stadium during the AM peak.

In summary, the undercounting of volume by the ASCT system indicates that the system received volume counts that were less than the actual demand and therefore was not providing optimal operation. Thus, the green time could not process the real traffic demand, which could be a contributing factor to the deterioration in ASCT performance in 2017.

\subsubsection{Deterioration due to Proportion of Vehicles Stopped $\left(P_{S}\right)$}

In this section, we compare the proportion of stopped vehicles under ASCT and TBC conditions. The average stopped proportion was calculated by

$$
\overline{P_{S}}=\frac{\sum_{i=1}^{n} \frac{V_{\text {Stopped }, i}}{V_{\text {total }, i}} \times 100 \%}{n}
$$

where $n$ is number of cycles; 
$V_{\text {Stopped }, i}$ is the number of stopped vehicles in cycle $i$;

$V_{\text {total, } i}$ is the number of total vehicles in cycle $i$, which is the sum of stopped and through vehicles;

$\bar{P}_{S}$ is the average proportion of stopped vehicles.

It should be noticed that in some cycles no vehicles stopped or passed through. For these cycles, $\bar{P}_{S}$ are invalid and not used in calculations and comparisons.

In Tables 28 and 31, a statistical test (97\% confidence level) showed the stopped-proportion change between ASCT and TBC.

Table 28. Comparison of Proportion of Vehicles Stopped under TBC 2017 and ASCT 2017 Conditions

\begin{tabular}{|c|c|c|c|c|c|c|c|c|c|}
\hline Intersection & $\begin{array}{c}\text { Time } \\
\text { periods }\end{array}$ & Approaches & $\begin{array}{c}\text { April } \\
\text { average } \\
\text { stopped } \\
\text { proportion }\end{array}$ & $\begin{array}{c}\text { March } \\
\text { average } \\
\text { stopped } \\
\text { proportion }\end{array}$ & $\begin{array}{l}\text { Change in } \\
\text { stopped } \\
\text { proportion } \\
\text { (Apr-Mar) }\end{array}$ & p-value & $\begin{array}{l}\text { Stopped } \\
\text { proportion } \\
\text { (Apr-Mar) }\end{array}$ & $\begin{array}{c}\text { Delay } \\
\text { change } \\
\text { (Apr-Mar) }\end{array}$ & PI \\
\hline \multirow{12}{*}{ Stadium } & \multirow{4}{*}{ AM } & NBT & $33.2 \%$ & $30.8 \%$ & $2.4 \%$ & 0.8538 & Unch & Inc & Det \\
\hline & & SBT & $46.0 \%$ & $37.4 \%$ & $8.6 \%$ & 0.1547 & Unch & Inc & Det \\
\hline & & EBT & $62.3 \%$ & $42.8 \%$ & $19.5 \%$ & 0.0075 & Inc & Inc & Det \\
\hline & & WBT & $47.7 \%$ & $48.0 \%$ & $-0.3 \%$ & 0.6560 & Unch & Unch & - \\
\hline & \multirow{4}{*}{ NP } & NBT & $42.6 \%$ & $20.2 \%$ & $22.4 \%$ & $8.26 \mathrm{E}-06$ & Inc & Inc & Det \\
\hline & & SBT & $41.1 \%$ & $32.3 \%$ & $8.8 \%$ & 0.1092 & Unch & Unch & Unch \\
\hline & & EBT & $64.1 \%$ & $40.3 \%$ & $23.8 \%$ & 0.0112 & Inc & Unch & Det \\
\hline & & WBT & $58.1 \%$ & $50.1 \%$ & $8.0 \%$ & 0.4028 & Unch & Unch & Det \\
\hline & \multirow{4}{*}{ PM } & NBT & $28.6 \%$ & $31.2 \%$ & $-2.6 \%$ & 0.5308 & Unch & Unch & Det \\
\hline & & SBT & $36.9 \%$ & $39.6 \%$ & $-2.7 \%$ & 0.6457 & Unch & Inc & Det \\
\hline & & EBT & $51.6 \%$ & $44.0 \%$ & $7.6 \%$ & 0.4142 & Unch & Inc & Det \\
\hline & & WBT & $65.5 \%$ & $55.2 \%$ & $10.3 \%$ & 0.0698 & Unch & Inc & Det \\
\hline \multirow{12}{*}{ Kirby } & \multirow{4}{*}{ AM } & NBT & $44.8 \%$ & $39.2 \%$ & $5.6 \%$ & 0.2959 & Unch & Inc & Det \\
\hline & & SBT & $50.2 \%$ & $47.0 \%$ & $3.2 \%$ & 0.7737 & Unch & Unch & Det \\
\hline & & EBT & $58.8 \%$ & $32.8 \%$ & $26.0 \%$ & 3.61E-07 & Inc & Inc & Det \\
\hline & & WBT & $63.3 \%$ & $55.0 \%$ & $8.3 \%$ & 0.2563 & Unch & Unch & Det \\
\hline & \multirow{4}{*}{ NP } & NBT & $53.5 \%$ & $64.5 \%$ & $-11.0 \%$ & 0.0447 & Unch & Dec & Imp \\
\hline & & SBT & $51.4 \%$ & $52.8 \%$ & $-1.4 \%$ & 0.8013 & Unch & Unch & Unch \\
\hline & & EBT & $74.2 \%$ & $73.0 \%$ & $1.2 \%$ & 0.8292 & Unch & Inc & Det \\
\hline & & WBT & $71.5 \%$ & $56.9 \%$ & $14.6 \%$ & 0.0527 & Inc & Inc & Det \\
\hline & \multirow{4}{*}{ PM } & NBT & $54.7 \%$ & $68.1 \%$ & $-13.4 \%$ & 0.0145 & Dec & Dec & $\operatorname{Imp}$ \\
\hline & & SBT & $58.1 \%$ & $46.5 \%$ & $11.6 \%$ & 0.0157 & Inc & Inc & Det \\
\hline & & EBT & $45.2 \%$ & $43.9 \%$ & $1.3 \%$ & 0.8502 & Unch & Unch & Unch \\
\hline & & WBT & $61.2 \%$ & $47.1 \%$ & $14.1 \%$ & 0.0113 & Inc & Unch & Det \\
\hline
\end{tabular}


Table 28. Comparison of Proportion of Vehicles Stopped in TBC 2017 and ASCT 2017 Conditions (Cont.)

\begin{tabular}{|c|c|c|c|c|c|c|c|c|c|}
\hline Intersection & $\begin{array}{c}\text { Time } \\
\text { periods }\end{array}$ & Approaches & $\begin{array}{c}\text { April } \\
\text { average } \\
\text { stopped } \\
\text { proportion }\end{array}$ & $\begin{array}{c}\text { March } \\
\text { average } \\
\text { stopped } \\
\text { proportion }\end{array}$ & $\begin{array}{c}\text { Change in } \\
\text { stopped } \\
\text { proportion } \\
\text { (Apr-Mar) }\end{array}$ & $p$-value & $\begin{array}{c}\text { Stopped } \\
\text { proportio } \\
\text { n (Apr- } \\
\text { Mar) }\end{array}$ & $\begin{array}{c}\text { Delay } \\
\text { change } \\
\text { (Apr-Mar) }\end{array}$ & PI \\
\hline \multirow{12}{*}{ St. Mary's } & \multirow{4}{*}{ AM } & NBT & $22.2 \%$ & $20.3 \%$ & $1.9 \%$ & 0.9522 & Unch & Unch & Unch \\
\hline & & SBT & $40.0 \%$ & $45.1 \%$ & $-5.1 \%$ & 0.3911 & Unch & Unch & Unch \\
\hline & & EBT & $73.2 \%$ & $83.4 \%$ & $-10.2 \%$ & 0.1111 & Unch & Unch & Unch \\
\hline & & WBT & $69.1 \%$ & $76.1 \%$ & $-7.0 \%$ & 0.4586 & Unch & Unch & Det \\
\hline & \multirow{4}{*}{ NP } & NBT & $32.2 \%$ & $27.6 \%$ & $4.6 \%$ & 0.2161 & Unch & Unch & Det \\
\hline & & SBT & $30.4 \%$ & $15.8 \%$ & $14.6 \%$ & 0.0001 & Inc & Inc & Det \\
\hline & & EBT & $84.8 \%$ & $86.2 \%$ & $-1.4 \%$ & 0.8169 & Unch & Unch & Unch \\
\hline & & WBT & $61.5 \%$ & $27.6 \%$ & $33.9 \%$ & 0.0037 & Inc & Unch & Det \\
\hline & \multirow{4}{*}{ PM } & NBT & $19.7 \%$ & $27.8 \%$ & $-8.1 \%$ & 0.0155 & Dec & Unch & Unch \\
\hline & & SBT & $23.6 \%$ & $17.7 \%$ & $5.9 \%$ & 0.0588 & Unch & Unch & Unch \\
\hline & & EBT & $85.6 \%$ & $64.4 \%$ & $21.2 \%$ & 0.0276 & Inc & Unch & Unch \\
\hline & & WBT & $71.6 \%$ & $54.8 \%$ & $16.8 \%$ & 0.0118 & Inc & Inc & Det \\
\hline \multirow{9}{*}{ Devonshire } & \multirow{3}{*}{ AM } & NBT & $18.6 \%$ & $8.6 \%$ & $10.0 \%$ & 0.0007 & Inc & Inc & Det \\
\hline & & SBT & $8.0 \%$ & $7.1 \%$ & $0.9 \%$ & 0.5180 & Unch & Unch & Unch \\
\hline & & EBL & $89.0 \%$ & $92.4 \%$ & $-3.4 \%$ & 0.4844 & Unch & Unch & Unch \\
\hline & \multirow{3}{*}{ NP } & NBT & $17.6 \%$ & $11.7 \%$ & $5.9 \%$ & 0.0442 & Unch & Unch & Det \\
\hline & & SBT & $22.1 \%$ & $10.5 \%$ & $11.6 \%$ & 0.0014 & Inc & Inc & Det \\
\hline & & EBL & $81.6 \%$ & $88.4 \%$ & $-6.8 \%$ & 0.1957 & Unch & Unch & Unch \\
\hline & \multirow{3}{*}{ PM } & NBT & $12.0 \%$ & $8.0 \%$ & $4.0 \%$ & 0.2048 & Unch & Unch & Det \\
\hline & & SBT & $19.7 \%$ & $11.1 \%$ & $8.6 \%$ & 0.0016 & Inc & Inc & Det \\
\hline & & EBL & $89.6 \%$ & $90.7 \%$ & $-1.1 \%$ & 0.8162 & Unch & Unch & $\operatorname{Imp}$ \\
\hline \multirow{12}{*}{ Windsor } & \multirow{4}{*}{ AM } & NBT & $51.8 \%$ & $38.0 \%$ & $13.8 \%$ & 0.0153 & Inc & $\operatorname{Inc}$ & Det \\
\hline & & SBT & $47.0 \%$ & $27.5 \%$ & $19.5 \%$ & 0.0187 & Inc & Unch & Det \\
\hline & & EBT & $76.1 \%$ & $72.2 \%$ & $3.9 \%$ & 0.7098 & Unch & Inc & Det \\
\hline & & WBT & $82.3 \%$ & $82.8 \%$ & $-0.5 \%$ & 0.5175 & Unch & Unch & Unch \\
\hline & \multirow{4}{*}{ NP } & NBT & $48.9 \%$ & $53.8 \%$ & $-4.9 \%$ & 0.4157 & Unch & Inc & Det \\
\hline & & SBT & $35.5 \%$ & $22.9 \%$ & $12.6 \%$ & 0.0014 & Inc & Unch & Unch \\
\hline & & EBT & $83.0 \%$ & $72.2 \%$ & $10.8 \%$ & 0.1172 & Unch & Unch & Unch \\
\hline & & WBT & $85.8 \%$ & $76.2 \%$ & $9.6 \%$ & 0.1459 & Unch & Unch & Unch \\
\hline & \multirow{4}{*}{ PM } & NBT & $64.2 \%$ & $60.0 \%$ & $4.2 \%$ & 0.4738 & Unch & Unch & Unch \\
\hline & & SBT & $50.7 \%$ & $34.9 \%$ & $15.8 \%$ & 0.0053 & Inc & Inc & Det \\
\hline & & EBT & $84.5 \%$ & $75.6 \%$ & $8.9 \%$ & 0.0722 & Unch & Inc & Det \\
\hline & & WBT & $76.4 \%$ & $55.1 \%$ & $21.3 \%$ & 0.0001 & Inc & Inc & Det \\
\hline
\end{tabular}

In 19 cases, the proportion of stopped vehicles increased. In 13 of them, the delay also increased. In the remaining 6 cases, the proportion of stopped vehicles increased; but delay remained unchanged. 
In all 13 cases, 8 on major streets and 5 on minor, the proportion of vehicles stopped and the delay increased; performance deteriorated. The average increase in the proportion stopped at major streets was $13.6 \%$ and at minor streets, $19.6 \%$

Table 29 shows the cases with deteriorated performances that could be explained by the proportion of vehicles stopped.

Table 29. Summary of Cases Explained by Proportion of Vehicles Stopped

\begin{tabular}{|c|c|c|c|c|}
\hline Intersections & Approach & AM Peak & Noon Peak & PM Peak \\
\hline \multirow{4}{*}{ Stadium } & NBT & Det & Det & Det \\
\hline & SBT & Det & Unch & Det \\
\hline & EBT & Det & Det & Det \\
\hline & WBT & $N A$ & Det & Det \\
\hline \multirow{4}{*}{ Kirby } & NBT & Det & Imp & Imp \\
\hline & SBT & Det & Unch & Det \\
\hline & EBT & Det & Det & Unch \\
\hline & WBT & Det & Det & Det \\
\hline \multirow{4}{*}{ St. Mary's } & NBT & Unch & Det & Unch \\
\hline & SBT & Unch & Det & Unch \\
\hline & EBT & Unch & Unch & Unch \\
\hline & WBT & Det & Det & Det \\
\hline \multirow{3}{*}{ Devonshire } & NBT & Det & Det & Det \\
\hline & SBT & Unch & Det & Det \\
\hline & EBL & Unch & Unch & Imp \\
\hline \multirow{4}{*}{ Windsor } & NBT & Det & Det & Unch \\
\hline & SBT & Det & Unch & Det \\
\hline & EBT & Det & Unch & Det \\
\hline & WBT & Unch & Unch & Det \\
\hline
\end{tabular}

Note: Highlighted cells indicate cases explained by proportion of stopped vehicles.

\subsubsection{Deterioration-Analysis Summary}

In section 4.5, we have presented the deterioration analysis by looking at arrival-type changes, average effective green changes, and $\mathrm{g} / \mathrm{C}$ ratio changes; additionally, in a few cases, there were other contributors: inadequate response to volume increase, pedestrian effects, volume miscounting, and proportion of vehicles stopped. The effects of phase plan on deterioration are presented in Appendix A.5 even though they did not yield a clear message. These analyses enabled us to provide some explanation for some of the deteriorated cases. The cases highlighted in Table 30 are the deteriorated cases for which we could provide some explanations. 
Table 30. All of the Deteriorated Cases that Were Explained

\begin{tabular}{|c|c|c|c|c|}
\hline Intersections & Approach & AM Peak & Noon Peak & PM Peak \\
\hline \multirow{4}{*}{ Stadium } & NBT & Det & Det $^{*}$ & Det \\
\hline & SBT & Det & Unch & Det \\
\hline & EBT & Det $^{*}$ & Det & Det \\
\hline & WBT & $N A$ & Det & Det \\
\hline \multirow{4}{*}{ Kirby } & NBT & Det & Imp & Imp \\
\hline & SBT & Det & Unch & Det $^{*}$ \\
\hline & EBT & Det $^{*}$ & Det & Unch \\
\hline & WBT & Det & Det $^{*}$ & Det \\
\hline \multirow{4}{*}{ St. Mary's } & NBT & Unch & $\mathrm{De}$ & Unch \\
\hline & SBT & Unch & Det $^{*}$ & Unch \\
\hline & EBT & Unch & Unch & Unch \\
\hline & WBT & Det & Det & $\operatorname{Det}^{*}$ \\
\hline \multirow{3}{*}{ Devonshire } & NBT & Det $^{*}$ & Det & Det \\
\hline & SBT & Unch & Det $^{*}$ & Det $^{*}$ \\
\hline & EBL & Unch & Unch & Imp \\
\hline \multirow{4}{*}{ Windsor } & NBT & Det $^{*}$ & Det & Unch \\
\hline & SBT & Det & Unch & Det $^{*}$ \\
\hline & EBT & Det & Unch & Det \\
\hline & WBT & Unch & Unch & Det $^{*}$ \\
\hline
\end{tabular}

Legend:

Green: Cases explained by deterioration of arrival types under ASCT 2017, as compared to TBC 2017 Blue: Cases explained by signal-timing changes (comparing ASCT 2017 to TBC 2017)

Orange: Cases explained by insufficient response to volume increase under ASCT 2017, as compared to TBC 2017

Star (*): Cases with higher proportion of stopped vehicles under ASCT 2017, as compared to TBC 2017

- $\quad$ Orange and blue/Green and blue/Green and star $\left({ }^{*}\right) /$ Blue and star $\left({ }^{*}\right) / O r a n g e$ and star $\left({ }^{*}\right) / G r e e n$ and blue and star $\left({ }^{*}\right)$ : Cases explained by more than one reason 


\section{CHAPTER 5: CONCLUSIONS}

The volume, delay, and queue length data from the field for TBC 2017 were measured and compared that for ASCT 2017, at the $97 \%$ confidence level. Field volumes were compared for 57 lane groups (approaches). Traffic volume for $7 \%$ of the lane groups increased significantly, did not change significantly on $72 \%$, and decreased significantly on $21 \%$. Field delays were compared for 57 lane groups, of which $56 \%$ showed significant increase, $40 \%$ showed no significant change, and $4 \%$ showed significant decrease. Queue length was compared for 57 lane groups. Of these 57 lane groups, 48\% showed significant increase in queue length, $48 \%$ showed no significant change, and $4 \%$ showed significant decrease.

Further analysis was carried out to determine ASCT performance at approach, intersection, and corridor levels. Based on the changes in volume, delay, and queue length combined, an overall performance indicator (PI) was determined for each approach of each intersection at each time period. The performance indicators are Imp (Improved), Unch (Unchanged), and Det (Deteriorated). As we considered the $97 \%$ confidence interval for individual comparisons of volume, delay, and queue length, so the PI presents the results at the $91 \%$ confidence level; the product of three individual confidence levels of $97 \%(0.97 * 0.97 * 0.97)$. One lane group was excluded from further analysis due to insufficient volume; of the 56 lane groups analyzed, the PI showed improvement in $5 \%$, remained unchanged in $32 \%$, but showed deterioration in $63 \%$. In summary, for $37 \%$ of the lane groups, performance under ASCT either improved or was unchanged; however, on $63 \%$ of the lane groups, performance deteriorated. Out of the 35 deteriorated cases (the 63\%), volume significantly increased in 3 , did not change significantly in 21 , and decreased significantly in 11 . The deterioration in the 3 cases can be attributed to the increase in volume and the system's inability to respond adequately to the increase. However, for the 25 lane groups in which volume did not change significantly, the deterioration in $\mathrm{PI}$ was not expected.

Further investigations were performed to find factors contributing to the ASCT performance deterioration. Out of 35 cases, deterioration in 20 cases could be explained by factors such as frequency of unfavorable arrival types under ASCT 2017, as compared to TBC 2017; a few cases of volume increase under ASCT 2017; ASCT miscount of traffic volumes; signal-timing changes under ASCT 2017; and an increased proportion of vehicles stopped under ASCT 2017. However, in the 15 remaining cases, there was no reasonable explanation for PI deterioration when ASCT was operating. 


\section{REFERENCES}

1. Schrank, David, Bill Eisele, and Tim Lomax. 2014 Urban mobility report: powered by Inrix Traffic Data. No. SWUTC/15/161302-1. 2015.

2. Trafficware. SynchroGreen Real-Time Adaptive Traffic Control System. Texas, 2012. Accessed November 9, 2018. https://www.trafficware.com/uploads/2/2/2/5/22256874/synchrogreen_technical_white_pap er_1.pdf.

3. Stevanovic, Aleksandar. Adaptive traffic control systems: domestic and foreign state of practice. No. Project 20-5 (Topic 40-03). 2010.

4. Cheek, Marshall, Charles Wetzel, and Chad Dickson. "SynchroGreen Real-Time Adaptive Traffic Control System Seminole County Deployment." In ITE 2012 Annual Meeting \& Exhibit Institute of Transportation Engineers (ITE). 2012.

5. So, J., A. Stevanovic, E. Posadas, and R. Awwad. "Field Evaluation of a SynchroGreen Adaptive Signal System." In T\&DI Congress 2014: Planes, Trains, and Automobiles, pp. 388-399. 2014.

6. Benekohal, Rahim F., Behnoush Garshasebi, Xueying Liu, and Hongjae Jeon. Evaluation of Adaptive Signal Control Technology-Volume 2: Comparison of Base Condition to the First Year after Implementation. FHWA-ICT-18-005. Illinois Center for Transportation, 2018.

7. Shaik, Mohammed Abdul Rawoof, Xueying Liu, and Rahim F. Benekohal. Evaluation of Adaptive Signal Control Technology-Volume 1: Before-Conditions Data Collection and Analysis. FHWAICT-17-008, Illinois Center for Transportation, 2017.

8. Highway Capacity Manual. HCM2010. Transportation Research Board, National Research Council, Washington, DC (2010).

9. Highway Capacity Software. HCS2010. McTrans Center, University of Florida, Gainesville, Florida (2010).

10. Luh, J. Z., and William G. Lothian. "Traffic Progression Assessment in Traffic Impact Studies." ITE Journal 61, no. 5 (1991): 17-21. 


\section{APPENDIX A: STATISTICAL COMPARISON AT CORRIDOR LEVEL}

\section{A.1 STATISTICAL DELAY COMPARISON}

Using the methodology for comparison in Chapter 4, t-tests were performed for the three time periods and for all through-lane groups in the study area, except for the eastbound approach of the intersection of Neil Street and Devonshire Drive, where the tests were performed for the protected left-turn lane rather than the through lane.

The details of the t-tests performed are presented in Tables 31 to 33. For each table, the column heading " $n$ " stands for the number of cycle-by-cycle observations obtained from the field for the subject lane group. The other columns show the field measurements, t-statistics, and p-values. EBL stands for the eastbound left-lane group.

A total of 56 tests was performed over the three time periods for volume, stopped delay, and queue length. We have pointed out the significant comparison with two confidence levels; an observed error in a comparison is considered as significant if the $p$-value of its t-test was less than $10 \%$ or $3 \%$. Based on each confidence level (the last two columns), the tests in which volume or stopped delay for ASCT 2017 conditions is significantly larger than that for TBC 2017 conditions are highlighted with pink, while those in which ASCT 2017 conditions are significantly lower than TBC 2017 conditions are highlighted with blue. 
Table 31. Statistical Comparison Between TBC2017 and ASCT2017 Conditions for Stopped Delay

\begin{tabular}{|c|c|c|c|c|c|c|c|c|c|c|c|c|c|c|c|c|c|}
\hline & & & \multicolumn{4}{|c|}{ April } & \multicolumn{4}{|c|}{ Feb } & & & & & & & \\
\hline \multicolumn{3}{|c|}{ Delay } & Mean & Variance & Std & $n$ & Mean & Variance & Std & $n$ & Pooled? & sp & df & T-statistic & P-value & \begin{tabular}{|l|l} 
(Alpha $=0.1$ ) Significant? \\
\end{tabular} & (Alpha $=0.03$ ) significant? \\
\hline \multirow{12}{*}{ stadium } & \multirow{4}{*}{ AM } & NBT & 6.77641198 & \begin{tabular}{|l|}
170.386966 \\
\end{tabular} & 13.053 & 58 & 1.827 & 16.138 & 4.017 & 58 & 0 & 1.793 & 114 & 2.75968337 & \begin{tabular}{|l|}
0.00674307 \\
\end{tabular} & $\overline{\text { YES }}$ & YES \\
\hline & & SBT & 7.62046574 & 82.910 & 9.105 & 58 & 3.605 & 22.969 & 4.793 & 58 & 1 & 7.276 & 114 & 2.97219974 & 0.00360772 & YES & YES \\
\hline & & $E B L$ & \begin{tabular}{|l|}
13.7531796 \\
\end{tabular} & 124.959 & 11.179 & 58 & 7.485 & 69.567 & 8.341 & 58 & 1 & 9.862 & 114 & 3.42262678 & 0.00086216 & YES & YES \\
\hline & & WBL & \begin{tabular}{|l|}
3.10344828 \\
\end{tabular} & 61.2522686 & 7.826 & 58 & 4.707 & 91.299 & 9.555 & 58 & 1 & 8.734 & 114 & \begin{tabular}{|l|}
-0.9886935 \\
\end{tabular} & \begin{tabular}{|l|}
0.32490696 \\
\end{tabular} & NO & NO \\
\hline & \multirow{4}{*}{ NP } & NBT & 6.83117882 & 42.475 & 6.517 & 65 & 1.922 & 12.950 & 3.599 & 63 & 1 & 5.286 & 126 & 5.25299797 & \begin{tabular}{|l|}
$6.1818 \mathrm{E}-07$ \\
\end{tabular} & YES & 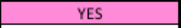 \\
\hline & & SBT & \begin{tabular}{|l|}
6.8261039 \\
\end{tabular} & 78.450 & 8.857 & 65 & 4.060 & 40.546 & 6.368 & 63 & 0 & 1.360 & 126 & 2.03313074 & \begin{tabular}{|l|}
0.04413999 \\
\end{tabular} & YES & NO \\
\hline & & EBL & \begin{tabular}{|l|}
7.56923077 \\
\end{tabular} & \begin{tabular}{|l|}
119.561538 \\
\end{tabular} & 10.934 & 65 & 4.776 & 77.835 & 8.822 & 63 & 1 & 9.951 & 126 & 1.58773168 & \begin{tabular}{|l|}
0.11485334 \\
\end{tabular} & NO & NO \\
\hline & & WBL & \begin{tabular}{|l|}
5.63076923 \\
\end{tabular} & 93.799 & 9.685 & 65 & 4.881 & 69.562 & 8.340 & 63 & 1 & 9.048 & 126 & \begin{tabular}{|l|}
0.46871331 \\
\end{tabular} & \begin{tabular}{|l|}
0.64008449 \\
\end{tabular} & NO & NO \\
\hline & \multirow{4}{*}{ PM } & NBT & \begin{tabular}{|l|}
5.85095518 \\
\end{tabular} & 40.323 & 6.350 & 59 & 5.012 & 44.811 & 6.694 & 59 & 1 & 6.524 & 116 & \begin{tabular}{|l|}
0.6984764 \\
\end{tabular} & \begin{tabular}{|l|}
0.48627725 \\
\end{tabular} & NO & NO \\
\hline & & SBT & \begin{tabular}{|l|}
7.66358472 \\
\end{tabular} & 81.061 & 9.003 & 59 & \begin{tabular}{|l|}
2.79873367 \\
\end{tabular} & 20.674 & 4.547 & 59 & 1 & 7.132 & 116 & \begin{tabular}{|l|l|}
3.70477375 \\
\end{tabular} & \begin{tabular}{|l|}
0.00032562 \\
\end{tabular} & YES & YES \\
\hline & & $E B L$ & \begin{tabular}{|l|}
7.95762712 \\
\end{tabular} & 149.916 & 12.244 & 59 & 3.549 & 43.421 & 6.589 & 59 & 1 & 9.832 & 116 & 2.43532402 & \begin{tabular}{|l|}
0.01640074 \\
\end{tabular} & YES & YES \\
\hline & & WBL & \begin{tabular}{|l|}
14.4083535 \\
\end{tabular} & 90.736 & 9.526 & 59 & 6.497 & 63.379 & 7.961 & 59 & 1 & 8.778 & 116 & \begin{tabular}{|l|}
4.89494946 \\
\end{tabular} & \begin{tabular}{|c|}
$3.206 \mathrm{E}-06$ \\
\end{tabular} & YES & YES \\
\hline \multirow{12}{*}{ Kirby } & \multirow{4}{*}{$A M$} & NBT & \begin{tabular}{|l|}
14.8541825 \\
\end{tabular} & \begin{tabular}{|l|}
36.6031008 \\
\end{tabular} & 6.050 & 28 & 10.000 & 60.940 & 7.806 & 28 & 1 & 6.984 & 54 & 2.60063875 & \begin{tabular}{|l|}
0.01197897 \\
\end{tabular} & YES & YES \\
\hline & & SBT & \begin{tabular}{|l|}
14.2783565 \\
\end{tabular} & 52.903 & 7.273 & 28 & 12.675 & 35.130 & 5.927 & 28 & 1 & 6.635 & 54 & \begin{tabular}{|l|}
0.90396306 \\
\end{tabular} & \begin{tabular}{|l|}
0.37003018 \\
\end{tabular} & NO & NO \\
\hline & & EBL & \begin{tabular}{|l|}
31.3354541 \\
\end{tabular} & 113.008 & 10.631 & 28 & 15.282 & 119.344 & 10.924 & 28 & 1 & 10.779 & 54 & \begin{tabular}{|l|}
5.57280916 \\
\end{tabular} & \begin{tabular}{|l|}
$8.1749 \mathrm{E}-07$ \\
\end{tabular} & YES & YES \\
\hline & & WBL & 21.8650974 & \begin{tabular}{|l|}
375.817544 \\
\end{tabular} & 19.386 & 28 & 23.189 & 199.806 & 14.135 & 28 & 1 & 16.965 & 54 & \begin{tabular}{|l|}
-0.2918848 \\
\end{tabular} & \begin{tabular}{|l|}
0.77149312 \\
\end{tabular} & NO & NO \\
\hline & \multirow{4}{*}{ NP } & NBT & \begin{tabular}{|l|}
13.7445861 \\
\end{tabular} & 58.117 & 7.623 & 31 & 19.592 & 119.795 & 10.945 & 31 & 1 & 9.432 & 60 & \begin{tabular}{|l|}
-2.4408543 \\
\end{tabular} & \begin{tabular}{|l|}
0.01762097 \\
\end{tabular} & YES & YES \\
\hline & & SBT & \begin{tabular}{|l|}
22.6067299 \\
\end{tabular} & 284.138 & 16.856 & 31 & 17.139 & 82.535 & 9.085 & 31 & 0 & 3.439 & 60 & \begin{tabular}{|l|}
1.58977571 \\
\end{tabular} & \begin{tabular}{|l|}
0.11714126 \\
\end{tabular} & NO & NO \\
\hline & & EBL & \begin{tabular}{|l|}
61.7690941 \\
\end{tabular} & \begin{tabular}{|l|}
936.096929 \\
\end{tabular} & 30.596 & 31 & 24.504 & 146.548 & 12.106 & 31 & 1 & 23.266 & 60 & 6.30573306 & \begin{tabular}{|c|}
$3.77 \mathrm{E}-08$ \\
\end{tabular} & YES & YES \\
\hline & & WBL & \begin{tabular}{|l|}
32.115752 \\
\end{tabular} & \begin{tabular}{|c|}
324.564 \\
\end{tabular} & 18.016 & 31 & 14.890 & 161.316 & 12.701 & 31 & 1 & 15.587 & 60 & \begin{tabular}{|l|}
4.3511137 \\
\end{tabular} & \begin{tabular}{|l|}
$5.3461 \mathrm{E}-05$ \\
\end{tabular} & YES & YES \\
\hline & \multirow{4}{*}{ PM } & NBT & \begin{tabular}{|l|}
21.1920718 \\
\end{tabular} & 167.000 & 12.923 & 29 & 29.155 & 68.039 & 8.249 & 29 & 1 & 10.841 & 56 & \begin{tabular}{|l|}
-2.7969296 \\
\end{tabular} & \begin{tabular}{|l|}
0.00705806 \\
\end{tabular} & $\begin{array}{l}\text { YES } \\
\end{array}$ & YES \\
\hline & & SBT & \begin{tabular}{|l|}
26.5363819 \\
\end{tabular} & 145.920 & 12.080 & 29 & \begin{tabular}{|l|}
19.6045915 \\
\end{tabular} & 61.576 & 7.847 & 29 & 1 & 10.186 & 56 & \begin{tabular}{|l|}
2.59142795 \\
\end{tabular} & \begin{tabular}{|l|}
0.01216578 \\
\end{tabular} & YES & YES \\
\hline & & EBL & \begin{tabular}{|l|}
20.7257484 \\
\end{tabular} & 273.268 & 16.531 & 29 & 20.916 & 139.334 & 11.804 & 29 & 1 & 14.363 & 56 & \begin{tabular}{|l|}
-0.0504708 \\
\end{tabular} & \begin{tabular}{|l|}
0.95992685 \\
\end{tabular} & NO & NO \\
\hline & & WBL & 30.4004622 & 266.962 & 16.339 & 29 & 25.566 & 183.336 & 13.540 & 29 & 1 & 15.005 & 56 & \begin{tabular}{|l|}
1.22686248 \\
\end{tabular} & \begin{tabular}{|l|}
0.22500748 \\
\end{tabular} & NO & NO \\
\hline & & NBT & \begin{tabular}{|l|}
6.5224352 \\
\end{tabular} & \begin{tabular}{|l|}
31.3661445 \\
\end{tabular} & 5.601 & 29 & 4.291 & 12.949 & 3.598 & 29 & 1 & 4.707 & 56 & 1.80527363 & \begin{tabular}{|l|}
0.07640859 \\
\end{tabular} & YES & NO \\
\hline & $A M$ & SBT & \begin{tabular}{|l|}
7.86086672 \\
\end{tabular} & 33.528 & 5.790 & 29 & 7.563 & 37.662 & 6.137 & 29 & 1 & 5.966 & 56 & \begin{tabular}{|l|}
0.19000521 \\
\end{tabular} & \begin{tabular}{|l|}
0.84999212 \\
\end{tabular} & NO & NO \\
\hline & AM & EBL & \begin{tabular}{|l|}
31.1009852 \\
\end{tabular} & 390.615 & 19.764 & 29 & 32.860 & 391.605 & 19.789 & 29 & 1 & 19.777 & 56 & \begin{tabular}{|l|}
-0.3386154 \\
\end{tabular} & \begin{tabular}{|l|}
0.73616585 \\
\end{tabular} & NO & NO \\
\hline & & WBL & \begin{tabular}{|l|}
16.0344828 \\
\end{tabular} & \begin{tabular}{|l|}
427.67734 \\
\end{tabular} & 20.680 & 29 & 20.356 & 232.301 & 15.241 & 29 & 1 & 18.166 & 56 & \begin{tabular}{|l|}
-0.9058095 \\
\end{tabular} & \begin{tabular}{|l|}
0.3689176 \\
\end{tabular} & NO & NO \\
\hline & & NBT & \begin{tabular}{|l|}
8.33931274 \\
\end{tabular} & 15.298 & 3.911 & 32 & 6.600 & 19.980 & 4.470 & 32 & 1 & 4.200 & 62 & 1.65695844 & \begin{tabular}{|l|}
0.10258036 \\
\end{tabular} & NO & NO \\
\hline & & SBT & \begin{tabular}{|l|}
5.93860063 \\
\end{tabular} & 15.734 & 3.967 & 32 & 2.682 & 5.889 & 2.427 & 32 & 0 & 0.822 & 62 & \begin{tabular}{|l|}
3.96140784 \\
\end{tabular} & \begin{tabular}{|l|l|}
0.000195 \\
\end{tabular} & YES & YES \\
\hline St Marys & NP & EBL & \begin{tabular}{|l|}
31.5082949 \\
\end{tabular} & \begin{tabular}{|l|}
398.924133 \\
\end{tabular} & 19.973 & 32 & 22.133 & 277.414 & 16.656 & 32 & 1 & 18.389 & 62 & \begin{tabular}{|l|}
2.03917981 \\
\end{tabular} & \begin{tabular}{|l|}
0.04570057 \\
\end{tabular} & YES & NO \\
\hline & & WBL & \begin{tabular}{|l|}
17.484375 \\
\end{tabular} & 497.266 & 22.299 & 32 & 19.207 & 353.736 & 18.808 & 32 & 1 & 20.628 & 62 & \begin{tabular}{|l|}
-0.3339826 \\
\end{tabular} & \begin{tabular}{|l|}
0.73951973 \\
\end{tabular} & NO & NO \\
\hline & & NBT & \begin{tabular}{|l|}
5.46004377 \\
\end{tabular} & 16.300 & 4.037 & 29 & 7.555 & 22.052 & 4.696 & 29 & 1 & 4.379 & 56 & \begin{tabular}{|l|}
-1.8218866 \\
\end{tabular} & \begin{tabular}{|l|}
0.07381417 \\
\end{tabular} & YES & NO \\
\hline & & SBT & \begin{tabular}{|l|}
4.61922284 \\
\end{tabular} & 6.661 & 2.581 & 29 & \begin{tabular}{|l|}
6.14584079 \\
\end{tabular} & 13.671 & 3.697 & 29 & 1 & 3.188 & 56 & \begin{tabular}{|l|}
-1.8232274 \\
\end{tabular} & \begin{tabular}{|l|}
0.07360804 \\
\end{tabular} & YES & NO \\
\hline & PM & EBL & \begin{tabular}{|l|}
23.2078818 \\
\end{tabular} & 324.119 & 18.003 & 29 & 15.378 & 188.407 & 13.726 & 29 & 1 & 16.008 & 56 & \begin{tabular}{|l|}
1.8623955 \\
\end{tabular} & 0.06779658 & YES & NO \\
\hline & & WBL & \begin{tabular}{|l|}
25.9606807 \\
\end{tabular} & 269.153 & 16.406 & 29 & 17.138 & 123.868 & 11.130 & 29 & 1 & 14.018 & 56 & 2.39660793 & \begin{tabular}{|l|}
0.01991103 \\
\end{tabular} & YES & YES \\
\hline & & NBT & \begin{tabular}{|l|}
2.03576048 \\
\end{tabular} & \begin{tabular}{|l|}
2.96204825 \\
\end{tabular} & 1.721 & 28 & 1.071 & 1.878 & 1.371 & 28 & 1 & 1.556 & 54 & 2.31926627 & \begin{tabular}{|l|}
0.02419261 \\
\end{tabular} & YES & YES \\
\hline & $A M$ & SBT & 1.12 & 5.079 & 2.254 & 28 & 0.864 & 3.095 & 1.759 & 28 & 1 & 2.022 & 54 & \begin{tabular}{|l|}
0.47395698 \\
\end{tabular} & \begin{tabular}{|l|}
0.63744139 \\
\end{tabular} & NO & NO \\
\hline & & $E B L$ & 45.64 & 470.478 & 21.691 & 28 & 43.153 & 365.202 & 19.110 & 28 & 1 & 20.441 & 54 & \begin{tabular}{|l|}
0.45517614 \\
\end{tabular} & \begin{tabular}{|l|}
0.6508074 \\
\end{tabular} & NO & NO \\
\hline & & NBT & 2.14 & 4.013 & 2.003 & 32 & 1.550 & 3.196 & $\begin{array}{l}1.788 \\
\end{array}$ & 32 & 1 & 1.899 & 62 & 1.24304709 & \begin{tabular}{|l|}
0.21853083 \\
\end{tabular} & NO & NO \\
\hline Devonshire & NP & SBT & 6.17 & 43.409 & 6.589 & 32 & 1.750 & 4.054 & 2.013 & 32 & 0 & 1.218 & 62 & \begin{tabular}{|l|}
3.62927387 \\
\end{tabular} & \begin{tabular}{|l|}
0.00057684 \\
\end{tabular} & YES & YES \\
\hline & & $E B L$ & 35.72 & 208.449 & 14.438 & 32 & 41.070 & 161.974 & 12.727 & 32 & 1 & 13.609 & 62 & \begin{tabular}{|l|}
-1.5724624 \\
\end{tabular} & \begin{tabular}{|l|}
0.12093307 \\
\end{tabular} & NO & NO \\
\hline & & NBT & \begin{tabular}{|l|}
1.59494665 \\
\end{tabular} & 3.508 & 1.873 & 28 & 0.910 & 2.771 & 1.665 & 28 & 1 & 1.772 & 54 & 1.44634536 & \begin{tabular}{|l|}
0.15386009 \\
\end{tabular} & NO & NO \\
\hline & PM & SBT & \begin{tabular}{|l|}
3.76620318 \\
\end{tabular} & 8.493 & 2.914 & 28 & 1.355 & 1.414 & 1.189 & 28 & 0 & 0.595 & 54 & \begin{tabular}{|l|}
4.05357914 \\
\end{tabular} & \begin{tabular}{|l|}
0.00016296 \\
\end{tabular} & YES & YES \\
\hline & & EBL & \begin{tabular}{|l|}
46.8596939 \\
\end{tabular} & 312.914 & 17.689 & 28 & 53.880 & 696.471 & 26.391 & 28 & 1 & 22.465 & 54 & \begin{tabular}{|l|}
-1.1692478 \\
\end{tabular} & \begin{tabular}{|l|}
0.24743924 \\
\end{tabular} & NO & NO \\
\hline & & NBT & 19.7215602 & \begin{tabular}{|l|}
189.09524 \\
\end{tabular} & 13.751 & 27 & 10.395 & 53.721 & 7.329 & 27 & 1 & 11.019 & 52 & $\begin{array}{l}.110087 \\
\end{array}$ & \begin{tabular}{|l|}
0.00303326 \\
\end{tabular} & YES & YES \\
\hline & & SBT & \begin{tabular}{|l|}
9.24444444 \\
\end{tabular} & 106.685 & 10.329 & 27 & 5.732 & 82.092 & 9.060 & 27 & 1 & 9.715 & 52 & 1.32825845 & \begin{tabular}{|l|l}
0.1898932 \\
\end{tabular} & NO & NO \\
\hline & AM & EBL & \begin{tabular}{|l|}
38.7110421 \\
\end{tabular} & 392.466 & 19.811 & 27 & 22.547 & 160.912 & 12.685 & 27 & 1 & 16.634 & 52 & \begin{tabular}{|l|}
.57038213 \\
\end{tabular} & \begin{tabular}{|l|}
0.00077755 \\
\end{tabular} & YES & YES \\
\hline & & WBL & \begin{tabular}{|l|}
33.9626984 \\
\end{tabular} & \begin{tabular}{|l|}
338.04413 \\
\end{tabular} & 18.386 & 27 & 30.797 & 392.718 & 19.817 & 27 & 1 & 19.115 & 52 & \begin{tabular}{|l|}
0.60854552 \\
\end{tabular} & \begin{tabular}{|l|}
0.54547496 \\
\end{tabular} & NO & NO \\
\hline & & NBT & \begin{tabular}{|l|}
23.1994771 \\
\end{tabular} & 266.948 & 16.339 & 31 & 12.483 & 69.169 & 8.317 & 30 & 1 & 13.028 & 59 & \begin{tabular}{|l|}
3.2116827 \\
\end{tabular} & \begin{tabular}{|l|}
0.00213803 \\
\end{tabular} & YES & YES \\
\hline & & SBT & \begin{tabular}{|l|}
10.2305404 \\
\end{tabular} & 43.672 & 6.608 & 31 & 7.086 & 47.889 & 6.920 & 30 & 0 & 1.734 & 59 & 1.81401125 & \begin{tabular}{|l|}
0.07476182 \\
\end{tabular} & YES & NO \\
\hline Windsor & NP & EBL & 35.7013825 & \begin{tabular}{|l|}
312.91758 \\
\end{tabular} & 17.689 & 31 & 30.080 & 323.512 & 17.986 & 30 & 1 & 17.836 & 59 & 1.23055261 & \begin{tabular}{|l|}
0.22337379 \\
\end{tabular} & NO & NO \\
\hline & & WBL & \begin{tabular}{|l|}
37.4344575 \\
\end{tabular} & 430.291 & 20.743 & 31 & 27.726 & 261.783 & 16.180 & 30 & 1 & 18.640 & 59 & 2.03363672 & \begin{tabular}{|l|}
0.04649338 \\
\end{tabular} & YES & NO \\
\hline & & NBT & \begin{tabular}{|l|}
25.2701598 \\
\end{tabular} & 248.027 & 15.749 & 30 & 19.419 & 87.272 & 9.342 & 30 & 1 & 12.948 & 58 & \begin{tabular}{|l|l|}
1.75020959 \\
\end{tabular} & \begin{tabular}{|l|}
0.0853706 \\
\end{tabular} & YES & NO \\
\hline & & SBT & \begin{tabular}{|l|}
19.4495301 \\
\end{tabular} & 123.275 & 11.103 & 30 & 12.906067 & 46.118 & 6.791 & 30 & 1 & 9.203 & 58 & 2.75372142 & \begin{tabular}{|l|}
0.00785558 \\
\end{tabular} & YES & YES \\
\hline & PM & EBL & \begin{tabular}{|l|}
29.4873443 \\
\end{tabular} & 187.766 & 13.703 & 30 & 20.165 & 134.908 & 11.615 & 30 & 1 & 12.702 & 58 & 2.84266131 & \begin{tabular}{|l|}
0.00616664 \\
\end{tabular} & YES & YES \\
\hline & & WBL & 39.1036011 & 271.757 & 16.485 & 30 & 21.540 & 106.572 & 10.323 & 30 & 1 & 13.754 & 58 & \begin{tabular}{|l|l|}
4.94575578 \\
\end{tabular} & \begin{tabular}{|l|}
$6.8352 \mathrm{E}-06$ \\
\end{tabular} & YES & YES \\
\hline
\end{tabular}


Table 32. Statistical Comparison Between TBC2017 and ASCT2017 Conditions for Volume

\begin{tabular}{|c|c|c|c|c|c|c|c|c|c|c|c|c|c|c|c|c|c|}
\hline & & & \multicolumn{4}{|c|}{ April } & \multicolumn{4}{|c|}{ Feb } & & & & & & & \\
\hline \multicolumn{3}{|c|}{ Volume } & Mean & Variance & Std & $n$ & Mean & Variance & Std & $n$ & Pooled? & $S p$ & $\mathrm{df}$ & T-statistic & P-value & (Alpha $=0.1)$ Significant? & (Alpha $=0.03$ ) significant? \\
\hline \multirow{12}{*}{ stadium } & \multirow{4}{*}{ AM } & NBT & 7.77586207 & \begin{tabular}{|l|}
27.1944949 \\
\end{tabular} & 5.215 & 58 & 8.6593557 & 34.678 & 5.889 & 58 & 1 & 5.562 & 114 & -0.8553971 & 0.39412557 & NO & NO \\
\hline & & SBT & 5.77586207 & 11.791 & 3.434 & 58 & 6.584 & 13.423 & 3.664 & 58 & 1 & 3.551 & 114 & -1.226437 & 0.22256143 & NO & NO \\
\hline & & $\mathrm{EBL}$ & 3.62068966 & 6.976 & 2.641 & 58 & 5.060 & 8.152 & 2.855 & 58 & 1 & 2.750 & 114 & \begin{tabular}{|l|}
-2.8184014 \\
\end{tabular} & \begin{tabular}{|l|}
0.00569158 \\
\end{tabular} & YES & YES \\
\hline & & WBL & 0.5 & 0.500 & 0.707 & 58 & 0.953 & 1.008 & 1.004 & 58 & 1 & 0.868 & 114 & \begin{tabular}{|l|}
-2.8081839 \\
\end{tabular} & 0.00586304 & YES & YES \\
\hline & \multirow{4}{*}{ NP } & NBT & 6.4 & 9.119 & 3.020 & 65 & 6.476 & 14.350 & 3.788 & 63 & 1 & 3.419 & 126 & \begin{tabular}{|l|}
-0.126026 \\
\end{tabular} & 0.8999122 & NO & NO \\
\hline & & SBT & 5.73846154 & 9.321 & 3.053 & 65 & 6.095 & 9.410 & 3.068 & 63 & 0 & 0.541 & 126 & \begin{tabular}{|l|}
-0.6593762 \\
\end{tabular} & 0.51085754 & NO & NO \\
\hline & & $\mathrm{EBL}$ & 1 & 1.063 & 1.031 & 65 & 1.635 & 2.139 & 1.462 & 63 & 1 & 1.262 & 126 & -2.84615 & \begin{tabular}{|l|l|}
0.00516742 \\
\end{tabular} & YES & YES \\
\hline & & WBL & 0.90769231 & 1.116 & 1.057 & 65 & 1.365 & 1.494 & 1.222 & 63 & 1 & 1.141 & 126 & -2.2672734 & 0.0250772 & YES & YES \\
\hline & \multirow{4}{*}{ PM } & NBT & 7.83050847 & 15.212 & 3.900 & 59 & 7.271 & 16.477 & 4.059 & 59 & 1 & 3.981 & 116 & \begin{tabular}{|l|}
0.7631909 \\
\end{tabular} & \begin{tabular}{|l|}
0.4468989 \\
\end{tabular} & NO & NO \\
\hline & & SBT & \begin{tabular}{|l|}
8.33898305 \\
\end{tabular} & 13.262 & 3.642 & 59 & 8.153 & 15.856 & 3.982 & 59 & 1 & 3.816 & 116 & \begin{tabular}{|l|}
0.26539056 \\
\end{tabular} & \begin{tabular}{|l|}
0.79117967 \\
\end{tabular} & NO & NO \\
\hline & & $\mathrm{EBL}$ & 1 & 1.034 & 1.017 & 59 & 2.068 & 3.409 & 1.846 & 59 & 1 & 1.491 & 116 & \begin{tabular}{|l|}
-3.890873 \\
\end{tabular} & \begin{tabular}{|l|}
0.00016712 \\
\end{tabular} & YES & YES \\
\hline & & WBL & 3.96610169 & 6.378 & 2.525 & 59 & 3.678 & 7.601 & 2.757 & 59 & 1 & 2.644 & 116 & \begin{tabular}{|l|}
0.59193826 \\
\end{tabular} & \begin{tabular}{|l|}
0.55504388 \\
\end{tabular} & No & No \\
\hline \multirow{12}{*}{ Kirby } & \multirow{4}{*}{$A M$} & NBT & 16.5714286 & \begin{tabular}{|l|}
12.9206349 \\
\end{tabular} & 3.595 & 28 & \begin{tabular}{|l|}
15.5616648 \\
\end{tabular} & 26.552 & 5.153 & 28 & 1 & 4.443 & 54 & \begin{tabular}{|l|}
0.85045288 \\
\end{tabular} & 0.39882862 & NO & NO \\
\hline & & SBT & 9.35714286 & 13.868 & 3.724 & 28 & 11.857 & 18.302 & 4.278 & 28 & 1 & 4.011 & 54 & \begin{tabular}{|l|}
-2.3317748 \\
\end{tabular} & \begin{tabular}{|l|}
0.02347278 \\
\end{tabular} & YES & YES \\
\hline & & EBL & \begin{tabular}{|l|}
13.1071429 \\
\end{tabular} & 8.914 & 2.986 & 28 & 12.859 & 15.612 & 3.951 & 28 & 1 & 3.502 & 54 & \begin{tabular}{|l|}
0.26505078 \\
\end{tabular} & \begin{tabular}{|l|}
0.79197951 \\
\end{tabular} & NO & No \\
\hline & & WBL & 5.21428571 & 8.471 & 2.910 & 28 & 9.325 & 13.268 & 3.643 & 28 & 1 & 3.297 & 54 & \begin{tabular}{|l|}
-4.665039 \\
\end{tabular} & \begin{tabular}{|l|}
$2.0722 \mathrm{E}-05$ \\
\end{tabular} & YES & YES \\
\hline & \multirow{4}{*}{ NP } & NBT & 11.2580645 & 9.731 & 3.119 & 31 & 11.097 & 14.890 & 3.859 & 31 & 1 & 3.509 & 60 & \begin{tabular}{|l|}
0.18098053 \\
\end{tabular} & 0.85699282 & NO & NO \\
\hline & & SBT & \begin{tabular}{|l|l|}
.16129032 \\
\end{tabular} & 9.273 & 3.045 & 31 & 10.129 & 10.583 & 3.253 & 31 & 0 & 0.800 & 60 & \begin{tabular}{|l|}
-1.2091926 \\
\end{tabular} & \begin{tabular}{|l|}
0.23133219 \\
\end{tabular} & NO & NO \\
\hline & & $E B L$ & 7 & 8.933 & 2.989 & 31 & 5.968 & \begin{tabular}{|l|l|}
7.83225806 \\
\end{tabular} & 2.799 & 31 & 1 & 2.895 & 60 & \begin{tabular}{|l|}
1.40365279 \\
\end{tabular} & \begin{tabular}{|l|}
0.16557692 \\
\end{tabular} & NO & NO \\
\hline & & WBL & 6.25806452 & 8.265 & 2.875 & 31 & 7.677 & 4.759 & 2.182 & 31 & 1 & 2.552 & 60 & \begin{tabular}{|l|}
-2.1898046 \\
\end{tabular} & \begin{tabular}{|l|l|}
0.03243753 \\
\end{tabular} & YES & NO \\
\hline & \multirow{4}{*}{ PM } & NBT & 13.5833333 & 9.993 & 3.161 & 29 & 12.379 & 14.815 & 3.849 & 29 & 1 & 3.522 & 56 & \begin{tabular}{|l|}
1.30178027 \\
\end{tabular} & 0.19832115 & NO & NO \\
\hline & & SBT & \begin{tabular}{|l|}
14.862069 \\
\end{tabular} & 17.623 & 4.198 & 29 & 16.759 & 18.904 & 4.348 & 29 & 1 & 4.274 & 56 & \begin{tabular}{|l|}
-1.689881 \\
\end{tabular} & \begin{tabular}{|l|}
0.09661101 \\
\end{tabular} & YES & NO \\
\hline & & $\mathrm{EBL}$ & 7.16129032 & 10.118 & 3.181 & 29 & 7.276 & 5.278 & 2.297 & 29 & 1 & 2.775 & 56 & \begin{tabular}{|l|}
-0.1572406 \\
\end{tabular} & \begin{tabular}{|l|}
0.87562077 \\
\end{tabular} & NO & NO \\
\hline & & WBL & 11.2413793 & 25.475 & 5.047 & 29 & 15.897 & 12.096 & 3.478 & 29 & 1 & 4.334 & 56 & \begin{tabular}{|l|}
-4.0898362 \\
\end{tabular} & \begin{tabular}{|l|l|}
0.00013951 \\
\end{tabular} & YES & YES \\
\hline & & NBT & 17.4827586 & \begin{tabular}{|l|}
30.044335 \\
\end{tabular} & 5.481 & 29 & \begin{tabular}{|l|}
19.2193611 \\
\end{tabular} & 34.633 & 5.885 & 29 & 1 & 5.687 & 56 & \begin{tabular}{|l|}
-1.162848 \\
\end{tabular} & \begin{tabular}{|l|}
0.2498226 \\
\end{tabular} & NO & NO \\
\hline & & SBT & 7.89655172 & 8.310 & 2.883 & 29 & 8.514 & 13.068 & 3.615 & 29 & 1 & 3.269 & 56 & \begin{tabular}{|l|}
-0.7195791 \\
\end{tabular} & \begin{tabular}{|l|}
0.47477662 \\
\end{tabular} & NO & NO \\
\hline & $A M$ & $\mathrm{EBL}$ & 4.75862069 & 7.404 & 2.721 & 29 & 5.166 & 4.629 & 2.151 & 29 & 1 & 2.453 & 56 & \begin{tabular}{|l|}
-0.6332083 \\
\end{tabular} & \begin{tabular}{|l|}
0.52917522 \\
\end{tabular} & NO & NO \\
\hline & & WBL & 1.17241379 & 1.648 & 1.284 & 29 & 3.059 & 5.089 & 2.256 & 29 & 1 & 1.835 & 56 & \begin{tabular}{|l|}
-3.9134623 \\
\end{tabular} & \begin{tabular}{|l|l|}
0.00024889 \\
\end{tabular} & YES & YES \\
\hline & & NBT & 16.46875 & 12.773 & 3.574 & 32 & 14.313 & 16.544 & 4.067 & 32 & 1 & 3.829 & 62 & 2.25273619 & \begin{tabular}{|l|}
0.02782481 \\
\end{tabular} & YES & YES \\
\hline & NP & SBT & 13.71875 & 15.434 & 3.929 & 32 & 11.500 & 8.710 & 2.951 & 32 & 0 & 0.869 & 62 & 2.55433215 & \begin{tabular}{|l|}
0.01310986 \\
\end{tabular} & YES & YES \\
\hline St Marys & NP & EBL & 3.21875 & 3.467 & 1.862 & 32 & 4.156 & 6.394 & 2.529 & 32 & 1 & 2.220 & 62 & \begin{tabular}{|l|}
-1.6888391 \\
\end{tabular} & \begin{tabular}{|l|}
0.09627411 \\
\end{tabular} & YES & NO \\
\hline & & WBL & 1.53125 & 2.064 & 1.436 & 32 & 3.969 & 3.193 & 1.787 & 32 & 1 & 1.621 & 62 & \begin{tabular}{|l|}
-6.0143671 \\
\end{tabular} & 1.0526E-07 & YES & YES \\
\hline & & NBT & 15.2413793 & 12.547 & 3.542 & 29 & 14.621 & 15.030 & 3.877 & 29 & 1 & 3.713 & 56 & 0.63650978 & \begin{tabular}{|l|}
0.5270375 \\
\end{tabular} & NO & NO \\
\hline & PM & SBT & 18.9310345 & 15.924 & 3.990 & 29 & 19.276 & 27.707 & 5.264 & 29 & 1 & 4.671 & 56 & \begin{tabular}{|l|}
-0.281129 \\
\end{tabular} & \begin{tabular}{|l|}
0.77964758 \\
\end{tabular} & NO & NO \\
\hline & PM & $E B L$ & 2.55172414 & 5.470 & 2.339 & 29 & 3.931 & 6.924 & 2.631 & 29 & 1 & 2.489 & 56 & \begin{tabular}{|l|}
-2.1098603 \\
\end{tabular} & \begin{tabular}{|l|}
0.03935207 \\
\end{tabular} & YES & NO \\
\hline & & WBL & 5.48275862 & 6.330 & 2.516 & 29 & 10.761 & 10.740 & 3.277 & 29 & 1 & 2.921 & 56 & \begin{tabular}{|l|}
-6.8797843 \\
\end{tabular} & \begin{tabular}{|l|l|}
$5.4669 \mathrm{E}-09$ \\
\end{tabular} & YES & YES \\
\hline & & NBT & 19.35 & \begin{tabular}{|l|l}
48.1640212 \\
\end{tabular} & 6.940 & 28 & 21.577 & 32.784 & 5.726 & 28 & 1 & 6.362 & 54 & \begin{tabular}{|l|}
-1.3099112 \\
\end{tabular} & \begin{tabular}{|l|}
0.19577121 \\
\end{tabular} & NO & NO \\
\hline & $A M$ & SBT & 7.5 & 9.815 & 3.133 & 28 & 7.835 & 10.376 & 3.221 & 28 & 1 & 3.177 & 54 & \begin{tabular}{|l|}
-0.3940173 \\
\end{tabular} & \begin{tabular}{|l|}
0.69511998 \\
\end{tabular} & NO & NO \\
\hline & & EBL & 3.32 & 3.041 & 1.744 & 28 & 3.639 & 5.373 & 2.318 & 28 & 1 & 2.051 & 54 & \begin{tabular}{|l|}
-0.5819451 \\
\end{tabular} & \begin{tabular}{|l|l|}
0.56302541 \\
\end{tabular} & NO & NO \\
\hline & & NBT & 15.375 & 13.468 & 3.670 & 32 & 13.120 & 13.339 & 3.652 & 32 & 1 & 3.661 & 62 & 2.46377969 & 0.01653586 & YES & YES \\
\hline Devonshire & NP & SBT & 13.31 & 12.286 & 3.505 & 32 & 12.340 & 6.555 & 2.560 & 32 & 0 & 0.767 & 62 & \begin{tabular}{|l|}
1.26411414 \\
\end{tabular} & \begin{tabular}{|l|}
0.21092099 \\
\end{tabular} & NO & NO \\
\hline & & $\mathrm{EBL}$ & 5.28 & 6.467 & 2.543 & 32 & 4.125 & 3.984 & 1.996 & 32 & 1 & 2.286 & 62 & 2.02109282 & \begin{tabular}{|l|l|}
0.04759346 \\
\end{tabular} & YES & NO \\
\hline & & NBT & 12.8214286 & 13.263 & 3.642 & 28 & 12.890 & 10.544 & 3.247 & 28 & 1 & 3.450 & 54 & \begin{tabular}{|l|}
-0.0743654 \\
\end{tabular} & 0.94099443 & NO & NO \\
\hline & PM & SBT & 21.7142857 & 23.693 & 4.868 & 28 & 21.070 & 29.772 & 5.456 & 28 & 1 & 5.170 & 54 & \begin{tabular}{|l|l|}
0.46625152 \\
\end{tabular} & \begin{tabular}{|l|}
0.64291091 \\
\end{tabular} & NO & NO \\
\hline & & $\mathrm{EBL}$ & 4.28571429 & 3.101 & 1.761 & 28 & 2.780 & 3.063 & 1.750 & 28 & 1 & 1.756 & 54 & \begin{tabular}{|l|}
3.20914637 \\
\end{tabular} & 0.00224166 & YES & YES \\
\hline & & NBT & 17 & 24 & 4.899 & 28 & \begin{tabular}{|l|}
19.0564158 \\
\end{tabular} & 43.128 & 6.567 & 27 & 1 & 5.778 & 53 & \begin{tabular}{|l|}
-1.3195488 \\
\end{tabular} & \begin{tabular}{|l|}
0.19265764 \\
\end{tabular} & NO & NO \\
\hline & $A M$ & SBT & 3.44444444 & 2.410 & 1.553 & 28 & 4.965 & 5.985 & 2.446 & 27 & 1 & 2.041 & 53 & \begin{tabular}{|l|}
-2.7634603 \\
\end{tabular} & \begin{tabular}{|l|}
0.00784716 \\
\end{tabular} & YES & YES \\
\hline & $\mathrm{AM}$ & $E B L$ & 11.7407407 & 11.046 & 3.323 & 28 & 13.017 & 17.879 & 4.228 & 27 & 1 & 3.794 & 53 & \begin{tabular}{|l|}
-1.2474021 \\
\end{tabular} & \begin{tabular}{|l|}
0.21773395 \\
\end{tabular} & NO & NO \\
\hline & & WBL & 5.85185185 & 8.285 & 2.878 & 28 & 7.113 & 11.708 & 3.422 & 27 & 1 & 3.157 & 53 & \begin{tabular}{|l|}
-1.480789 \\
\end{tabular} & 0.14458357 & NO & NO \\
\hline & & NBT & 10.6451613 & 18.770 & 4.332 & 31 & 10.100 & 11.748 & 3.428 & 31 & 1 & 3.906 & 60 & \begin{tabular}{|l|}
0.54944804 \\
\end{tabular} & \begin{tabular}{|l|}
0.58473734 \\
\end{tabular} & NO & NO \\
\hline Windsor & & SBT & 7.58064516 & 6.252 & 2.500 & 31 & 7.600 & 8.800 & 2.966 & 31 & 0 & 0.697 & 60 & -0.0277766 & \begin{tabular}{|l|}
0.97793252 \\
\end{tabular} & NO & NO \\
\hline Windsor & $\mathrm{NP}$ & $\mathrm{EBL}$ & 6.4516129 & 7.989 & 2.827 & 31 & 5.700 & 8.217 & 2.867 & 31 & 1 & 2.847 & 60 & \begin{tabular}{|l|}
1.03951464 \\
\end{tabular} & \begin{tabular}{|l|}
0.30273642 \\
\end{tabular} & NO & NO \\
\hline & & WBL & 4.29032258 & 4.013 & 2.003 & 31 & 4.300 & 5.734 & 2.395 & 31 & 1 & 2.208 & 60 & \begin{tabular}{|l|}
-0.0172582 \\
\end{tabular} & 0.98628787 & NO & NO \\
\hline & & NBT & 8.06666667 & 8.271 & 2.876 & 30 & 8.867 & 8.051 & 2.837 & 30 & 1 & 2.857 & 58 & \begin{tabular}{|l|l|}
-1.0845912 \\
\end{tabular} & 0.28259059 & NO & NO \\
\hline & $P M$ & SBT & 13.7666667 & 28.530 & 5.341 & 30 & 15.400 & 20.731 & 4.553 & 30 & 1 & 4.963 & 58 & \begin{tabular}{|l|}
-1.2746302 \\
\end{tabular} & \begin{tabular}{|l|}
0.20752316 \\
\end{tabular} & NO & NO \\
\hline & PM & $\mathrm{EBL}$ & 6.16666667 & 4.282 & 2.069 & 30 & 6.867 & 5.430 & 2.330 & 30 & 1 & 2.204 & 58 & \begin{tabular}{|l|}
-1.2303131 \\
\end{tabular} & \begin{tabular}{|l|}
0.22354658 \\
\end{tabular} & NO & NO \\
\hline & & WBL & 10.3333333 & 11.954 & 3.457 & 30 & 11.267 & 15.237 & 3.903 & 30 & 1 & 3.687 & 58 & \begin{tabular}{|l|}
-0.9803618 \\
\end{tabular} & \begin{tabular}{|l|}
0.33097932 \\
\end{tabular} & NO & NO \\
\hline
\end{tabular}




\section{A.2 STATISTICAL QUEUE-LENGTH COMPARISON}

Using the methodology for comparison described in Chapter 4, t-tests were performed for all lane groups for both TBC 2017 and ASCT 2017 conditions. The tests include all through movements at the intersections of Neil Street with Stadium Drive, Kirby Avenue, St. Mary's Road, and Windsor Road; and for NBT, SBT, and EBL of Neil Street and Devonshire Drive.

The details of the t-tests performed are presented in Table 33. In this table, the column heading " $n$ " stands for the number of cycle-by-cycle observations obtained from the field for the subject lane group. A total of 56 tests was performed for the average queue-length comparisons. We have pointed out the significant comparison with two confidence levels; an observed error in a comparison is considered as significant if the $\mathrm{p}$-value of its t-test was less than $10 \%$ or $3 \%$. Based on each confidence level (the last two columns), the queue-length values under ASCT 2017 conditions that are significantly larger than for TBC 2017 conditions are highlighted with pink, while those in which ASCT 2017 conditions are significantly lower than TBC 2017 conditions are highlighted with blue. 
Table 33. Statistical Comparison Between TBC2017 and ASCT2017 Conditions for Average Queue Length

\begin{tabular}{|c|c|c|c|c|c|c|c|c|c|c|c|c|c|c|c|c|c|}
\hline & & & \multicolumn{4}{|c|}{ April } & \multicolumn{4}{|c|}{ Feb } & \multirow[b]{2}{*}{$\begin{array}{l}\text { Pooled? } \\
\end{array}$} & \multirow[b]{2}{*}{ Sp } & \multirow[b]{2}{*}{ df } & \multirow[b]{2}{*}{\begin{tabular}{|l|} 
T-statistic \\
\end{tabular}} & \multirow[b]{2}{*}{$\begin{array}{l}\text { P-value } \\
\end{array}$} & \multirow{3}{*}{\begin{tabular}{|c|} 
(Alpha $=0.1)$ Significant? \\
YES
\end{tabular}} & \multirow{3}{*}{\begin{tabular}{|l|} 
(Alpha $=0.03)$ significant? \\
YES
\end{tabular}} \\
\hline & ue Len & & Mean & Variance & Std & $n$ & Mean & Variance & Std & $n$ & & & & & & & \\
\hline \multirow{12}{*}{ stadium } & \multirow{4}{*}{$A M$} & NBT & \begin{tabular}{|l|}
1.94827586 \\
\end{tabular} & 5.41833031 & 2.328 & 58 & 1.138 & 1.314 & 1.146 & 58 & 0 & 0.341 & 114 & 2.37849352 & 0.01904614 & & \\
\hline & & SBT & \begin{tabular}{|l|}
2.37931034 \\
\end{tabular} & 5.433 & 2.331 & 58 & 1.707 & 4.316 & 2.078 & 58 & 1 & 2.208 & 114 & \begin{tabular}{|l|}
1.64013131 \\
\end{tabular} & \begin{tabular}{|l|}
0.1037344 \\
\end{tabular} & NO & NO \\
\hline & & EBL & 2.32758621 & 3.803 & 1.950 & 58 & 1.397 & 1.928 & 1.388 & 58 & 1 & 1.693 & 114 & 2.96191384 & 0.0037214 & YES & YES \\
\hline & & WBL & \begin{tabular}{|l|}
0.27586207 \\
\end{tabular} & 0.309 & 0.555 & 58 & 0.086 & 0.080 & 0.283 & 58 & 1 & 0.441 & 114 & 2.31674668 & \begin{tabular}{|l|}
0.02230378 \\
\end{tabular} & YES & YES \\
\hline & & NBT & 2.44615385 & 4.751 & 2.180 & 65 & 0.683 & 1.285 & 1.133 & 63 & 1 & 1.745 & 126 & \begin{tabular}{|l|}
5.7162069 \\
\end{tabular} & $7.4664 \mathrm{E}-08$ & YES & YES \\
\hline & & SBT & 2.33846154 & 6.259 & 2.502 & 65 & 1.730 & 2.910 & 1.706 & 63 & 0 & 0.377 & 126 & \begin{tabular}{|l|}
1.61157155 \\
\end{tabular} & \begin{tabular}{|l|}
0.10955738 \\
\end{tabular} & NO & NO \\
\hline & NP & EBL & \begin{tabular}{|l|}
0.70769231 \\
\end{tabular} & \begin{tabular}{|l|}
0.96009615 \\
\end{tabular} & 0.980 & 65 & 0.381 & 0.401 & 0.633 & 63 & 1 & 0.828 & 126 & 2.23303616 & \begin{tabular}{|l|}
0.02731159 \\
\end{tabular} & YES & YES \\
\hline & & WBL & 0.6 & 0.713 & 0.844 & 65 & 0.444 & 0.509 & 0.713 & 63 & 1 & 0.783 & 126 & \begin{tabular}{|l|}
1.12436978 \\
\end{tabular} & 0.26299364 & NO & NO \\
\hline & & NBT & \begin{tabular}{|l|}
2.16949153 \\
\end{tabular} & 3.109 & 1.763 & 59 & 1.458 & 1.908 & 1.381 & 59 & 1 & 1.584 & 116 & 2.44134262 & 0.01614335 & YES & YES \\
\hline & & SBT & \begin{tabular}{|l|}
3.30508475 \\
\end{tabular} & 10.629 & 3.260 & 59 & 1.695 & 3.285 & 1.812 & 59 & 1 & 2.638 & 116 & \begin{tabular}{|l|}
3.31566212 \\
\end{tabular} & 0.00122081 & YES & YES \\
\hline & PM & EBL & \begin{tabular}{|l|}
0.52542373 \\
\end{tabular} & 0.564 & 0.751 & 59 & 0.45 & \begin{tabular}{|l|}
0.45508475 \\
\end{tabular} & 0.675 & 59 & 1 & 0.714 & 116 & \begin{tabular}{|l|}
0.57389092 \\
\end{tabular} & \begin{tabular}{|l|}
0.5671527 \\
\end{tabular} & NO & NO \\
\hline & & WBL & \begin{tabular}{|l|}
2.57627119 \\
\end{tabular} & 3.662 & 1.914 & 59 & 1.119 & 1.831 & 1.353 & 59 & 1 & 1.657 & 116 & \begin{tabular}{|l|l|}
4.77726937 \\
\end{tabular} & \begin{tabular}{|l|}
$5.2445 \mathrm{E}-06$ \\
\end{tabular} & YES & YES \\
\hline & & NBT & \begin{tabular}{|l|}
8.89285714 \\
\end{tabular} & \begin{tabular}{|l|l|}
7.87698413 \\
\end{tabular} & 2.807 & 28 & 5.214 & 12.397 & 3.521 & 28 & 1 & 3.184 & 54 & 4.32305268 & $6.6612 \mathrm{E}-05$ & YES & YES \\
\hline & se & SBT & \begin{tabular}{|l|}
4.92857143 \\
\end{tabular} & 7.550 & 2.748 & 28 & 4.464 & 5.962 & 2.442 & 28 & 1 & 2.599 & 54 & \begin{tabular}{|l|}
0.66835323 \\
\end{tabular} & \begin{tabular}{|l|}
0.50675509 \\
\end{tabular} & NO & NO \\
\hline & AM & EBL & \begin{tabular}{|l|}
8.35714286 \\
\end{tabular} & 3.275 & 1.810 & 28 & 3.714 & 10.138 & 3.184 & 28 & 1 & 2.590 & 54 & \begin{tabular}{|l|}
6.70820393 \\
\end{tabular} & \begin{tabular}{|l|}
$1.2262 \mathrm{E}-08$ \\
\end{tabular} & YES & YES \\
\hline & & WBL & \begin{tabular}{|l|}
2.82142857 \\
\end{tabular} & 5.485 & 2.342 & 28 & 2.920 & 5.660 & 2.379 & 28 & 1 & 2.361 & 54 & \begin{tabular}{|l|}
-0.1562361 \\
\end{tabular} & \begin{tabular}{|l|}
0.87642959 \\
\end{tabular} & NO & NO \\
\hline & & NBT & \begin{tabular}{|l|}
6.80645161 \\
\end{tabular} & 8.161 & 2.857 & 31 & 7.323 & 3.826 & 1.956 & 31 & 1 & 2.448 & 60 & \begin{tabular}{|l|}
-0.8300077 \\
\end{tabular} & \begin{tabular}{|l|}
0.40982477 \\
\end{tabular} & NO & NO \\
\hline & & SBT & 4.93548387 & 7.129 & 2.670 & 31 & 5.516 & 5.325 & 2.308 & 31 & 0 & 0.634 & 60 & \begin{tabular}{|l|}
-0.9160968 \\
\end{tabular} & \begin{tabular}{|l|}
0.36328357 \\
\end{tabular} & NO & NO \\
\hline Kirby & NP & EBL & \begin{tabular}{|l|}
5.03225806 \\
\end{tabular} & 7.23225806 & 2.689 & 31 & 4.258 & 4.798 & 2.190 & 31 & 1 & 2.453 & 60 & 1.24278396 & 0.21878243 & NO & NO \\
\hline & & WBL & 3.03225806 & 5.099 & 2.258 & 31 & 3.290 & 5.346 & 2.312 & 31 & 1 & 2.285 & 60 & \begin{tabular}{|l|}
-0.4445817 \\
\end{tabular} & \begin{tabular}{|l|}
0.65822167 \\
\end{tabular} & NO & NO \\
\hline & & NBT & \begin{tabular}{|l|}
8.79166667 \\
\end{tabular} & 8.346 & 2.889 & 29 & 7.655 & 1.234 & 1.111 & 29 & 0 & 0.575 & 56 & \begin{tabular}{|l|}
1.97734925 \\
\end{tabular} & 0.05293245 & YES & NO \\
\hline & & SBT & \begin{tabular}{|l|}
10.3448276 \\
\end{tabular} & 17.663 & 4.203 & 29 & 7.345 & 4.163 & 2.040 & 29 & 0 & 0.868 & 56 & \begin{tabular}{|l|}
3.45813467 \\
\end{tabular} & \begin{tabular}{|l|}
0.00104622 \\
\end{tabular} & YES & YES \\
\hline & PM & $\mathrm{EBL}$ & \begin{tabular}{|l|}
3.55172414 \\
\end{tabular} & 4.685 & 2.164 & 29 & 3.207 & 3.741 & 1.934 & 29 & 1 & 2.053 & 56 & 0.63971639 & 0.52496557 & NO & NO \\
\hline & & WBL & 6.96551724 & 3.106 & 1.762 & 29 & 7.310 & 3.793 & 1.948 & 29 & 1 & 1.857 & 56 & \begin{tabular}{|l|}
-0.7069805 \\
\end{tabular} & \begin{tabular}{|l|l|}
0.48251019 \\
\end{tabular} & NO & NO \\
\hline & & NBT & \begin{tabular}{|l|}
3.82758621 \\
\end{tabular} & \begin{tabular}{|l|}
6.93349754 \\
\end{tabular} & 2.633 & 29 & 3.034 & 3.392 & 1.842 & 29 & 1 & 2.272 & 56 & \begin{tabular}{|l|}
1.3291721 \\
\end{tabular} & 0.18918118 & NO & NO \\
\hline & & SBT & \begin{tabular}{|l|}
3.10344828 \\
\end{tabular} & 3.382 & 1.839 & 29 & 3.034 & 2.749 & 1.658 & 29 & 1 & 1.751 & 56 & \begin{tabular}{|l|}
0.14999665 \\
\end{tabular} & \begin{tabular}{|l|}
0.8813062 \\
\end{tabular} & NO & NO \\
\hline & AM & EBL & \begin{tabular}{|l|}
3.51724138 \\
\end{tabular} & 5.616 & 2.370 & 29 & 2.759 & 3.047 & 1.746 & 29 & 1 & 2.081 & 56 & \begin{tabular}{|l|}
1.38803531 \\
\end{tabular} & \begin{tabular}{|l|}
0.17062407 \\
\end{tabular} & NO & NO \\
\hline & & WBL & \begin{tabular}{|l|}
0.93103448 \\
\end{tabular} & 1.281 & 1.132 & 29 & 1.103 & 2.239 & 1.496 & 29 & 1 & 1.327 & 56 & \begin{tabular}{|l|}
-0.4949005 \\
\end{tabular} & 0.62260657 & NO & NO \\
\hline & & NBT & 5.53125 & 6.386 & 2.527 & 32 & 3.375 & 3.661 & 1.913 & 32 & 1 & 2.241 & 62 & 3.84811204 & 0.00028385 & YES & YES \\
\hline & NP & SBT & 4.3125 & 3.383 & 1.839 & 32 & 1.500 & 1.742 & 1.320 & 32 & 0 & 0.400 & 62 & \begin{tabular}{|l|}
7.02781928 \\
\end{tabular} & \begin{tabular}{|l|}
$1.9245 \mathrm{E}-09$ \\
\end{tabular} & YES & YES \\
\hline St Marys & NP & $\mathrm{EBL}$ & 2.4375 & \begin{tabular}{|l|}
2.64112903 \\
\end{tabular} & 1.625 & 32 & 2.094 & 3.314 & 1.820 & 32 & 1 & 1.725 & 62 & \begin{tabular}{|l|}
0.79687471 \\
\end{tabular} & \begin{tabular}{|l|}
0.42856488 \\
\end{tabular} & NO & NO \\
\hline & & WBL & 1 & 1.935 & 1.391 & 32 & 1.688 & 3.060 & 1.749 & 32 & 1 & 1.581 & 62 & -1.7399544 & 0.08682897 & YES & NO \\
\hline & & NBT & \begin{tabular}{|l|}
3.03448276 \\
\end{tabular} & 3.749 & 1.936 & 29 & 4.103 & 7.167 & 2.677 & 29 & 1 & 2.336 & 56 & \begin{tabular}{|l|}
-1.7423116 \\
\end{tabular} & 0.08694377 & YES & NO \\
\hline & $P M$ & SBT & \begin{tabular}{|l|}
4.31034483 \\
\end{tabular} & 5.293 & 2.301 & 29 & 3.207 & 2.241 & 1.497 & 29 & 1 & 1.941 & 56 & 2.16483229 & \begin{tabular}{|l|}
0.03467799 \\
\end{tabular} & YES & NO \\
\hline & PM & EBL & \begin{tabular}{|l|l|}
1.72413793 \\
\end{tabular} & 2.850 & 1.688 & 29 & 1.207 & 1.670 & 1.292 & 29 & 1 & 1.503 & 56 & \begin{tabular}{|l|}
1.31019894 \\
\end{tabular} & \begin{tabular}{|l|}
0.19547741 \\
\end{tabular} & NO & NO \\
\hline & & WBL & \begin{tabular}{|l|}
3.96551724 \\
\end{tabular} & 5.677 & 2.383 & 29 & 2.759 & 6.690 & 2.586 & 29 & 1 & 2.487 & 56 & \begin{tabular}{|l|}
1.84814887 \\
\end{tabular} & \begin{tabular}{|l|}
0.06986392 \\
\end{tabular} & YES & NO \\
\hline & & NBT & 3.607 & \begin{tabular}{|l|}
4.83994709 \\
\end{tabular} & 2.200 & 28 & 1.643 & 1.794 & 1.339 & 28 & 1 & 1.821 & 54 & \begin{tabular}{|l|}
4.0353157 \\
\end{tabular} & 0.00017299 & YES & YES \\
\hline & $\mathrm{AM}$ & SBT & 0.67 & 0.671 & 0.819 & 28 & 0.464 & 0.554 & 0.744 & 28 & 1 & 0.783 & 54 & \begin{tabular}{|l|}
0.9835555 \\
\end{tabular} & \begin{tabular}{|l|}
0.32972053 \\
\end{tabular} & NO & NO \\
\hline & & $\mathrm{EBL}$ & 3.07 & 2.513 & 1.585 & 28 & 2.536 & 2.480 & 1.575 & 28 & 1 & 1.580 & 54 & \begin{tabular}{|l|}
1.26518781 \\
\end{tabular} & \begin{tabular}{|l|l|}
0.21123639 \\
\end{tabular} & NO & NO \\
\hline & & NBT & 2.65 & 3.330 & 1.825 & 32 & 1.590 & 2.636 & 1.624 & 32 & 1 & 1.727 & 62 & 2.45498708 & 0.01690812 & YES & YES \\
\hline Devonshire & NP & SBT & 3.25 & 9.226 & 3.037 & 32 & 1.281 & 1.112 & 1.054 & 32 & 0 & 0.568 & 62 & \begin{tabular}{|l|l|}
3.46380603 \\
\end{tabular} & \begin{tabular}{|c|}
0.00097145 \\
\end{tabular} & YES & YES \\
\hline & & $E B L$ & 4.4 & 4.830 & 2.198 & 32 & 3.650 & 3.459 & 1.860 & 32 & 1 & 2.036 & 62 & \begin{tabular}{|l|}
1.47368055 \\
\end{tabular} & 0.145627 & NO & NO \\
\hline & & NBT & 1.64285714 & 2.979 & 1.726 & 28 & 0.780 & 0.989 & 0.995 & 28 & 1 & 1.409 & 54 & 2.29201885 & 0.02582909 & YES & YES \\
\hline & PM & $\mathrm{SBT}$ & \begin{tabular}{|l|}
4.42857143 \\
\end{tabular} & 7.661 & 2.768 & 28 & 2.250 & 2.713 & 1.647 & 28 & 1 & 2.278 & 54 & \begin{tabular}{|l|}
3.57907344 \\
\end{tabular} & \begin{tabular}{|l|}
0.00073814 \\
\end{tabular} & YES & YES \\
\hline & & $\mathrm{EBL}$ & \begin{tabular}{|l|}
3.71428571 \\
\end{tabular} & 3.323 & 1.823 & 28 & 2.570 & 3.217 & 1.794 & 28 & 1 & 1.808 & 54 & \begin{tabular}{|l|}
2.36774626 \\
\end{tabular} & \begin{tabular}{|l|}
0.02150805 \\
\end{tabular} & YES & YES \\
\hline & & NBT & \begin{tabular}{|l|}
10.037037 \\
\end{tabular} & \begin{tabular}{|l|}
15.4985755 \\
\end{tabular} & 3.937 & 27 & 5.704 & 13.755 & 3.709 & 27 & 1 & 3.824 & 52 & \begin{tabular}{|l|l|}
4.16307857 \\
\end{tabular} & 0.00011839 & YES & YES \\
\hline & & SBT & \begin{tabular}{|l|l|}
1.51851852 \\
\end{tabular} & 2.413 & 1.553 & 27 & 0.926 & 1.071 & 1.035 & 27 & 1 & 1.320 & 52 & \begin{tabular}{|l|}
1.64959917 \\
\end{tabular} & \begin{tabular}{|l|}
0.10505367 \\
\end{tabular} & NO & NO \\
\hline & $A M$ & EBL & \begin{tabular}{|l|}
9.44444444 \\
\end{tabular} & 13.103 & 3.620 & 27 & 7.778 & 9.795 & 3.130 & 27 & 1 & 3.384 & 52 & \begin{tabular}{|l|}
1.8098276 \\
\end{tabular} & \begin{tabular}{|l|}
0.07610339 \\
\end{tabular} & YES & NO \\
\hline & & WBL & \begin{tabular}{|l|l|}
4.85185185 \\
\end{tabular} & 7.285 & 2.699 & 27 & 4.111 & 7.641 & 2.764 & 27 & 1 & 2.732 & 52 & \begin{tabular}{|l|}
0.99627096 \\
\end{tabular} & \begin{tabular}{|l|}
0.3237321 \\
\end{tabular} & NO & NO \\
\hline & & NBT & \begin{tabular}{|l|}
5.80645161 \\
\end{tabular} & 10.228 & 3.198 & 31 & 5.333 & 11.057 & 3.325 & 30 & 1 & 3.261 & 59 & 0.56645259 & 0.57323471 & NO & NO \\
\hline Windsor & & SBT & 2.83870968 & 4.673 & 2.162 & 31 & 2.033 & 4.999 & 2.236 & 30 & 0 & 0.563 & 59 & 1.42959535 & \begin{tabular}{|l|}
0.15810721 \\
\end{tabular} & NO & NO \\
\hline Windsor & NP & $\mathrm{EBL}$ & 5.29032258 & \begin{tabular}{|l|}
8.07956989 \\
\end{tabular} & 2.842 & 31 & 4.000 & 5.655 & 2.378 & 30 & 1 & 2.624 & 59 & \begin{tabular}{|l|}
1.91968913 \\
\end{tabular} & \begin{tabular}{|l|}
0.05973661 \\
\end{tabular} & YES & NO \\
\hline & & WBL & \begin{tabular}{|l|}
3.86666667 \\
\end{tabular} & 4.395 & 2.097 & 31 & 2.900 & 3.541 & 1.882 & 30 & 1 & 1.994 & 59 & \begin{tabular}{|l|}
1.89299913 \\
\end{tabular} & \begin{tabular}{|l|}
0.06326605 \\
\end{tabular} & YES & NO \\
\hline & & NBT & 5 & 2.897 & 1.702 & 30 & 5.333 & 7.609 & 2.758 & 30 & 1 & 2.292 & 58 & \begin{tabular}{|l|}
-0.563282 \\
\end{tabular} & 0.57541411 & NO & NO \\
\hline & 89 & SBT & \begin{tabular}{|l|}
7.23333333 \\
\end{tabular} & 19.564 & 4.423 & 30 & 5.300 & 7.045 & 2.654 & 30 & 1 & 3.648 & 58 & 2.05282295 & \begin{tabular}{|l|}
0.04461025 \\
\end{tabular} & YES & NO \\
\hline & PM & $\mathrm{EBL}$ & \begin{tabular}{|l|}
4.93333333 \\
\end{tabular} & 3.237 & 1.799 & 30 & 5.433 & 4.047 & 2.012 & 30 & 1 & 1.908 & 58 & \begin{tabular}{|l|}
-1.0147251 \\
\end{tabular} & 0.31445129 & NO & NO \\
\hline & & WBL & 8 & 7.379 & 2.716 & 30 & 7.400 & 13.628 & 3.692 & 30 & 1 & 3.241 & 58 & \begin{tabular}{|l|}
0.71701944 \\
\end{tabular} & \begin{tabular}{|l|}
0.47623979 \\
\end{tabular} & NO & NO \\
\hline
\end{tabular}




\section{APPENDIX B: COMBINATION ANALYSIS (DELAY VS. VOLUME, QUEUE LENGTH VS. VOLUME)}

\section{B.1 DELAY AND VOLUME COMBINATION ANALYSIS}

Table 34 shows the combined-analysis results for delay and volume. In the table, " $D$ " is the abbreviation for delay and " $V$ " for volume. The upward arrow " $\uparrow$ " stands for increase, downward arrow " $\downarrow$ "for decrease, and dash "—"for unchanged. For instance, the column heading "D $\uparrow \& \vee \downarrow$ " stands for the category with increased delay and decreased volume. And the cells with entries "yes" signify that these lane groups (row heads) fall into the corresponding categories (column heads). 
Table 34. Combined Analysis for Delay and Volume

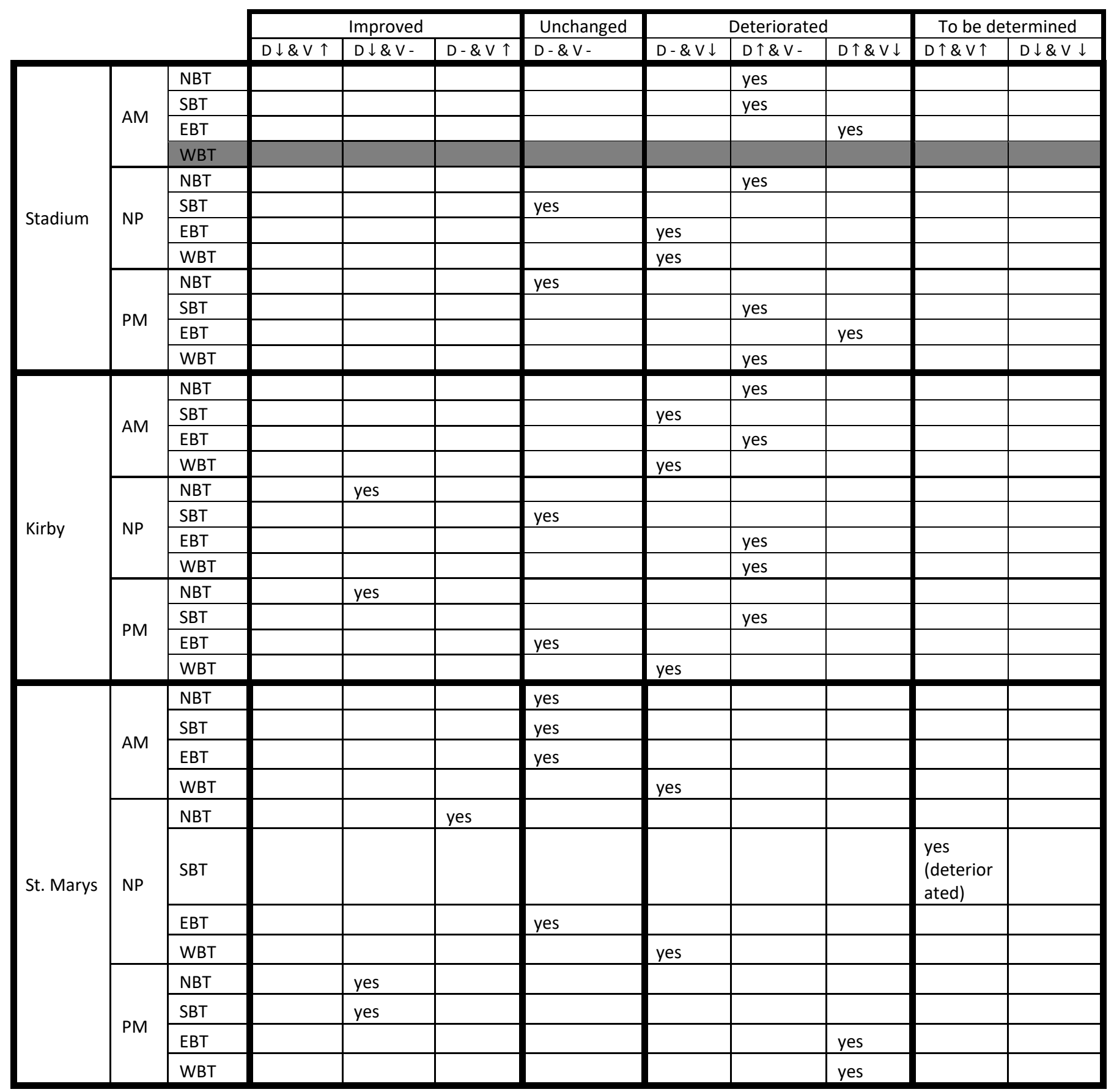


Table 34. Combined Analysis for Delay and Volume (Continued)

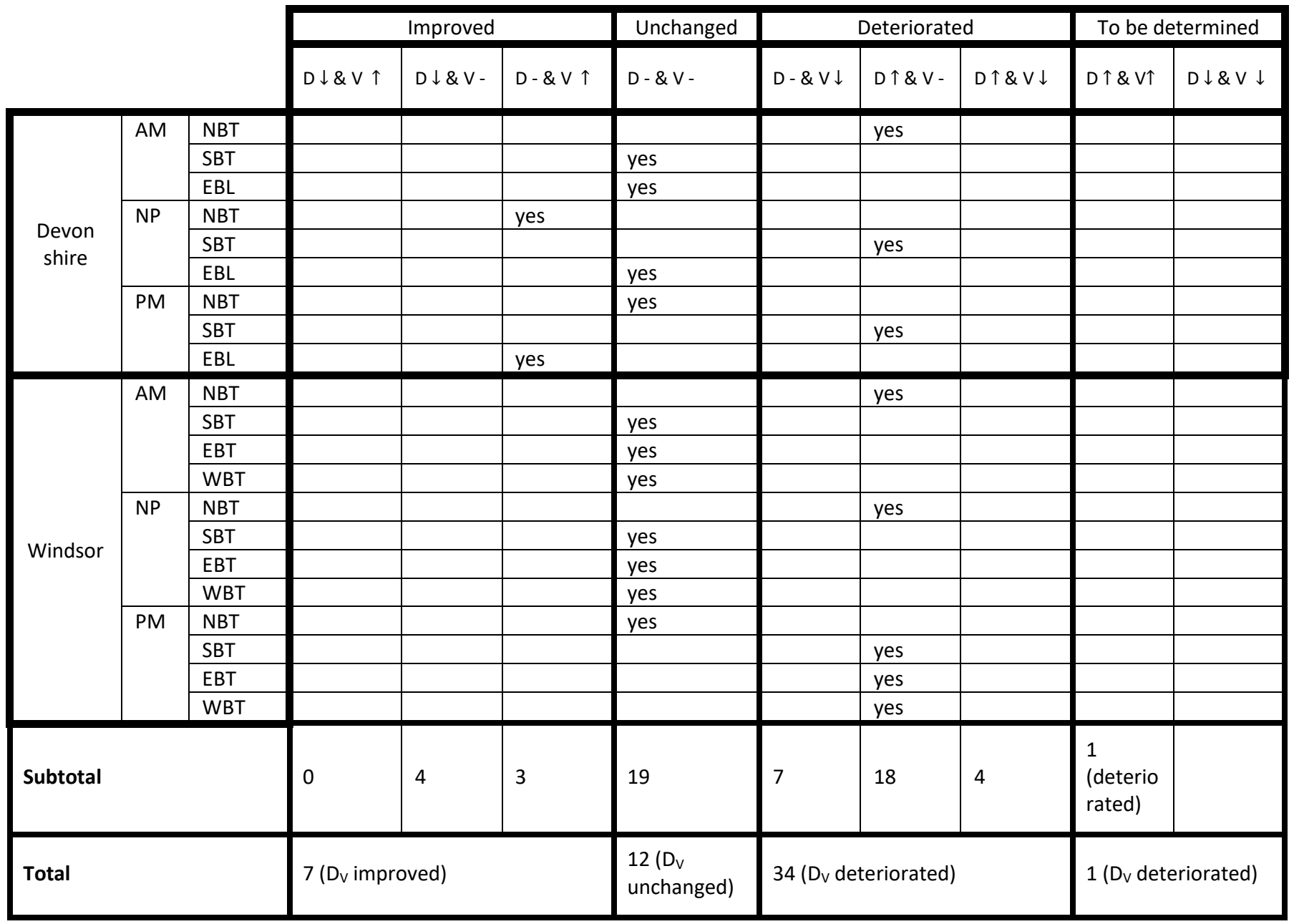




\section{B.2 APPLICATION OF HCS IN DETERMINING CONDITION OF CASES WITH BOTH INCREASED OR DECREASED DELAY AND VOLUME}

For the cases of "To be Determined," the lane groups for which both delay and volume significantly increased (or decreased), HCS 2010 was used to estimate the expected delay increases (or decreases) due to volume changes. In the HCS estimations, all the inputs except for volume were the same for both TBC 2017 and ASCT 2017 runs. Thus by entering the volumes for TBC 2017 and ASCT 2017 conditions for the subject lane group, the estimated changes in delay solely due to the volume changes can be obtained, which are then compared to the field stopped-delay discrepancies. As a result, if the field stopped-delay increases after ASCT implementation and the measured discrepancy are larger than the estimated increase due to volume, it indicates that ASCT implementation leads to a longer delay, and thus traffic performance for the subject lane group potentially deteriorates. If the field discrepancy equals the estimated values, the delay change for the subject lane group is solely due to volume change. Otherwise, the ASCT implementation shortens the field delay for the subject lane group and improves its traffic performance.

In the study, three lane groups were found for which both delay and volume significantly increased, including the eastbound through traffic at Neil Street and Stadium Drive during PM peak, and the northbound and southbound through traffic at Neil Street and Knollwood Drive during the noon peak (NP). Table 35 shows the delay discrepancy comparison results. The field delay discrepancy is larger than the HCS estimates, both numerically and by percent on St. Mary's, NP, SB. This finding means the field delay increases on this lane group after ASCT implementation is due not only to volume increase but also to the system's inappropriate performance. Therefore, this lane group was also considered as a lane group with potentially deteriorated $D_{V}$.

Table 35. Delay Discrepancy Comparison, HCS vs. Field

\begin{tabular}{|l|c|l|l|l|l|l|}
\hline \multirow{2}{*}{ Lane groups } & \multirow{2}{*}{$\begin{array}{c}\text { Volume difference } \\
\text { in HCS runs }\end{array}$} & \multicolumn{2}{l|}{ HCS discrepancy } & Field discrepancy & \multirow{2}{*}{ Results } \\
\cline { 3 - 6 } & Numerical & $\%$ & Numerical & $\%$ & \\
\hline St. Mary's NP SB & 68 & 0.153 & $2 \%$ & 3.257 & $121 \%$ & deteriorated Dv \\
\hline
\end{tabular}

\section{B.3 QUEUE LENGTH AND VOLUME COMBINATION ANALYSIS}

Table 36 shows the combined analysis results for queue and volume. In the table, " $Q$ " is the abbreviation for queue and "V" for volume. The upward arrow " $\uparrow$ " stands for increase, downward arrow " $\downarrow$ "for decrease, and dash "—"for unchanged. For instance, the column heading " $Q \uparrow \& \vee \downarrow$ " stands for the category with increased queue length and decreased volume. The cells with entries " 1 " signify that these lane groups (row heads) fall into the corresponding categories (column heads). 
Table 36. Combined Analysis for Queue and Volume

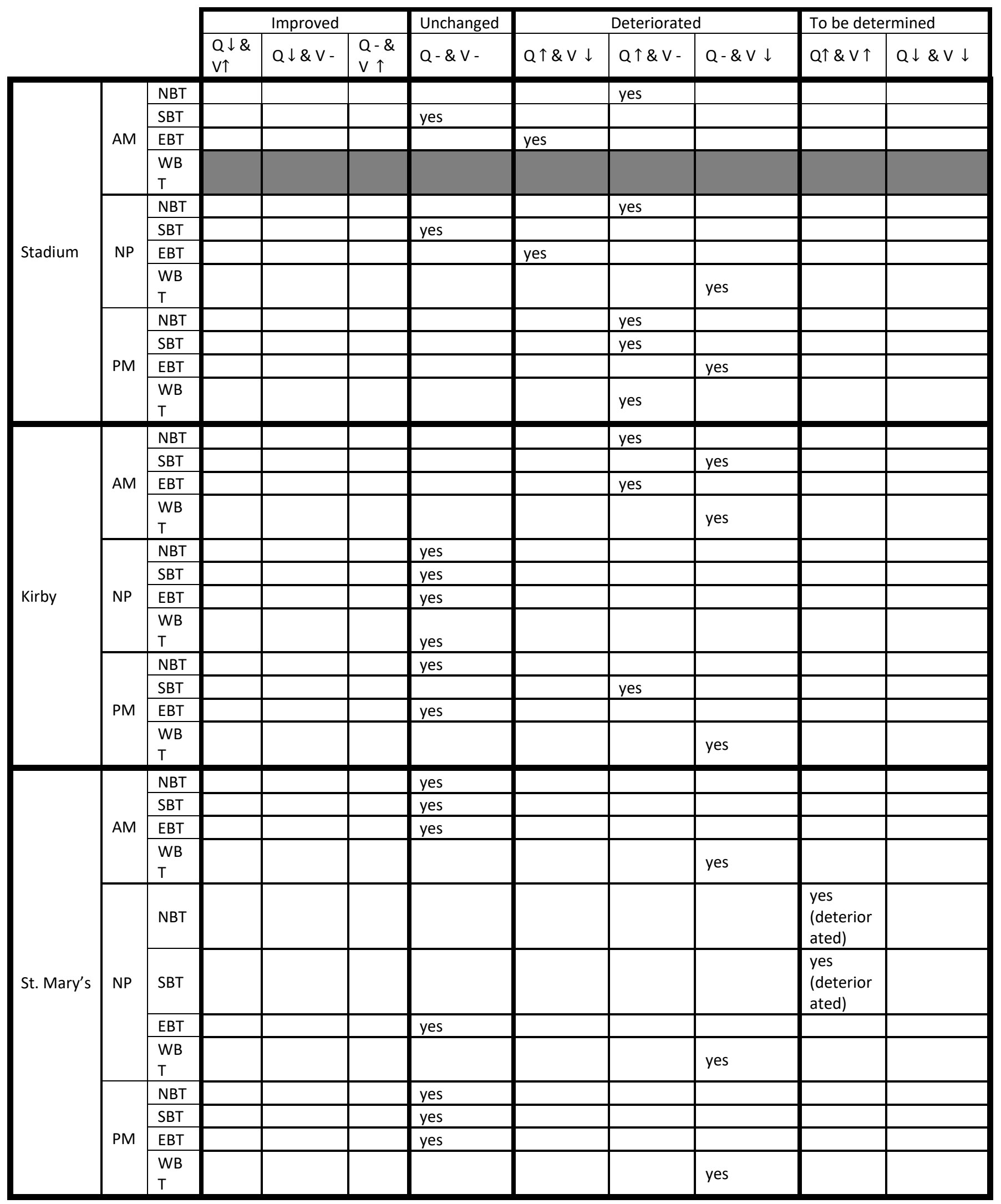


Table 36. Combined Analysis for Queue and Volume (Cont.)

\begin{tabular}{|c|c|c|c|c|c|c|c|c|c|c|c|}
\hline & & & \multicolumn{3}{|c|}{ Improved } & \multirow{2}{*}{$\begin{array}{l}\text { Unchanged } \\
\mathrm{Q}-\& \mathrm{~V}-\end{array}$} & \multicolumn{3}{|c|}{ Deteriorated } & \multicolumn{2}{|c|}{ To be determined } \\
\hline & & & $\begin{array}{l}\mathrm{Q} \downarrow \\
\& \mathrm{~V} \uparrow\end{array}$ & $\mathrm{Q} \downarrow \& \mathrm{~V}-$ & $\begin{array}{l}\text { Q- \& } \\
\vee \uparrow\end{array}$ & & $\mathrm{Q} \uparrow \& \mathrm{~V} \downarrow$ & $\overline{Q \uparrow \& V-}$ & $Q-\& V \downarrow$ & $\begin{array}{l}\mathrm{Q} \uparrow \& \vee \\
\uparrow\end{array}$ & $\mathrm{Q} \downarrow \& V \downarrow$ \\
\hline \multirow{9}{*}{ Devonshire } & \multirow{3}{*}{$A M$} & NBT & & & & & & yes & & & \\
\hline & & SBT & & & & yes & & & & & \\
\hline & & EBL & & & & yes & & & & & \\
\hline & \multirow[t]{3}{*}{ NP } & NBT & & & & & & & & $\begin{array}{l}\text { yes } \\
\text { (deterio } \\
\text { rated) }\end{array}$ & \\
\hline & & SBT & & & & & & yes & & & \\
\hline & & EBL & & & yes & & & & & & \\
\hline & \multirow[b]{3}{*}{ PM } & NBT & & & & & & yes & & & \\
\hline & & SBT & & & & & & yes & & & \\
\hline & & EBL & & & & & & & & $\begin{array}{l}\text { yes } \\
\text { (improv } \\
\text { ed) }\end{array}$ & \\
\hline \multirow{12}{*}{ Windsor } & \multirow{4}{*}{ AM } & NBT & & & & & & yes & & & \\
\hline & & SBT & & & & & & & yes & & \\
\hline & & EBT & & & & yes & & & & & \\
\hline & & WBT & & & & yes & & & & & \\
\hline & \multirow{4}{*}{ NP } & NBT & & & & yes & & & & & \\
\hline & & SBT & & & & yes & & & & & \\
\hline & & EBT & & & & yes & & & & & \\
\hline & & WBT & & & & yes & & & & & \\
\hline & \multirow{4}{*}{ PM } & NBT & & & & yes & & & & & \\
\hline & & SBT & & & & yes & & & & & \\
\hline & & EBT & & & & yes & & & & & \\
\hline & & WBT & & & & yes & & & & & \\
\hline Subtotal & & & 0 & 0 & 1 & 27 & 2 & 13 & 9 & $\begin{array}{l}3 \\
\text { (deterio } \\
\text { rated) } \\
1 \\
\text { (improv } \\
\text { ed) }\end{array}$ & 0 \\
\hline \multicolumn{3}{|l|}{ Total } & \multicolumn{3}{|c|}{1 ( $Q_{v}$ improved) } & $\begin{array}{l}27\left(Q_{v}\right. \\
\text { unchanged) }\end{array}$ & \multicolumn{3}{|c|}{$24\left(Q_{v}\right.$ deteriorated $)$} & \multicolumn{2}{|c|}{$\begin{array}{l}3\left(Q_{v} \text { deteriorated }\right) \\
1\left(Q_{v} \text { improved }\right)\end{array}$} \\
\hline
\end{tabular}

\section{B.4 APPLICATION OF HCS IN DETERMINING CONDITION OF CASES WITH BOTH INCREASED OR DECREASED QUEUE LENGTH AND VOLUME}

For the cases "To be determined," the lane groups where both delay and volume significantly increased (or decreased), the same method in delay comparison was used to estimate the expected queue changes due to the volume changes. For the lane groups for which both queue and volume significantly increased, the performance potentially deteriorated if the field-measured queue increased 
more than the expected value due to volume increase. For the lane groups with significantly decreased queue and volume, deteriorated $Q_{v}$ was defined as when the field-measured queue decreased less than the expected value due to volume decrease, while improvement happened when the field-queue decrease was more than expected. Improved $Q_{v}$ was defined as when the field queue increase was less than the expected value. Comparison results of the field-measured and expected queue changes are shown in Table 37.

Table 37. Queue-Discrepancy Comparison, HCS vs. Field

\begin{tabular}{|l|c|l|l|l|l|l|}
\hline \multirow{2}{*}{ Lane groups } & \multirow{2}{*}{$\begin{array}{c}\text { Volume difference } \\
\text { in HCS runs }\end{array}$} & \multicolumn{2}{l|}{ HCS discrepancy } & \multicolumn{2}{l|}{ Field discrepancy } & \multirow{2}{*}{ Results } \\
\cline { 3 - 7 } & Numerical & $\%$ & Numerical & $\%$ & \\
\hline St. Mary's NP NB & 67 & 1.1 & $17 \%$ & 2.151 & $64 \%$ & Qv deteriorated \\
\hline St. Mary's NP SB & 68 & 0.8 & $22 \%$ & 2.813 & $188 \%$ & Qv deteriorated \\
\hline Devonshire NP NB & 72 & 0 & $0 \%$ & 1.06 & $67 \%$ & Qv deteriorated \\
\hline Devonshire PM EBL & 41 & 3.1 & $62 \%$ & 1.09 & $42 \%$ & Qv improved \\
\hline
\end{tabular}




\section{APPENDIX C: DETAILED SIGNAL TIMING CHANGE CALCULATIONS}

\section{C.1. ENTIRE TIME LENGTH AND ENTIRE GREEN TIME}

It should be noted that the entire studied time length (i.e. $\sum_{i=1}^{n} C_{i}$ ) must be kept the same in both TBC 2017 and ASCT 2017 for studying the average effective green-time changes and average g/C ratio changes; that is:

$$
\sum_{i=1}^{n} C_{i_{-} A p r i l} \approx \sum_{i=1}^{n} C_{i_{-} M a r c h}
$$

where

$\sum_{i=1}^{n} C_{i}$ : the entire studied time length during the whole analysis period;

$\boldsymbol{C}_{\boldsymbol{i}}$ : cycle length of the $i_{t h}$ Cycle;

$\boldsymbol{n}$ : number of cycles during the whole analysis period.

Specific entire time-length-calculation results are shown in Table 38. In this table, the differences of entire studied time length and entire effective green-time length between ASCT 2017 and TBC 2017 were calculated, respectively:

$$
\begin{aligned}
& \text { Diff__ }=\sum_{i=1}^{n} C_{i_{-} \text {April }}-\sum_{i=1}^{n} C_{i_{-} M a r c h} \\
& \text { Diff_G }=\sum_{i=1}^{n} G_{i_{-} \text {April }}-\sum_{i=1}^{n} G_{i_{-} M a r c h}
\end{aligned}
$$

It should be also noted that the entire green time must be the same for studying the average effective green-time changes and average $\mathrm{g} / \mathrm{C}$ ratio changes, that is:

$$
\begin{aligned}
& \sum_{i=1}^{n} C_{i \_A p r i l \_G T}=\sum_{i=1}^{n} C_{i \_A p r i l \_g c} \\
& \sum_{i=1}^{n} C_{i \_M a r c h \_G T}=\sum_{i=1}^{n} C_{i \_M a r c h \_g c}
\end{aligned}
$$

where

$\sum_{i=1}^{n} C_{i_{-} M a r c h \_G T}$ is the entire studied time under TBC 2017 for average effective green-time changes;

$\sum_{i=1}^{n} C_{i_{-} M a r c h \_g c}$ is the entire studied time under TBC 2017 for average g/C ratios changes;

$\sum_{i=1}^{n} C_{i_{-} A p r i l \_G T}$ is the entire studied time under ASCT 2017 for average effective green-time changes;

$\sum_{i=1}^{n} C_{i_{-} A p r i l \_g c}$ is the entire studied time under ASCT 2017 for average g/C ratios changes; 
Table 38. Entire Studied Time Length and Effective Green Time Comparison for Each Intersection under ASCT 2017 and TBC 2017

\begin{tabular}{|c|c|c|c|c|c|c|c|c|c|c|}
\hline & & & & April & & & March & & Con & risons \\
\hline Intersection & Time period & Approach & $n$ & $\sum_{i=1}^{n} C_{i}$ & $\sum_{i=1}^{n} G_{i}$ & $n$ & $\sum_{i=1}^{n} C_{i}$ & $\sum_{i=1}^{n} G_{i}$ & $\sum_{i=1}^{n} C_{i \text { _April }}-\sum_{i=1}^{n} C_{i \_ \text {March }}$ & $\sum_{i=1}^{n} G_{i \text { April }}-\sum_{i=1}^{n} G_{i \_ \text {March }}$ \\
\hline \multirow{12}{*}{ Stadium } & \multirow{4}{*}{ AM } & NBT & \multirow{4}{*}{58} & \multirow{4}{*}{3530} & 1859 & \multirow{4}{*}{64} & \multirow{4}{*}{3518} & 1813 & \multirow{4}{*}{12} & 46 \\
\hline & & SBT & & & 1859 & & & 1813 & & 46 \\
\hline & & EBT & & & 986 & & & 950 & & 36 \\
\hline & & WBT & & & 986 & & & 950 & & 36 \\
\hline & \multirow{4}{*}{ NP } & NBT & \multirow{4}{*}{65} & \multirow{4}{*}{3581} & 1856 & \multirow{4}{*}{63} & \multirow{4}{*}{3572} & 1991 & \multirow{4}{*}{9} & -135 \\
\hline & & SBT & & & 1856 & & & 1991 & & -135 \\
\hline & & EBT & & & 958 & & & 838 & & 120 \\
\hline & & WBT & & & 958 & & & 838 & & 120 \\
\hline & \multirow{4}{*}{ PM } & NBT & & & 1833 & & & 1840 & & -7 \\
\hline & & SBT & 50 & 3560 & 1833 & 50 & 3510 & 1840 & 30 & -7 \\
\hline & & EBT & 59 & 3560 & 1031 & 59 & 3540 & 1004 & 20 & 27 \\
\hline & & WBT & & & 1031 & & & 1004 & & 27 \\
\hline & & NBT & & & 1154 & & & 1136 & & 18 \\
\hline & PM & SBT & 27 & 3287 & 1441 & 30 & 3300 & 1395 & 18 & 46 \\
\hline & AIM & EBT & 21 & 3282 & 938 & 30 & 3300 & 1129 & -18 & -191 \\
\hline & & WBT & & & 1043 & & & 1032 & & 11 \\
\hline & & NBT & & & 1396 & & & 1282 & & 114 \\
\hline Kixhy & (R & SBT & 21 & 2011 & 1361 & 21 & 2010 & 1274 & 1 & 87 \\
\hline Kırby & NP & EBT & 31 & 3411 & 701 & 31 & 3410 & 1054 & 1 & -353 \\
\hline & & WBT & & & 850 & & & 1132 & & -282 \\
\hline & & NBT & & & 1266 & & & 1281 & & -15 \\
\hline & PM & SBT & 20 & 3194 & 1283 & 20 & & 1295 & 14 & -12 \\
\hline & PM & EBT & 29 & 3494 & 878 & 29 & 3480 & 907 & 14 & -29 \\
\hline & & WBT & & & 1020 & & & 1072 & & -52 \\
\hline & & NBT & & & 1897 & & & 1971 & & -74 \\
\hline & $A M$ & SBT & 29 & 3492 & 2262 & 32 & 3520 & 2373 & -28 & -111 \\
\hline & AM & EBT & 29 & 3492 & 641 & 32 & 3520 & 580 & -28 & 61 \\
\hline & & WBT & & & 696 & & & 581 & & 115 \\
\hline & & NBT & & & 1764 & & & 1959 & & -195 \\
\hline Ct Map's & & SBT & 32 & 3527 & 2029 & 32 & 3520 & 2156 & 12 & -127 \\
\hline St. Mary's & NP & EBT & 32 & 3532 & 658 & 32 & 3520 & 622 & 12 & 36 \\
\hline & & WBT & & & 743 & & & 701 & & 42 \\
\hline & & NBT & & & 2012 & & & 1765 & & 247 \\
\hline & & SBT & & & 2004 & & & 1818 & & 186 \\
\hline & PM & EBT & 29 & 3463 & 454 & 29 & 3480 & 651 & -17 & -197 \\
\hline & & WBT & & & 842 & & & 1032 & & -190 \\
\hline & & NBT & & & 2702 & & & 2695 & & 7 \\
\hline & AM & SBT & 28 & 3373 & 2558 & 31 & 3411 & 2585 & -38 & -27 \\
\hline & & EBL & & & 360 & & & 372 & & -12 \\
\hline & & NBT & & & 2639 & & & 2700 & & -61 \\
\hline Devonshire & NP & SBT & 32 & 3532 & 2368 & 32 & 3520 & 2507 & 12 & -139 \\
\hline & & EBL & & & 549 & & & 465 & & 84 \\
\hline & & NBT & & & 2635 & & & 2714 & & -79 \\
\hline & PM & SBT & 28 & 3463 & 2532 & 28 & 3480 & 2556 & -17 & -24 \\
\hline & & EBL & & & 403 & & & 335 & & 68 \\
\hline & & NBT & & & 1420 & & & 1477 & & -57 \\
\hline & AM & SBT & 28 & 3352 & 1481 & 30 & 3300 & 1588 & 52 & -107 \\
\hline & AM & EBT & 28 & 3352 & 884 & 30 & 3300 & 914 & 52 & -30 \\
\hline & & WBT & & & 733 & & & 614 & & 119 \\
\hline & & NBT & & & 1402 & & & 1482 & & -80 \\
\hline & MD & SBT & 31 & 3287 & 1544 & 30 & 3000 & 1643 & 27 & -99 \\
\hline Windsor & NP & EBT & 31 & 3387 & 642 & 30 & 3409 & 830 & -22 & -188 \\
\hline & & WBT & & & 719 & & & 841 & & -122 \\
\hline & & NBT & & & 1141 & & & 1205 & & -64 \\
\hline & PM & SBT & 30 & 3551 & 1267 & 30 & 3600 & 1502 & 49 & -235 \\
\hline & PM & EBT & 30 & 3551 & 899 & 30 & 3600 & 908 & -49 & -9 \\
\hline & & WBT & & & 926 & & & 979 & & -53 \\
\hline
\end{tabular}


- The $\boldsymbol{D} \boldsymbol{i f f} \boldsymbol{f}_{-} \boldsymbol{C}$ varied from 1 to 52 seconds. Considering the largest $\boldsymbol{D} \boldsymbol{i f f} \boldsymbol{C}_{-}$: 52 seconds, the difference means the entire studied time between TBC 2017 and ASCT 2017 varied less than half of one cycle length (55-60 seconds). If the time difference was evenly distributed to each cycle, for example, $52 / 30=1.73$ seconds difference for each cycle; and this small amount can be ignored. Hence, the entire studied time lengths in ASCT 2017 and TBC 2017 were considered similar, that is to say, $\sum_{i=1}^{n} C_{i_{-} \text {April }} \approx \sum_{i=1}^{n} \boldsymbol{C}_{\boldsymbol{i}_{-} \text {March }}$ was acceptable. 


\section{C.2 DETAILED CYCLE-LENGTH-CALCULATION RESULTS}

Table 39. Comparison of Average Cycle Length under ASCT 2017 and TBC 2017

\begin{tabular}{|c|c|c|c|c|c|c|c|c|c|}
\hline \multirow[b]{2}{*}{ Intersection } & \multirow[b]{2}{*}{$\begin{array}{l}\text { Time } \\
\text { period }\end{array}$} & \multicolumn{3}{|c|}{ April } & \multicolumn{3}{|c|}{ March } & \multicolumn{2}{|c|}{ Test results } \\
\hline & & $\begin{array}{c}\text { Cycle- } \\
\text { length } \\
\text { average }\end{array}$ & $\begin{array}{l}\text { Cycle- } \\
\text { length } \\
\text { variance }\end{array}$ & $\begin{array}{l}\text { Cycle- } \\
\text { length } \\
\text { range }\end{array}$ & $\begin{array}{c}\text { Cycle- } \\
\text { length } \\
\text { average }\end{array}$ & $\begin{array}{c}\text { Cycle- } \\
\text { length } \\
\text { variance }\end{array}$ & $\begin{array}{l}\text { Cycle- } \\
\text { length } \\
\text { range }\end{array}$ & p-value & $\begin{array}{l}\text { Cycle- } \\
\text { length } \\
\text { change }\end{array}$ \\
\hline \multirow{3}{*}{ Stadium } & AM & 60.862 & 12.612 & $58-70$ & 54.969 & 2.348 & $53-59$ & $1.203 \mathrm{E}-18$ & Inc \\
\hline & NP & 55.092 & 2.991 & $50-60$ & 56.698 & 16.569 & $53-68$ & 0.0049 & Dec \\
\hline & PM & 60.339 & 12.642 & $54-68$ & 60.000 & 0.000 & $60-60$ & 0.4669 & Unch \\
\hline \multirow{3}{*}{ Kirby } & AM & 121.556 & 14.949 & $119-134$ & 110.000 & 0.069 & 109-111 & $1.023 \mathrm{E}-14$ & Inc \\
\hline & NP & 110.032 & 43.699 & $98-118$ & 110.000 & 0.000 & $110-110$ & 0.9785 & Unch \\
\hline & PM & 120.483 & 48.544 & $110-133$ & 120.000 & 0.000 & $120-120$ & 0.7119 & Unch \\
\hline \multirow{3}{*}{ St. Mary's } & AM & 120.414 & 11.608 & 119-137 & 110.000 & 0.000 & $110-110$ & $6.263 \mathrm{E}-16$ & Inc \\
\hline & NP & 110.375 & 1.661 & $110-116$ & 110.000 & 0.000 & $110-110$ & 0.1099 & Unch \\
\hline & PM & 119.414 & 40.894 & $110-132$ & 120.000 & 0.000 & $120-120$ & 0.6254 & Unch \\
\hline \multirow{3}{*}{ Devonshire } & AM & 120.464 & 11.962 & $119-137$ & 110.032 & 0.032 & $110-111$ & $2.654 \mathrm{E}-15$ & Inc \\
\hline & NP & 110.400 & 1.766 & $110-116$ & 110.000 & 0.000 & 110-110 & 0.11 & Unch \\
\hline & PM & 119.607 & 40.544 & $110-132$ & 120.000 & 0.000 & $120-120$ & 0.7466 & Unch \\
\hline \multirow{3}{*}{ Windsor } & AM & 119.714 & 47.175 & $88-132$ & 110.000 & 0.000 & $110-110$ & $4.740 \mathrm{E}-08$ & Inc \\
\hline & NP & 109.258 & 6.865 & $100-114$ & 113.633 & 72.447 & 110-135 & 0.0108 & Dec \\
\hline & PM & 118.367 & 64.309 & 107-133 & 120.000 & 0.000 & $120-120$ & 0.2738 & Unch \\
\hline
\end{tabular}

From Table 39, of the 15 cases, 5 significantly increased, 2 significantly decreased, and the other 8 cases were unchanged. The 5 increased cases all happened at AM time periods. There were also two cases showing cycle lengths significantly decreased at Stadium NP and Windsor NP, with both caused by pedestrian activities; detailed analyses were discussed in section 4.5.4. 
C.3 DETAILED AVERAGE EFFECTIVE GREEN-TIME-COMPARISON RESULTS

Table 40. Statistical Comparison Between TBC2017 and ASCT2017 Conditions, Average Effective Green Time

\begin{tabular}{|c|c|c|c|c|c|c|c|c|c|c|c|c|}
\hline Intersection & Time periods & Approaches & $\begin{array}{c}\text { April average } \\
\text { effective } \\
\text { green time }\end{array}$ & $\begin{array}{c}\text { April } \\
\text { effective } \\
\text { green time } \\
\text { variance }\end{array}$ & $\begin{array}{c}\text { March } \\
\text { average } \\
\text { effective } \\
\text { green time }\end{array}$ & $\begin{array}{c}\text { March } \\
\text { effective } \\
\text { green time } \\
\text { variance }\end{array}$ & p-value & $\begin{array}{c}\text { Effective } \\
\text { green time } \\
\text { change } \\
\text { (Apr-Mar) }\end{array}$ & $\begin{array}{c}\text { Volume } \\
\text { change } \\
\text { (Apr-Mar) }\end{array}$ & $\begin{array}{c}\text { Delay change } \\
\text { (Apr-Mar) }\end{array}$ & $\begin{array}{l}\text { Queue } \\
\text { length } \\
\text { change } \\
\text { (Apr-Mar) }\end{array}$ & PI \\
\hline \multirow{12}{*}{ Stadium } & \multirow{4}{*}{ AM } & NBT & 32.06 & 14.239 & 28.32 & 7.327 & $1.08 \mathrm{E}-08$ & $\operatorname{Inc}$ & Unch & Inc & Inc & Det \\
\hline & & SBT & 32.06 & 14.239 & 28.32 & 7.327 & $1.08 \mathrm{E}-08$ & Inc & Unch & Inc & Unch & Det \\
\hline & & EBT & 17.01 & 12.597 & 14.85 & 11.109 & 0.0007 & Inc & Dec & Inc & Inc & Det \\
\hline & & WBT & 17.01 & 12.597 & 14.85 & 11.109 & 0.0007 & Inc & Dec & Unch & Inc & - \\
\hline & \multirow{4}{*}{ NP } & NBT & 28.55 & 9.982 & 31.60 & 16.440 & $6.05 \mathrm{E}-06$ & Dec & Unch & Inc & Inc & Det \\
\hline & & SBT & 28.55 & 9.982 & 31.60 & 16.440 & $6.05 \mathrm{E}-06$ & Dec & Unch & Unch & Unch & Unch \\
\hline & & EBT & 14.75 & 12.532 & 13.30 & 15.323 & 0.0301 & Unch & Dec & Unch & Inc & Det \\
\hline & & WBT & 14.75 & 12.532 & 13.30 & 15.323 & 0.0301 & Unch & Dec & Unch & Unch & Det \\
\hline & \multirow{4}{*}{ PM } & NBT & 31.07 & 16.040 & 31.19 & 18.140 & 0.7791 & Unch & Unch & Unch & Inc & Det \\
\hline & & SBT & 31.07 & 16.040 & 31.19 & 18.140 & 0.7791 & Unch & Unch & Inc & Inc & Det \\
\hline & & EBT & 17.47 & 11.833 & 17.01 & 18.140 & 0.5221 & Unch & Dec & Inc & Unch & Det \\
\hline & & WBT & 17.47 & 11.833 & 17.01 & 18.140 & 0.5221 & Unch & Unch & Inc & Inc & Det \\
\hline \multirow{12}{*}{ Kirby } & \multirow{4}{*}{ AM } & NBT & 42.74 & 32.276 & 37.87 & 7.154 & 0.0002 & Inc & Unch & $\operatorname{lnc}$ & Inc & Det \\
\hline & & SBT & 53.37 & 98.473 & 46.50 & 35.017 & 0.0032 & Inc & Dec & Unch & Unch & Det \\
\hline & & EBT & 34.73 & 3.2422 & 37.63 & 21.982 & $3.22 \mathrm{E}-03$ & Dec & Unch & $\operatorname{Inc}$ & Inc & Det \\
\hline & & WBT & 38.62 & 34.7977 & 38.21 & 26.333 & 0.7877 & Unch & Dec & Unch & Unch & Det \\
\hline & \multirow{4}{*}{ NP } & NBT & 45.03 & 57.766 & 41.35 & 31.570 & 0.0346 & Unch & Unch & Dec & Unch & Imp \\
\hline & & SBT & 43.90 & 57.357 & 41.10 & 35.957 & 0.1110 & Unch & Unch & Unch & Unch & Unch \\
\hline & & EBT & 22.62 & 67.058 & 34.00 & 36.090 & 4.82E-08 & Dec & Unch & Inc & Unch & Det \\
\hline & & WBT & 27.42 & 52.359 & 36.52 & 13.052 & $4.46 \mathrm{E}-08$ & Dec & Unch & Inc & Unch & Det \\
\hline & \multirow{4}{*}{ PM } & NBT & 48.69 & 50.542 & 49.27 & 31.965 & 0.7474 & Unch & Unch & Dec & Unch & Imp \\
\hline & & SBT & 44.24 & 35.975 & 44.66 & 10.377 & 0.7450 & Unch & Unch & Inc & Inc & Det \\
\hline & & EBT & 30.27 & 21.791 & 31.27 & 4.4335 & 0.2995 & Unch & Unch & Unch & Unch & Unch \\
\hline & & WBT & 35.17 & 38.638 & 36.96 & 21.337 & 0.2181 & Unch & Dec & Unch & Unch & Det \\
\hline \multirow{12}{*}{ St. Mary's } & \multirow{4}{*}{ AM } & NBT & 65.42 & 95.116 & 61.59 & 39.512 & 0.0779 & Unch & Unch & Unch & Unch & Unch \\
\hline & & SBT & 78.00 & 83.453 & 74.15 & 41.226 & 0.0649 & Unch & Unch & Unch & Unch & Unch \\
\hline & & EBT & 22.11 & 44.966 & 18.14 & 25.673 & 0.0109 & Inc & Unch & Unch & Unch & Unch \\
\hline & & WBT & 24.01 & 21.079 & 18.17 & 23.870 & $1.13 \mathrm{E}-05$ & Inc & Dec & Unch & Unch & Det \\
\hline & \multirow{4}{*}{ NP } & NBT & 55.12 & 66.757 & 61.21 & 51.577 & 0.0024 & Dec & Inc & Unch & Inc & Det \\
\hline & & SBT & 63.40 & 69.871 & 67.37 & 42.902 & 0.0385 & Unch & Inc & Inc & Inc & Det \\
\hline & & EBT & 20.58 & 45.145 & 19.45 & 24.387 & 0.4482 & Unch & Unch & Unch & Unch & Unch \\
\hline & & WBT & 23.23 & 16.064 & 21.92 & 21.918 & 0.2329 & Unch & Dec & Unch & Unch & Det \\
\hline & \multirow{4}{*}{ PM } & NBT & 69.38 & 92.259 & 60.87 & 59.106 & 0.0005 & Inc & Unch & Unch & Unch & Unch \\
\hline & & SBT & 69.11 & 109.670 & 62.69 & 49.599 & 0.0086 & Inc & Unch & Unch & Unch & Unch \\
\hline & & EBT & 15.67 & 12.034 & 22.46 & 14.118 & 1.93E-09 & Dec & Unch & Unch & Unch & Unch \\
\hline & & WBT & 29.04 & 38.663 & 35.60 & 8.667 & $7.88 \mathrm{E}-06$ & Dec & Dec & Inc & Unch & Det \\
\hline \multirow{9}{*}{ Devonshire } & \multirow{3}{*}{ AM } & NBT & 96.49 & 23.581 & 86.92 & 19.292 & $8.34 \mathrm{E}-11$ & Inc & Unch & Inc & Inc & Det \\
\hline & & SBT & 91.35 & 111.528 & 83.37 & 73.047 & 0.0022 & Inc & Unch & Unch & Unch & Unch \\
\hline & & EBL & 12.87 & 17.735 & 12.01 & 18.880 & 0.4434 & Unch & Unch & Unch & Unch & Unch \\
\hline & & NBT & 82.46 & 52.519 & 84.38 & 18.370 & 0.2018 & Unch & Inc & Unch & $\operatorname{Inc}$ & Det \\
\hline & NP & SBT & 73.99 & 136.973 & 78.35 & 66.065 & 0.0889 & Unch & Unch & Inc & Inc & Det \\
\hline & & EBL & 17.17 & 33.668 & 14.52 & 18.370 & 0.0424 & Unch & Unch & Unch & Unch & Unch \\
\hline & & NBT & 94.10 & 63.222 & 96.92 & 12.819 & 0.0951 & Unch & Unch & Unch & Inc & Det \\
\hline & PM & SBT & 90.42 & 129.115 & 91.28 & 129.115 & 0.7440 & Unch & Unch & Inc & Inc & Det \\
\hline & & EBL & 14.41 & 21.284 & 11.98 & 12.819 & 0.0321 & Unch & Inc & Unch & Inc & Imp \\
\hline & & NBT & 50.71 & 185.433 & 49.23 & 57.482 & 0.6167 & Unch & Unch & Inc & Inc & Det \\
\hline & $A M$ & SBT & 52.89 & 163.101 & 52.93 & 51.264 & 0.9862 & Unch & Dec & Unch & Unch & Det \\
\hline & AIVI & EBT & 31.58 & 90.745 & 30.47 & 26.185 & 0.5865 & Unch & Unch & Inc & Unch & Det \\
\hline & & WBT & 26.19 & 29.915 & 20.47 & 11.220 & $2.09 \mathrm{E}-05$ & Inc & Unch & Unch & Unch & Unch \\
\hline & & NBT & 45.21 & 41.778 & 49.40 & 103.407 & 0.0617 & Unch & Unch & Inc & Unch & Det \\
\hline ndser & NP & SBT & 49.79 & 88.295 & 54.77 & 101.523 & 0.0507 & Unch & Unch & Unch & Unch & Unch \\
\hline Vvinusor & Nor & EBT & 20.71 & 9.561 & 27.67 & 30.668 & $2.75 \mathrm{E}-07$ & Dec & Unch & Unch & Unch & Unch \\
\hline & & WBT & 23.19 & 59.058 & 28.03 & 34.602 & 0.0078 & Dec & Unch & Unch & Unch & Unch \\
\hline & & NBT & 38.03 & 65.909 & 40.17 & 31.909 & 0.2428 & Unch & Unch & Unch & Unch & Unch \\
\hline & PM & SBT & 42.23 & 64.585 & 50.07 & 59.844 & 0.0003 & Dec & Unch & $\operatorname{lnc}$ & Unch & Det \\
\hline & PIVI & EBT & 29.97 & 25.582 & 30.27 & 8.447 & 0.7794 & Unch & Unch & Inc & Unch & Det \\
\hline & & WBT & 30.87 & 30.999 & 32.63 & 15.444 & 0.1616 & Unch & Unch & Inc & Unch & Det \\
\hline
\end{tabular}




\section{APPENDIX D: DETAILED COMPARISON OF SYSTEM VOLUME COUNTS AND FIELD VOLUME COUNTS}

AM:

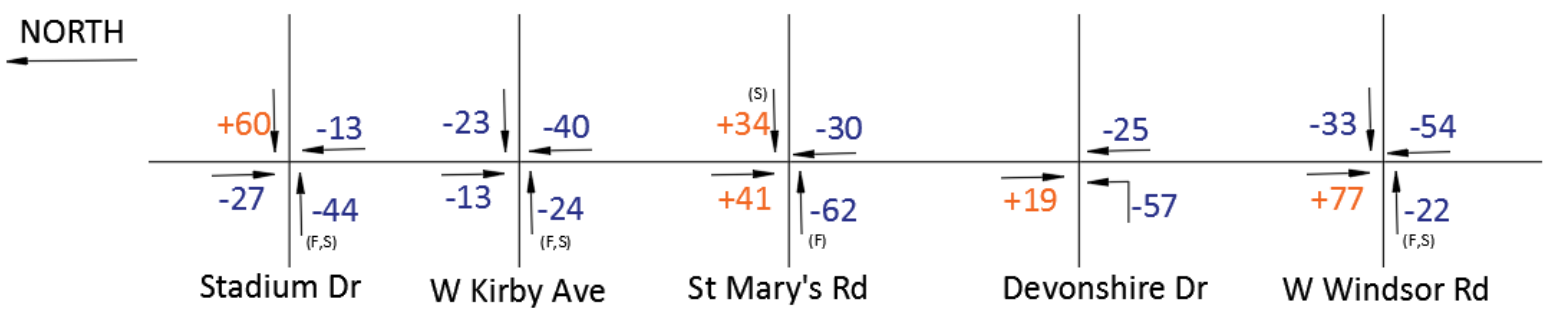

NP:

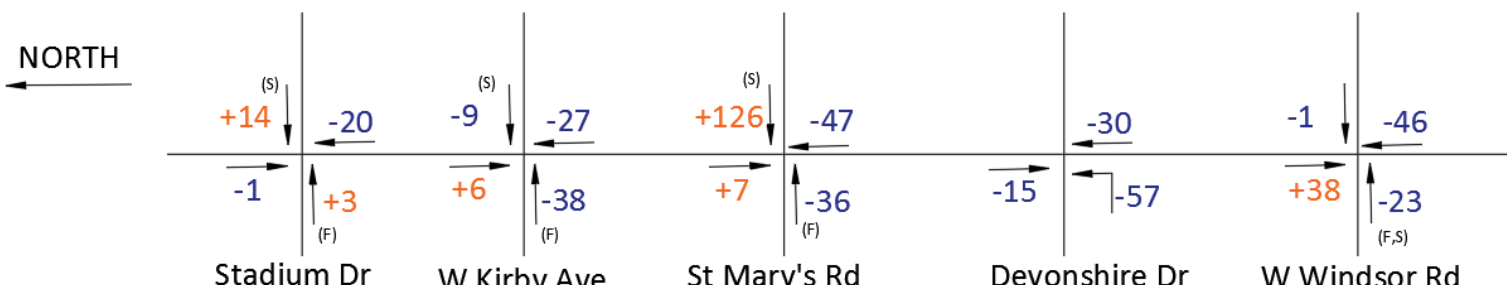

PM:

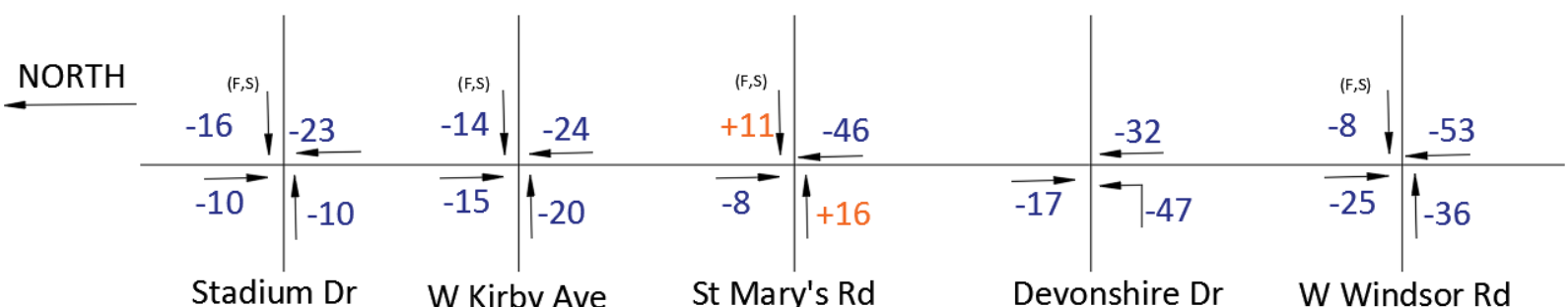

Figure 12. Comparison of system volume counts and field volume counts (\%) in April 2017.

Notes:

1. +: System overcounted, -: system undercounted.

2. (F) indicates the highest-volume approach, based on field data.

3. (S) indicates the highest-volume approach, based on system data.

4. The number represents the percentage (\%) increased or decreased.

5. The comparison base is the field data. 
AM:

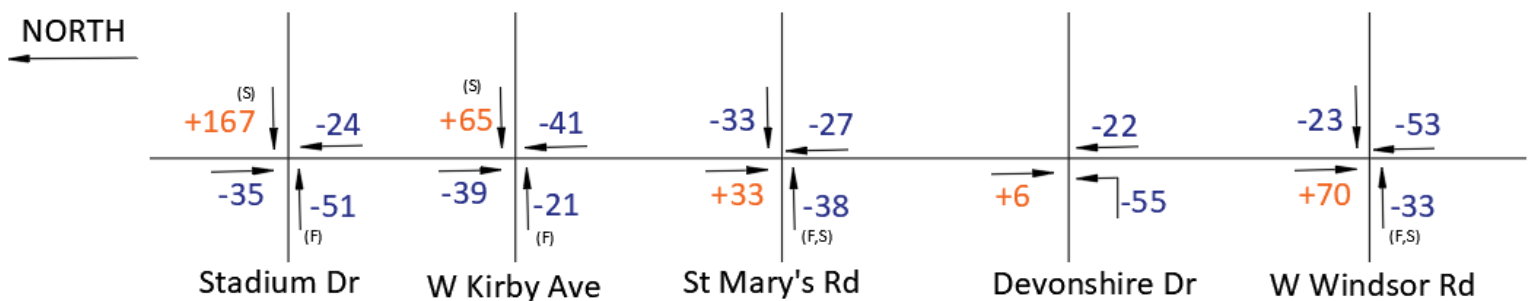

NP:

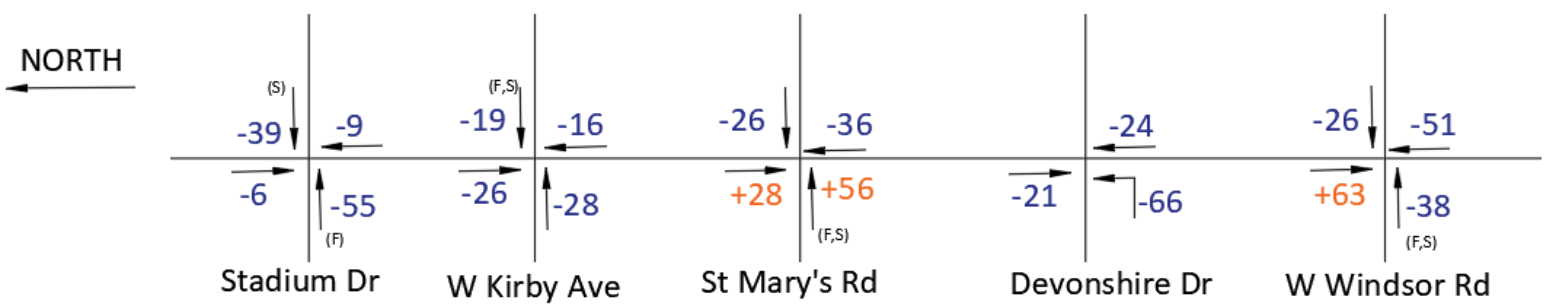

PM:

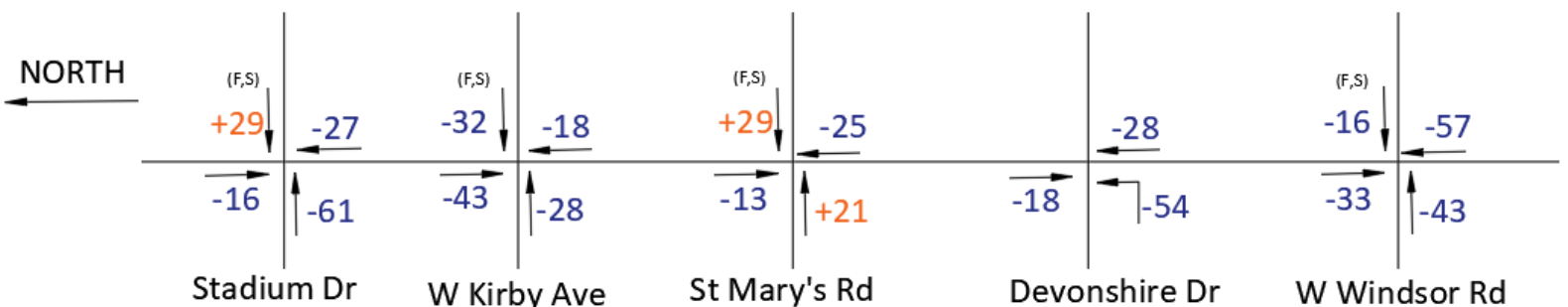

Figure 13. Comparison of system volume counts and field volume counts (\%) in March 2017.

Notes:

1. +: System overcounted, -: system undercounted.

2. (F) indicates the highest-volume approach, based on field data.

3. (S) indicates the highest-volume approach, based on system data.

4. The number represents the percentage (\%) increased or decreased.

5. The comparison base is the field data. 


\section{APPENDIX E: PHASE PLANS}

Based on signal-timing information, there were six types of phase plans at either minor or major streets. The detailed phase plans are shown in Figures 14 and 15.

Type 1:

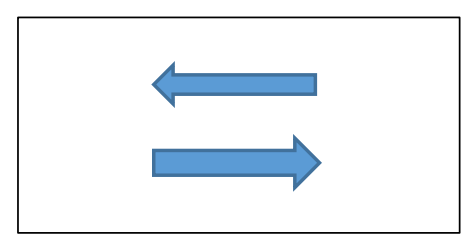

Type 2: Protected
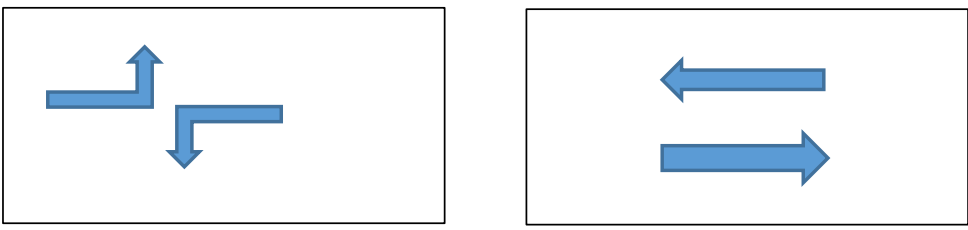

Type 3: Protected and EB Protected-Permitted
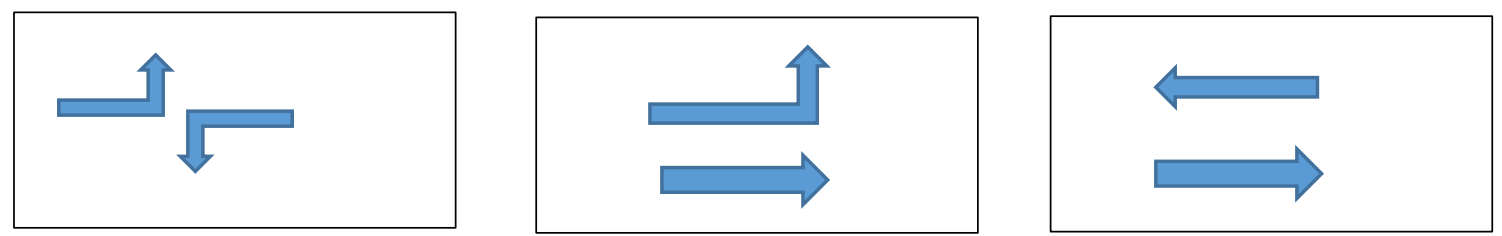

Type 4: Protected and WB Protected-Permitted
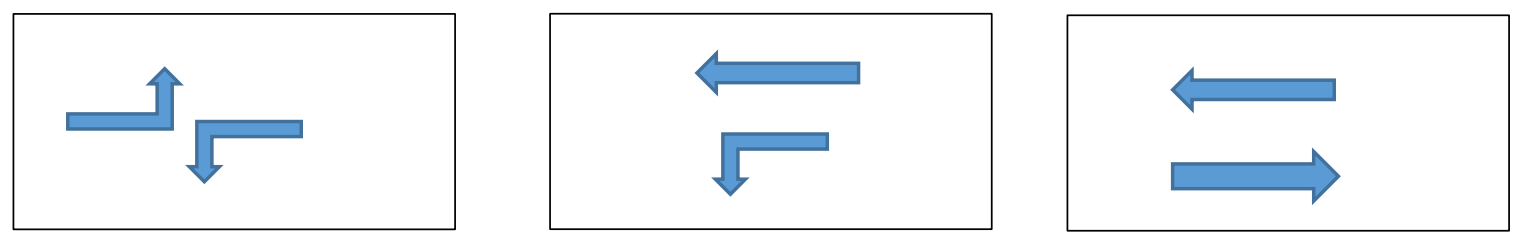

Type 5: EB Protected-Permitted
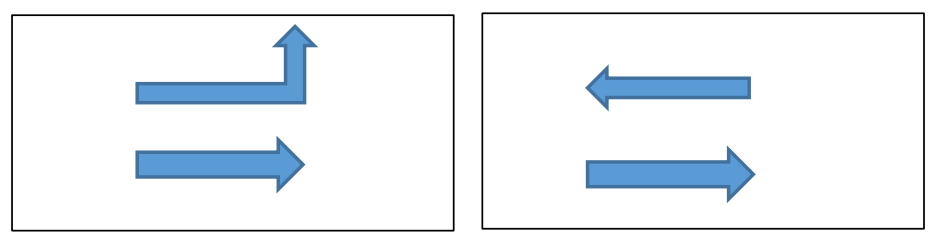

Type 6: WB Protected-Permitted
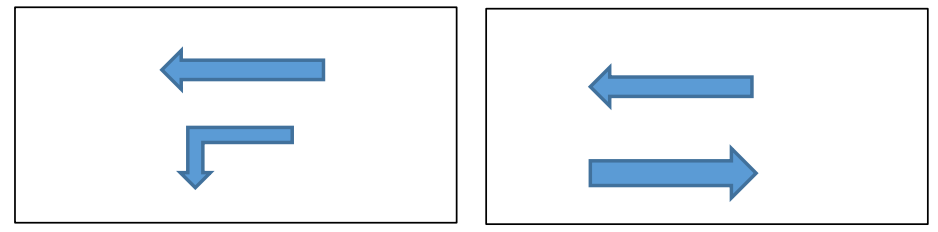

Figure 14. Minor streets' possible phase plan. 
Type 11:

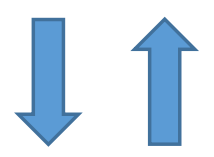

Type 12: Protected

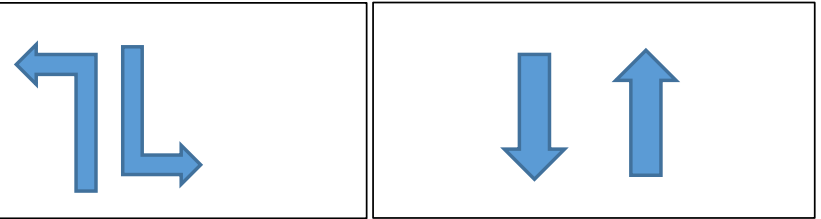

Type 13: Protected and NB Protected-Permitted
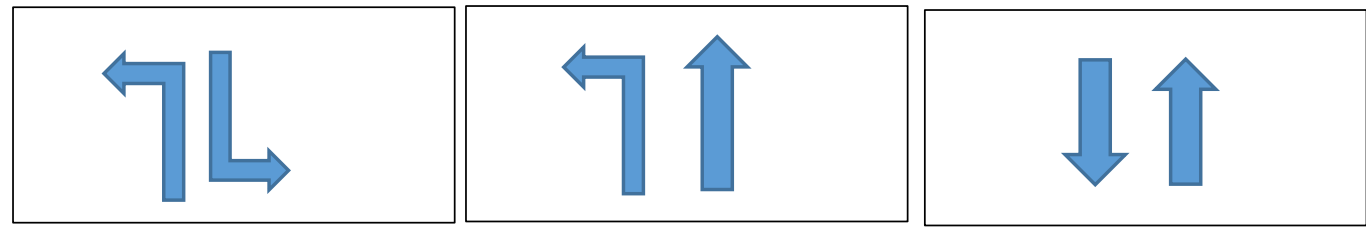

Type 14: Protected and SB Protected-Permitted
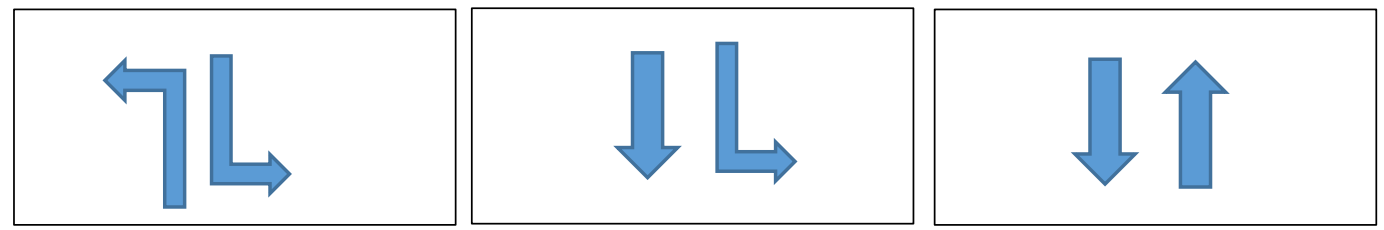

Type 15: NB Protected-Permitted
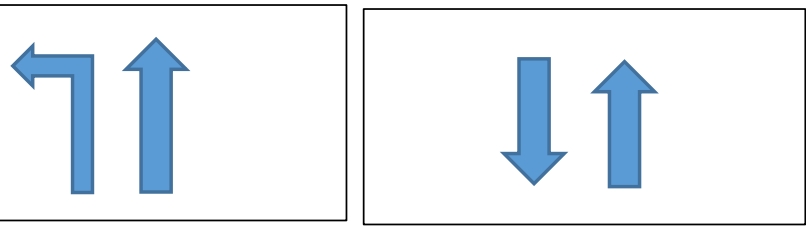

Type 16: SB Protected-Permitted
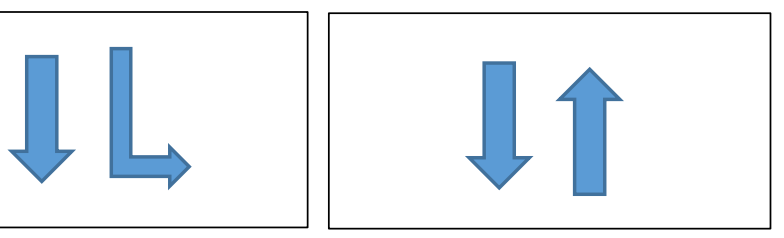

Figure 15. Major streets' possible phase plans. 


\section{E.1. PHASE EFFECTS}

We defined overlapped phase plans as shown by Types 3, 4, 13, or 14 in Figures 14 and 15. Protected phase plans were shown by Types 2 or 12 . The overlapped phases were expected to happen more frequently under ASCT and less frequently under TBC. However, in some cases, it did not meet our expectation.

Table 42. Overlapped Phases and Protected Phases, Numbers in ASCT 2017 and TBC 2017

\begin{tabular}{|c|c|c|c|c|c|c|}
\hline \multirow{2}{*}{ Intersection } & \multirow{2}{*}{ Time } & \multirow{2}{*}{ Phase type } & \multicolumn{2}{|c|}{ Major } & \multicolumn{2}{|c|}{ Minor } \\
\hline & & & ASCT & TBC & ASCT & TBC \\
\hline \multirow{6}{*}{ Kirby } & \multirow{2}{*}{ AM } & Overlapped & $10 / 28$ & $2 / 30$ & $13 / 28$ & $0 / 30$ \\
\hline & & Protected & $4 / 28$ & $9 / 30$ & $8 / 28$ & $16 / 30$ \\
\hline & \multirow{2}{*}{ NP } & Overlapped & $7 / 31$ & $0 / 32$ & $15 / 31$ & $15 / 32$ \\
\hline & & Protected & $16 / 31$ & $21 / 32$ & $11 / 31$ & $7 / 32$ \\
\hline & \multirow{2}{*}{ PM } & Overlapped & $8 / 31$ & $4 / 29$ & $14 / 31$ & $20 / 29$ \\
\hline & & Protected & $14 / 31$ & $15 / 29$ & $11 / 31$ & $5 / 29$ \\
\hline \multirow{6}{*}{ St. Mary's } & \multirow{2}{*}{ AM } & Overlapped & $4 / 29$ & $3 / 32$ & $2 / 29$ & $0 / 32$ \\
\hline & & Protected & $1 / 29$ & $1 / 32$ & $4 / 29$ & $6 / 32$ \\
\hline & \multirow{2}{*}{ NP } & Overlapped & $5 / 32$ & $3 / 32$ & $9 / 32$ & $0 / 32$ \\
\hline & & Protected & $2 / 32$ & $1 / 32$ & $8 / 32$ & $13 / 32$ \\
\hline & \multirow{2}{*}{ PM } & Overlapped & $3 / 29$ & $0 / 30$ & $10 / 29$ & $16 / 30$ \\
\hline & & Protected & $1 / 29$ & $2 / 30$ & $2 / 29$ & $1 / 30$ \\
\hline \multirow{6}{*}{ Windsor } & \multirow{2}{*}{ AM } & Overlapped & $1 / 28$ & $0 / 32$ & $5 / 28$ & $21 / 32$ \\
\hline & & Protected & $9 / 28$ & $6 / 32$ & $15 / 28$ & $5 / 32$ \\
\hline & \multirow{2}{*}{ NP } & Overlapped & $3 / 31$ & $0 / 31$ & $1 / 31$ & $0 / 31$ \\
\hline & & Protected & $15 / 31$ & $13 / 31$ & $24 / 31$ & $26 / 31$ \\
\hline & \multirow{2}{*}{ PM } & Overlapped & $8 / 30$ & $11 / 30$ & $7 / 30$ & $5 / 30$ \\
\hline & & Protected & $14 / 30$ & $6 / 30$ & $21 / 30$ & $23 / 30$ \\
\hline
\end{tabular}

From Table 42, there are three cases in minor streets and one case in major streets that showed the overlapped phases occur more under TBC and less under ASCT. That indicated the phase allocation in these four cases did not meet our expectations because we expected the adaptive signal could develop more overlapped phases. 


\section{APPENDIX F: SYSTEM TECHNICAL ERRORS OBSERVED IN THE FIELD}

Through observations and data reductions, we discovered some issues existing in the system. The issues, or errors, were categorized as combining cycles or splitting cycles spontaneously, wrongly allocating green time at minor streets, and wrongly counting the traffic volume.

\section{F.1 COMBINING CYCLES}

System combined two consecutive cycles spontaneously, leading to cycle lengths twice as long as the normal cycles, as shown in Table 43.

Table 43. System Issue of Combining Cycles

\begin{tabular}{|l|l|l|l|l|l|}
\hline & Approaches & $\begin{array}{l}\text { Timestamps in } \\
\text { our recorded } \\
\text { video }\end{array}$ & $\begin{array}{l}\text { Observed } \\
\text { cycle } \\
\text { length } \\
\text { (sec) }\end{array}$ & $\begin{array}{l}\text { System- } \\
\text { recorded } \\
\text { time }\end{array}$ & $\begin{array}{l}\text { System- } \\
\text { recorded } \\
\text { cycle } \\
\text { length } \\
\text { (sec) }\end{array}$ \\
\hline Winsor, April 12 NP & All & $0: 51: 16-0: 54: 44$ & $\begin{array}{l}100 \\
106\end{array}$ & $13: 05: 52$ PM & 206 \\
\hline Kirby, April 12 NP & All & $0: 24: 09-0: 27: 43$ & $\begin{array}{l}98 \\
116\end{array}$ & $12: 40: 05$ PM & 214 \\
\hline Kirby, April 12 NP & All & $0: 48: 01-0: 51: 39$ & $\begin{array}{l}100 \\
118\end{array}$ & $13: 03: 58$ PM & 218 \\
\hline Kirby, April 12 NP & All & $1: 02: 23-1: 05: 58$ & $\begin{array}{l}113 \\
107\end{array}$ & $13: 18: 19$ PM & 220 \\
\hline Kirby, April 12 PM & All & $0: 34: 58-0: 38: 50$ & $\begin{array}{l}112 \\
120\end{array}$ & $17: 08: 02$ PM & 232 \\
\hline
\end{tabular}

\section{F.2 SPLITTING CYCLES}

Table 44 shows a case that the system split one long cycle into two separate cycles. This happened at Devonshire Road during April NP.

Table 44. System Issue of Splitting Cycle

\begin{tabular}{|l|l|l|l|l|l|}
\hline & Approaches & $\begin{array}{l}\text { Timestamps in } \\
\text { our recorded } \\
\text { video }\end{array}$ & $\begin{array}{l}\text { Observed } \\
\text { cycle } \\
\text { length(sec) }\end{array}$ & $\begin{array}{l}\text { System- } \\
\text { recorded time }\end{array}$ & $\begin{array}{l}\text { System- } \\
\text { recorded } \\
\text { cycle length } \\
\text { (sec) }\end{array}$ \\
\hline $\begin{array}{l}\text { Devonshire, April 13 } \\
\text { NP }\end{array}$ & All & $\begin{array}{l}0: 20: 36- \\
0: 24: 20\end{array}$ & 224 & $\begin{array}{l}12: 27: 34 \mathrm{PM} \\
12: 29: 28 \mathrm{PM}\end{array}$ & $\begin{array}{l}114 \\
110\end{array}$ \\
\hline
\end{tabular}




\section{F.3 GREEN TIME WRONGLY ALLOCATED TO MINOR STREETS}

The system did not allocate WBT green time at Windsor NP on one cycle although a queue existed, as shown in Table 45.

Table 45. Green Time Wrongly Allocated to Minor Streets

\begin{tabular}{|l|l|l|l|l|l|}
\hline & Approaches & $\begin{array}{l}\text { Timestamps in } \\
\text { our recorded } \\
\text { video }\end{array}$ & $\begin{array}{l}\text { Observed } \\
\text { cycle } \\
\text { length(sec) }\end{array}$ & $\begin{array}{l}\text { System- } \\
\text { recorded time }\end{array}$ & $\begin{array}{l}\text { System- } \\
\text { recorded } \\
\text { cycle length } \\
\text { (sec) }\end{array}$ \\
\hline $\begin{array}{l}\text { Winsor, April 12 } \\
\text { NP }\end{array}$ & WBT & $\begin{array}{l}0: 16: 11- \\
0: 18: 00\end{array}$ & 224 & $12: 30: 58 \mathrm{PM}$ & 110 \\
\hline
\end{tabular}

\section{F.4 VOLUME MISCOUNTED BY SYSTEM}

Table 46 shows a specific example detected at Stadium, AM.

Table 46. Example of Volume Miscount by System

\begin{tabular}{|l|l|l|l|}
\hline & Approaches & $\begin{array}{l}\text { Timestamps in our } \\
\text { recorded video }\end{array}$ & Description \\
\hline $\begin{array}{l}\text { Stadium, April } \\
\text { 11 AM }\end{array}$ & WBT & $\begin{array}{l}0: 15: 44-0: 15: 58 \\
\text { A series of cars (grey, black, grey } \\
\text { van, red truck) on NB activated the } \\
\text { specified area in counting of WBT }\end{array}$ \\
\hline
\end{tabular}
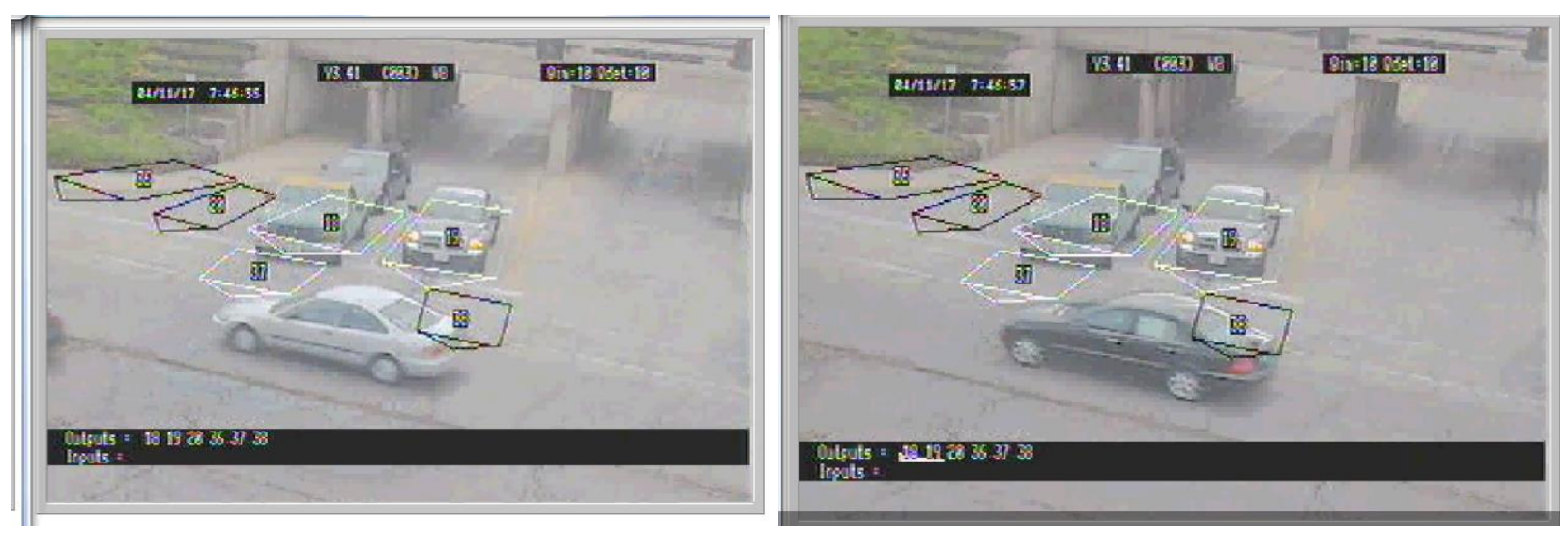


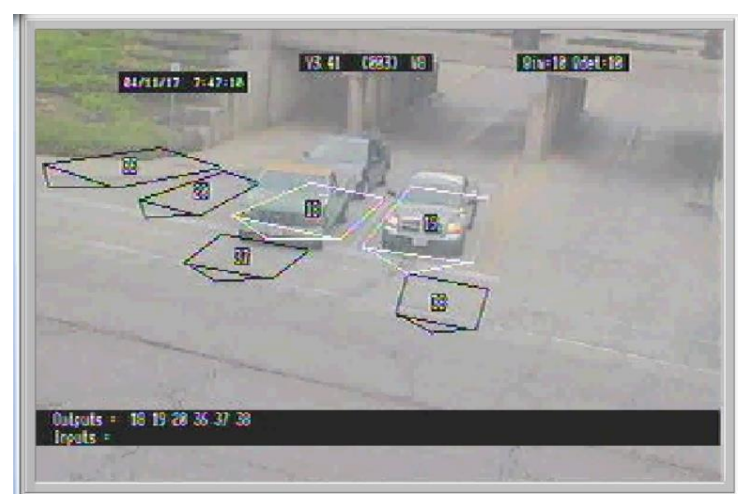

Figure 16. Snapshot of the mismatching case at minor street.

In the snapshot, the grey car activated the detection zone for counting of the minor streets, and the following black car also activated that area; but the vehicles on minor streets should be activating these detection zones; hence, the miscounting occurred. . 


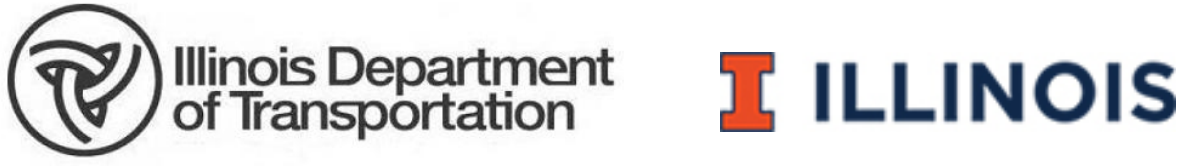

